\title{
A REVIEW OF THE STRATEGY FOR THE NORTHEAST ASIA POWER SYSTEM INTERCONNECTION
}

Kaoru Ogino

NO. 30

December 2020

\author{
ADB EAST ASIA \\ WORKING PAPER SERIES
}




\section{ADB East Asia Working Paper Series}

\section{A Review of the Strategy for the Northeast Asia Power System Interconnection}

Kaoru Ogino

No. 30 | December 2020
Kaoru Ogino is a principal infrastructure finance specialist at the Asian Development Bank. He is a part-time lecturer and visiting research fellow at the University of Tokyo. 
(C) 2020 Asian Development Bank 6 ADB Avenue, Mandaluyong City, 1550 Metro Manila, Philippines

Tel +632 8632 4444; Fax +63286362444

www.adb.org

Some rights reserved. Published in 2020.

Printed in the Philippines

Publication Stock No. WPS200386-2

DOI: http://dx.doi.org/10.22617/WPS200386-2

The views expressed in this publication are those of the authors and do not necessarily reflect the views and policies of the Asian Development Bank (ADB) or its Board of Governors or the governments they represent.

ADB does not guarantee the accuracy of the data included in this publication and accepts no responsibility for any consequence of their use. The mention of specific companies or products of manufacturers does not imply that they are endorsed or recommended by ADB in preference to others of a similar nature that are not mentioned.

By making any designation of or reference to a particular territory or geographic area, or by using the term "country" in this document, $A D B$ does not intend to make any judgments as to the legal or other status of any territory or area.

This work is available under the Creative Commons Attribution 3.0 IGO license (CC BY 3.0 IGO)

https://creativecommons.org/licenses/by/3.0/igo/. By using the content of this publication, you agree to be bound by the terms of this license. For attribution, translations, adaptations, and permissions, please read the provisions and terms of use at https://www.adb.org/terms-use\#openaccess.

This CC license does not apply to non-ADB copyright materials in this publication. If the material is attributed to another source, please contact the copyright owner or publisher of that source for permission to reproduce it. $\mathrm{ADB}$ cannot be held liable for any claims that arise as a result of your use of the material.

Please contact pubsmarketing@adb.org if you have questions or comments with respect to content, or if you wish to obtain copyright permission for your intended use that does not fall within these terms, or for permission to use the ADB logo.

Corrigenda to ADB publications may be found at http://www.adb.org/publications/corrigenda.

Notes:

In this publication, "\$” refers to United States dollars.

ADB recognizes "China" as the People's Republic of China, "Korea" as the Republic of Korea, and

"Russia" as the Russian Federation.

The ADB East Asia Working Paper Series is a forum for stimulating discussion and eliciting feedback on ongoing and recently completed research and policy studies undertaken by the East Asia Department of the Asian Development Bank (ADB) staff, consultants, or resource persons. The series deals with key economic and development problems, as well as conceptual, analytical, or methodological issues relating to project/program economic analysis, and statistical data and measurement. The series aims to enhance the knowledge on Asia's development and policy challenges; strengthen analytical rigor and quality of ADB's country partnership strategies, and its subregional and country operations; and improve the quality and availability of statistical data and development indicators for monitoring development effectiveness.

The ADB East Asia Working Paper Series is a quick-disseminating, informal publication whose titles could subsequently be revised for publication as articles in professional journals or chapters in books. The series is maintained by the East Asia Department. 


\section{CONTENTS}

TABLES AND FIGURES iv

ACKNOWLEDGMENTS vi vi

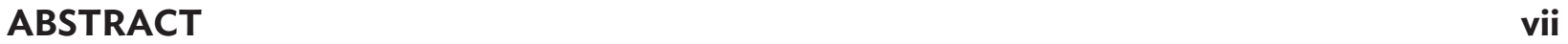

ABBREVIATIONS viii

EXECUTIVE SUMMARY $\quad$ x

$\begin{array}{lll}\text { I. INTRODUCTION } & 1\end{array}$

A. Interconnecting Power Systems in Northeast Asia $\quad 1$

B. Objectives of the NAPSI Study 2

$\begin{array}{lll}\text { II. } & \text { RENEWABLE ENERGY ASSESSMENT }\end{array}$

A. $\quad$ Renewable Electricity in the Northeast Asia Region 4

B. Mongolia 6

C. Other Countries 12

III. CLEAN ENERGY-BASED INTERCONNECTED NORTHEAST ASIA REGION POWER SYSTEM
A. Method 15
B. Modeling Power Trade and Interconnections in the Northeast Asia Region System 18
C. Options for Mongolian Grid Development 23
D. Northeast Region Interconnection Development Pathways $\quad 31$
E. Technical and Economic Assessments of the Simulation Results 37

IV. DISCUSSIONS ON ISSUES AND CONCERNS 46
A. Political Aspects $\quad 47$
B. Commercial Aspects 50
C. Regulatory Aspects 53
D. Conclusion of Grid Configuration and Transmission Interconnection 56

IV. WAYS FORWARD WITH DEVELOPMENT PRIORITIES $\quad 57$

A. $\quad$ Specific Project Investment Plans $\quad 57$

B. Project and Financial Structuring $\quad 60$

C. Legal and Regulatory Frameworks in Mongolia 61

D. Institutional Development and Regional Interconnection Authority 64

$\begin{array}{lc}\text { REFERENCES } & 68\end{array}$ 


\section{TABLES AND FIGURES}

\section{TABLES}

$1 \quad$ Northeast Asia GDP, Population, Electricity Consumption, and Carbon Dioxide Emission, 2018

2 Key Assumptions of the Least-Cost Generation Expansion Simulation 9

3 Sample Criteria of Constraints 11

$4 \quad$ Sample Criteria of Ranking 11

5 Baseline Power Generation Assumption for Each Regional Grid System Area 16

\section{FIGURES}

$1 \quad$ Energy Mix of Power Generation Sources of Northeast Asia Region Countries, 2018

2 Tariffs of Electricity Consumption of Northeast Asia Region Countries, 2018

3 Electricity Supply Structure of Mongolia, $2018 \quad 7$

$4 \quad$ Wind Speed Values and Scores 11

$5 \quad$ Solar Radiation Values and Scores 11

$6 \quad$ Mongolia's Renewable Energy Potential, Including Wind (192 GW) 11 and Solar Photovoltaic (1,166 GW)

$7 \quad$ Northeast Asia Region's Generation Mix from 2016 to 2036

8 Cross-Border Power Trade in Northeast Asia, as of March 202019

9 Existing Grid Systems of Mongolia, as of March 2020

10 Development Scenarios of Interconnections for Renewable Energy Production 21 in South Gobi of Mongolia

11 Load Flow of Gross-Border Interconnections under Scenario 2: 10 GW Renewable Energy 22

12 Quarantined Direct Current Configuration, Scenario 2 24

13 Quarantined Direct Current Configuration 25

14 Integrated Direct Current Configuration, Scenario 2 26

15 Integrated Direct Current Configuration 26

16 Integrated Alternating Current Configuration, Scenario 2 27

17 Integrated Alternating Current Configuration 28

18 Cost of Transmission Infrastructure Investments in Mongolia, Scenarios 1 and $2 \quad 30$

$19 \quad$ Ultra-High Voltage Projects in Operation and Under Construction of the State Grid 33 Corporation of China 
20 Structural Diagram of East Siberian and Far East Trunk Transmission Grid in the Russian Federation

$21 \quad$ Northeast Asia Region Interconnection Scheme under Scenarios 1 and 2

$22 \quad$ Northeast Asia Region Interconnection Scheme under Scenario 33

23 Northeast Asia Region Countries' Interconnection Costs-Scenarios 1, 2, and $3 \quad 40$ (Integrated Alternating Current Option)

24 Investment Costs for Northeast Asia Region Interconnection and Mongolia's Renewable Energy Generation-Scenarios 1, 2, and 3

25 Mongolia's Gross and Net Benefits from Northeast Asia Region Power System Integration 42

26 Wind Power Projects-Comparison of Capital Expenditures and Capacity Factors for 203643 in Japan, Mongolia, and the Republic of Korea

27 Solar Photovoltaic Projects-Comparison of Capital Expenditures and Capacity Factors for 2036 in Japan, Mongolia, and the Republic of Korea

28 Changes in the Energy Generation Mix of Northeast Asia Region 45

29 Carbon Reduction Impacts of Mongolia's Renewable Energy and Northeast Asia 45 Region Interconnection

30 Northeast Asia Region Countries' 2018 Electricity Tariffs and Potential Power Flow under the Free Power Trading Market

31 Alternative Commercial Arrangements for the First Phase 55

32 Specific Investment Priority Projects 


\section{ACKNOWLEDGMENTS}

This working paper examines the Asian Development Bank's policy and advisory technical assistance studies independently. It reviews and summarizes their essential results, and provides some additional analysis stemming from discussions, insights, and suggestions offered by various experts from government agencies, academe, and research and development institutions.

The author thanks James Lynch, director general, East Asia Department (EARD); and Teresa Kho, deputy director general, EARD for their support for this publication. We are grateful for support from Sujata Gupta, director, Sustainable Infrastructure Division, EARD; and Shannon Cowlin, principal energy specialist, EARD. This work also benefited greatly from input from peer reviewers including Joonho Hwang, Jinmiao Xu, Aruna Wanniachchi Kankanamalage, Yumiko Tamura, Anand Ganbaatar, and Declan F. Magee (Asian Development Bank). The author also acknowledges the support of Gloria Gerilla-Teknomo, Precious Dungca, Jackie Moreno, Angel Villarez, and Abraham B. Villanueva.

The author specially thanks Sakari Oksanen for his technical input and contribution. Further valuable comments were provided during the review process of Gwyndaf Garbutt and Paul Komor.

The author also appreciates having valuable support and advice from various officials and experts: Anna Bessarahova, B. Byambasaikhan, Baldorj Chimeddorji, Chang Sang Cho, Seok-Jai Choi, Tserenpil Davaasuren, Artur Fishchuk, Baasanjav Ganbold, Gurbuz Gonul, Young-Soo Han, Shota Ichimura, Kohji Iwakami, Seok Hwan Jeon, Hyun Jae Kang, Keun Soo Kang, Jung Hwan Kim, Sung Eun Kim, Hyun Ko, Ja-Yoon Koo, Dongil Lee, Mi-Jin Lee, Sanghoon Lee, Philippe Lienhart, Hongpeng Liu, Kyungjun Moon, Mikiyasu Nakayama, Sangmin Nam, Mika Ohbayashi, B. Ovgor, Sergey Podkovalnikov, Vasily Pospelov, Atsumasa Sakai, Seok-Hong Shin, Ho-Seung Song, Tumen Tegshjargal, T. Tugsbilguun, Baajikhuu Tuguldur, Michael Williamson, Lei Xiaomeng, Shigeru Yamamura, B. Yeren-Ulzii, Jae Young Yoon, Yibin Zhang, and Changchun Zhou. 


\begin{abstract}
The study for the Northeast Asia Power System Interconnection indicated that the various benefits of cross-border electricity trading represent a largely untapped opportunity for the region, including Japan, Mongolia, the People's Republic of China (PRC), the Republic of Korea (ROK), and the Russian Federation. In particular, Mongolia's South Gobi has vast renewable energy potential that could be exploited and exported for regional use. The total size of Mongolia's potential solar and wind power resources for exportation is 1,358 gigawatts, which represents $37 \%$ of the region's expected electricity demand in 2036. These energy resources can offer opportunities to increase power trade, improve energy security, and reduce carbon dioxide emissions at the regional level. Initially, Mongolia should focus on exporting its renewable energy without trying to use it for domestic consumption to avoid touching on complicating issues of grid interconnection and integration of renewable energy into its own transmission systems. The PRC is expected to play a pivotal role in developing interconnections from Mongolia because of its proximity to South Gobi and the size of its market for power trading. The ROK is also in a strategic position to incentivize the power demand and initiate investments into the vast potential of wind and solar energy in Mongolia, which would be transmitted through the PRC to the ROK, where a bilateral scheme of the PRC-ROK interconnection is currently in advanced discussions. This tripartite interconnection can benefit potentially from further electricity imports from the Russian Federation through Mongolia to supplement and balance the variability of renewable energy supply from Mongolia to the PRC, in case renewable energy exports are increased at more than a certain level. In the future, it might also be possible to extend the interconnection from the ROK/Russian Federation to Japan. As an immediate way to future further studies, it is crucial to look into the mobilization of public and private actors to develop renewable energy in South Gobi, and to pursue power purchase agreements and investments in two key interconnections: between Mongolia and the PRC and between the PRC and the ROK.
\end{abstract}

Keywords: interconnection, Mongolia, Northeast Asia, power trading, power export and import, solar power, renewable energy, wind power. 


\section{ABBREVIATIONS}

\begin{tabular}{|c|c|c|}
\hline$A D B$ & - & Asian Development Bank \\
\hline$A C$ & - & alternating current \\
\hline B2B & - & back-to-back \\
\hline $\mathrm{CHP}$ & - & combined heat and power \\
\hline $\mathrm{CO}_{2}$ & - & carbon dioxide \\
\hline DC & - & direct current \\
\hline DPRK & - & the Democratic People's Republic of Korea \\
\hline EDF & - & Électricité de France \\
\hline ERC & - & Energy Regulatory Commission (Mongolia) \\
\hline FGC & - & Federal Grid Company (Russia) \\
\hline GDP & - & gross domestic product \\
\hline GESP & - & generation expansion simulation program \\
\hline $\mathrm{GHI}$ & - & global horizontal irradiance \\
\hline GIS & - & geographical information system \\
\hline GW & - & gigawatt \\
\hline GWh & - & gigawatt-hour \\
\hline HV & - & high-voltage \\
\hline HVAC & - & high-voltage alternating current \\
\hline HVDC & - & high-voltage direct current \\
\hline IDGC Siberia & - & Interregional Distribution Grid Company of Siberia \\
\hline IRENA & - & International Renewable Energy Agency \\
\hline KEPCO & - & Korea Electric Power Corporation \\
\hline$k V$ & - & kilovolt \\
\hline $\mathrm{kW}$ & - & kilowatt \\
\hline $\mathrm{kWh}$ & - & kilowatt-hour \\
\hline LCC & - & line-commutated converter \\
\hline LCOE & - & levelized cost of energy \\
\hline MOU & - & memorandum of understanding \\
\hline MW & - & megawatt \\
\hline MWh & - & megawatt-hour \\
\hline NAPSI & - & Northeast Asia Power System Interconnection \\
\hline NEA & - & Northeast Asia \\
\hline P2P & - & point-to-point \\
\hline PPA & - & power purchase agreement \\
\hline PRC & - & People's Republic of China \\
\hline ROK & - & Republic of Korea \\
\hline SGCC & - & State Grid Corporation of China \\
\hline
\end{tabular}




$\begin{array}{lll}\text { TSO } & - & \text { transmission system operator } \\ \text { TWh } & - & \text { terawatt-hour } \\ \text { UES } & - & \text { Unified Electricity System (Russia) } \\ \text { UHV } & - & \text { ultra-high voltage } \\ \text { UN-ESCAP } & - & \text { United Nations Economic and Social Commission of Asia and Pacific } \\ \text { UNESCO } & - & \text { United Nations Educational, Scientific and Cultural Organization } \\ \text { VSC } & - & \text { voltage source converter }\end{array}$




\title{
EXECUTIVE SUMMARY
}

\author{
This document is a summary and reassessment of the Strategy for Northeast Asia Power System \\ Interconnection (the NAPSI Study).
}

The NAPSI Study is built on a set of analytic studies on renewable energy resources and costs, electricity markets, and grid developments in the Northeast Asia (NEA) region for the next 20 years, starting 2016. The NAPSI Study was requested by the Ministry of Energy of Mongolia and supported by a technical assistance from the Asian Development Bank (ADB). The process of the NAPSI Study has been highly consultative, seeking input from the governments of the stakeholder countries, as well as public and private organizations. The results were shared with contributors through a round of workshops organized by the ADB technical assistance consultant team, led by Électricité de France, and the study itself was finalized in 2020.

Regional interconnection offers opportunities to increase trade, improve energy security, and reduce carbon dioxide emissions.

The NAPSI Study indicated that the various benefits of cross-border electricity trading represent a largely untapped opportunity for the NEA region, including Japan, Mongolia, the People's Republic of China (PRC), the Republic of Korea (ROK), and the Russian Federation. These NEA countries have substantial renewable energy potential and the aspiration to increase the share of renewables in their energy mix. They have differences in their investment environments, energy production structure and resource base, and consequent costs of primary energy and power generation. Therefore, the establishment of international interconnections in the region would create opportunities for arbitrage trading with electricity, and provide increased mutual energy security and system flexibility. Also, it could help move toward the reduction of carbon dioxide and particulate emissions throughout the region.

The data collected and analyzed by the NAPSI Study verifies both the economic and technological feasibility of the regional interconnection scheme it outlines.

The NAPSI Study documents the economic rationale of the regional interconnection scheme and verifies that the differences in structure and energy mixes of the NEA region countries are economically conducive to developing regional energy trade once the necessary infrastructure has been established. This trading can be anticipated to be mutually beneficial. The NAPSI Study shows that each country has domestic renewable resources and, intermittently, may act as either an exporter or importer of electricity. The study also reveals that Japan, the PRC, and the ROK have the most consistent demand for imported energy, whereas the Russian Federation and Mongolia have more abundant unexploited renewable resources in remote areas. Moreover, because of higher costs and lower capacity factors, producing renewable energy in Japan or the ROK would be less beneficial than producing the same amount of renewable energy in Mongolia.

In addition, the NAPSI Study-and the experience gained from the existing gigawatt (GW)-range solar photovoltaic and wind installations and power interconnections around the world-indicates that there should be no technical challenges to establishing the proposed interconnections using currently available technologies. 
The NAPSI Study verifies the existence of substantial untapped renewable resources in South Gobi ready to be exported for the benefit of the region, but it also indicates that the development of Mongolian renewable energy is not practical without regional interconnection.

The NAPSI Study estimates the best and most economically exploitable resources in Mongolia at 192 GW of wind energy and 1,166 GW of solar power, favorably located close to the PRC border in the Gobi Desert. The total size of Mongolia's exploitable renewable energy resources for exportation is $1,358 \mathrm{GW}$. Such significant resource potential represents 52\% of the 2016 NEA's whole electricity demand and 37\% of the 2036 NEA's demand forecast. Mongolia's domestic power demand is such, however, that developing these resources in a practical and profitable manner will require significant expansion of cross-border transmission infrastructure. Mongolia should focus on exporting its renewable energy without trying to use it for domestic consumption initially. This will avoid touching on complicating issues of grid interconnection and renewable energy integration to Mongolia's domestic transmission systems (Mongolia has already curtailed domestic renewable energy output since the country's transmission and backup generation capacity and system are not adequate to control and absorb renewable energy intermittency.)

The PRC is expected to play a pivotal role in developing interconnections from Mongolia because of its proximity to South Gobi and the size of its market for power trading. Also, the ROK is in a strategic position to incentivize the power demand and initiate investments into the vast potential of wind and solar in Mongolia to be transmitted through the PRC to the ROK. This tripartite interconnection can possibly benefit from further electricity imports from the Russian Federation through Mongolia to supplement and balance the variability of renewable energy supply from Mongolia to the PRC in case renewable energy exports are increased more than a certain level. In the future, the interconnection might be extended from the ROK/the Russian Federation to Japan.

In accordance with these points, the report provides recommendations for the stepwise development of the Mongolian grid for regional interconnections.

The NAPSI Study presents a vision of a long-term interconnectivity scheme for the NEA region, but many of the recommendations depend on an open access regulatory environment that has not yet been established in the region. The author of this report, therefore, recommends the stepwise development of the Mongolian renewable energy and interconnection infrastructure along with the development of a set of bilateral power trading and transmission agreements involving Mongolia, the PRC, and the ROK.

As to the development of transmission lines, the author believes that the most practical starting point is to develop dedicated lines to serve as the infrastructure base for power export from Mongolia's South Gobi Desert. This could also be expanded in the future to meet the needs of Mongolian domestic consumption.

The recommendations of this review do not preclude the future development of either the Mongolian grid or regional interconnections as outlined by the NAPSI Study. This paper offers the following as immediate next steps:

(i) Mobilize public and private actors to develop the South Gobi renewable base, and pursue investments in two key interconnections: between Mongolia and the PRC and between the PRC and the ROK. 
(ii) Study various options to balance the variability of renewable generation in South Gobi for a long-term purpose, and the consequent investments in associated transmission infrastructure with the PRC and/or the Russian Federation.

(iii) Start to function the NEA regional secretariat together with the region's governments and/or international organizations as a multilateral unit that can lead and pursue the implementation of interconnectivity development in the region in a coordinated manner, bringing various regional and bilateral interconnectivity initiatives forward. 


\section{INTRODUCTION}

The role of this document is to examine, summarize, and comment upon the results of the Strategy for Northeast Asia Power System Interconnection study (NAPSI Study), for the benefit of the stakeholders, and to provide an assessment of the possible ways forward. The assumptions, methodological choices, and conclusions of the NAPSI Study belong to the consulting team that authored it, in agreement with the participating countries on the steering committee, and are not the product of this paper's work. However, the author provides independent views and assessments based on some additional analysis stemming from discussions, insights, and suggestions offered by various experts from government agencies, academe, and research and development institutions.

The NAPSI Study is a wide-ranging and voluminous set of documents. Sections II and III of this paper focus on gathering, summarizing, and interpreting the NAPSI Study findings. Sections IV and V then represent a response from this paper's author to the conclusions drawn by the NAPSI Study by departing from the NAPSI Study's recommendation and suggesting ways forward with development priorities.

\section{A. Interconnecting Power Systems in Northeast Asia}

The utility of cross-border electricity trading is based on the complementarities in primary energy endowments within the Northeast Asia region (NEA), which includes Japan, the Republic of Korea (ROK), Mongolia, the People's Republic of China (PRC), and the Russian Federation. All NEA countries are currently dependent on fossil fuels-such as coal, natural gas, and oil-which in 2018 covered $70 \%$ of the region's electricity generation (BP, 2019). ' However, each of these countries is working to diversify their energy mixes to include more low-carbon energy. These efforts can be accelerated through regional cooperation in exploiting and sharing renewable energy. Mongolia, the PRC, and the Russian Federation are already trading electricity, but regional cross-border exchange of electricity stands as a largely untapped opportunity to harness the various benefits from combining renewable energy development and international interconnections in the region.

Through new and strengthened cross-country interconnections, the countries could reallocate and redirect the structural and temporal surpluses of electricity supplies-particularly from solar, wind, and hydropower resources-at low marginal cost. These could then replace fossil fuel-based electricity generation, which has a higher marginal cost and is also more polluting. Further, transboundary trading with energy and grid services can provide mutual energy security, cumulative system stability, and steady renewable electricity supply. Such an approach would also help reduce system losses, air pollution, and greenhouse gas emissions. ${ }^{2}$

While these prospective benefits come at the cost of investments in building and strengthening crossborder power transmission and generation infrastructure, these investments could also enhance regional economic cooperation as well as increase both investment activity and job creation. Overall,

\footnotetext{
The NEA region's electricity mix comprised 56\% coal, 13\% gas, 1\% fuel oil, $15 \%$ hydropower, $7 \%$ nuclear, and $8 \%$ renewable energy such as solar and wind power in 2018.

2 Because of the coronavirus disease (COVID-19) pandemic, the electricity demand decreased. However, the COVID-19 situation highlighted advantages of renewable energy's resilience. They included much less fuel imports, faster construction, and simpler operations.
} 
such transboundary economic cooperation could eventually contribute to maintaining and deepening peace and stability in the region.

The idea of an interconnected NEA is not new. Several studies by various stakeholders, including utility companies and research institutions, have explored the idea. ${ }^{3}$ Mongolia takes a central position in most of these studies. This is partly because of its geographic location between the PRC and the Russian Federation, but also on account of its vast solar and wind energy resources that would enable the country to serve as a major supplier to its neighboring countries, including Japan and the ROK. Logically, Mongolia has made the development of its energy resources a priority. The 2015 State Policy on Energy indicates that Mongolia intends to become an energy-exporting country by means of efficient and environmentally friendly technology (Government of Mongolia, 2018).

In this context, the Government of Mongolia sought technical assistance (TA) in 2015 from the Asian Development Bank (ADB) to start preparing a strategy for a Northeast Asia Power System Interconnection whose aim is to exploit and export Mongolia's abundant renewable energy. Basing itself on the resulting study of the NAPSI Strategy, this paper reviews and summarizes that study's research results while reassessing the findings in the context of additional information. This paper also provides further considerations pointing to potential issues and concerns that may merit follow-up studies or actions as possible ways forward. The information base of this paper draws not only from the TA reports, but also from personal communications that took place during a series of workshops and international conferences conducted in relation to this TA project. ${ }^{4}$

\section{B. Objectives of the NAPSI Study}

The NAPSI Study was motivated by the need to have a comprehensive and updated analysis of the power systems and markets in NEA countries. At the same time, it aimed to analyze and specify Mongolia's role as a supplier of renewable energy to the region in light of Mongolia's least-cost capacity expansion plan. The NAPSI Study revises the previous analyses with the latest technical and cost assumptions, taking into consideration local costs in each of the five countries, while providing a coherent vision for the entire region.

The 2-year NAPSI Study was undertaken in 2017-2019. The study's coverage period was extended for a 20-year horizon from 2016 to 2036. It includes three distinct master plans:

(i) Resource analysis of the wind and solar potential of Mongolia, which is the most comprehensive one carried out thus far, covering technical and commercial potential through a multistage ranking process, and a least-cost generation expansion plan for Mongolia.

(ii) Market assessment for power trade on an interconnected NEA electricity system associated with a cost-benefit analysis of interconnection versus an isolated system, with and without the solar and wind power export capacity located in the Gobi Desert in southern Mongolia (South Gobi Province of Mongolia).

3 In 2011, the concept of "Super Grid” was initiated by the Japanese private company Soft Bank Group's founder to interconnect the power grid systems from Northeast Asia through Southeast Asia to South Asia. Following this, the PRC and the ROK, as well as other organizations (e.g., the Energy Charter, the United Nations Economic and Social Commission for Asia and the Pacific), started launching separate studies. NEA power grid connectivity initiatives have been a very popular topic, producing an abundance of reports in addition to those we have mentioned here.

4 The author is thankful to the participants of these workshops for the conversations that have informed this document. The sensitivity of the bilateral and multilateral topics, however, requires that the absolute anonymity of all persons be ensured. For this reason, specific contributors or contributions have not been identified within this document. 
(iii) Power network planning studies toward NEA interconnection considering three scenarios of 5 gigawatts (GW), $10 \mathrm{GW}$, and $100 \mathrm{GW}$ of renewable power capacity expansion in South Gobi. These include the grid analysis for comparing the merits of alternating current (AC) and direct current (DC) transmission systems, as well as load flow and fault current analysis for assessing various grid extension options.

The NAPSI Study consists of a set of seven reports, including (i) the inception report, (ii) a market and power trade assessment and the feasibility of an interconnected regional system, (iii) a report on the planning and evaluation criteria and underlying assumptions for the studies, (iv) analysis of the Mongolian power system and assessment of the renewable energy potential, ( $v$ ) a study of the required transmission grid development, (vi) the conditions of the enabling environment for regional power trade and discussion on coordinated action to manage a regionally interconnected system, and (vii) the final report. These reports were provided by the consultant team during 2017 to 2019 and disclosed on the ADB website in February 2020 (ADB, n.d.).

The NAPSI Study is not only a technical and economic analysis, but is also meant for knowledgesharing for Northeast Asian interconnectivity development. The NAPSI Study was organized as a highly consultative process with stake-holding organizations from the five countries-including governments, academia, think tanks, utility companies, and regulators - who all attended the TA steering committee workshops. These workshops were organized in Ulaanbaatar (June 2017); Gwangju, ROK (November 2017); Tokyo (March 2018); Beijing (October 2018); and Ulaanbaatar (February 2019). The Steering Committee meetings and presentations of the NAPSI Study's results took place in coordination with the process of the Northeast Asia Regional Power Interconnection and Cooperation Forum organized by the United Nations Economic and Social Commission of Asia and Pacific (UN-ESCAP), including workshops in Ulaanbaatar (October 2018 and June 2019) and at the Korea International Renewable Energy Conference (the Eighth KIREC) in Seoul (October 2019).

Strengthening regional electricity sector cooperation has been on the agenda of the highest-level political leaders in many regions. The concept has gained momentum and the region's governments have intensified efforts to promote bilateral and multilateral arrangements for electricity interconnections. The maxim of the NAPSI Study also aligns with ADB's support for other regions, including (i) the Greater Mekong Subregion (GMS) Power Trade and Interconnection program, (ii) regional energy cooperation of the South Asia Subregional Economic Cooperation (SASEC), and (iii) regional power integration of the Central Asia Regional Economic Cooperation (CAREC). The NAPSI Study for the Mongolian Ministry of Energy was made possible by ADB with the financial support from (i) the Climate Change Fund, (ii) the People's Republic of China's Regional Cooperation and Poverty Reduction Fund, and (iii) the Republic of Korea's e-Asia and Knowledge Partnership Fund.

The strategy for the NAPSI Study was developed by a consulting group led by Électricite de France (EDF). EDF is a French utility company and one of the leading investors in low-carbon energy. The EDF Group covers a wide range of services from generation to trading and transmission grids. It is a major party in the European interconnected system. EDF's partner for the study was NovaTerra, Mongolia. NovaTerra is an investment, project management, and advisory firm providing capital and business assistance to international and domestic companies in Mongolia.

The China Electric Power Research Institute (CEPRI) and Hangzhou Dianzi University were largely in charge of the grid and system studies. CEPRI is a comprehensive and multidisciplinary research institute affiliated with the State Grid Corporation of China (SGCC), the world's largest utility company. The Russian company Rosseti PJSC (Rosseti)-which manages the federal grid and 
15 interregional distribution grid companies in 80 regions of the Russian Federation-was an active contributor to the NAPSI Study, providing data and reviewing the study's results particularly with respect to aspects concerning Siberia and the Russian Federation's Far East. The Korea Electric Power Corporation (KEPCO) provided valuable comments and guidance for the team. The NAPSI Study also benefitted from the assistance of the Renewable Energy Institute in Japan, which gave the consultant team data and information on Japan's power system and valuable suggestions and discussions for the NEA interconnectivity strategy.

There was also close coordination with international organizations, including ADB, UN-ESCAP, International Renewable Energy Agency (IRENA), Energy Charter, and Global Energy Interconnection Development and Cooperation Organization (GEIDCO).

\section{RENEWABLE ENERGY ASSESSMENT}

\section{A. Renewable Electricity in the Northeast Asia Region}

The NEA region is one of the most important economic regions of the world. It represents about one-fourth of both the worldwide gross domestic product (GDP) and population (Table 1). It also accounts for almost $40 \%$ of global greenhouse gas emissions, which mostly stem from power generation (Table 1).

\section{Table 1: Northeast Asia Gross Domestic Product, Population, Electricity Consumption, and Carbon Dioxide Emission, 2018}

\begin{tabular}{lcccc}
\hline Country & $\begin{array}{c}\text { GDP } \\
(\$ \text { billion })\end{array}$ & $\begin{array}{c}\text { Population } \\
(\text { million })\end{array}$ & $\begin{array}{c}\text { Electricity } \\
\text { Consumption } \\
(\text { TWh })^{\mathrm{a}}\end{array}$ & $\begin{array}{c}\mathrm{CO}_{2} \text { Emission } \\
\text { (million tons) }^{-}\end{array}$ \\
\hline Mongolia & 13 & 3 & 7 & 28 \\
People's Republic of China & 13,608 & 1,428 & 7,112 & 10,065 \\
Republic of Korea & 1,619 & 51 & 594 & 659 \\
Japan & 4,971 & 127 & 1,052 & 1,162 \\
Russian Federation & 1,658 & 146 & 1,111 & 1,711 \\
\hline Northeast Asia (Total) & 21,869 & 1,755 & 9,875 & 13,625 \\
World & 85,931 & 7,593 & 26,615 & 36,573 \\
\hline Share of Northeast Asia & $\mathbf{2 5 \%}$ & $\mathbf{2 3}$ & $\mathbf{3 7 \%}$ & $\mathbf{3 7 \%}$ \\
\hline
\end{tabular}

$\mathrm{CO}_{2}=$ carbon dioxide, $\mathrm{DP}=$ gross domestic product, $\mathrm{TWh}$ = terawatt-hour.

a Includes only domestic power production (TWh) and excludes power imported from other countries.

Source: BP (2019); Global Carbon Project (n.d.); World Bank (n.d.a, n.d.b). 
All five countries in the region have substantial renewable energy potential and the aspiration to increase the share of renewables in their energy mix. While most of their electricity production is currently sourced from fossil fuels, the energy mixes of each have different characteristics (Figure 1), as well as dissimilar tariffs on electricity consumption (Figure 2) because of widely ranging differences in available resources, electricity production costs, regulatory requirements, and investment environments.

These differences support the idea of arbitrage trading of electricity through interconnections between the countries in the region. Each country can be both an importer and an exporter of electricity, and each one has domestic renewable resources. Japan, the PRC, and the ROK, however, have the strongest demand for imported renewable energy. Mongolia and the Russian Federation, on the other hand, have significant untapped renewable energy resources in remote areas that could be developed to satisfy wider regional demand through cross-border interconnections.

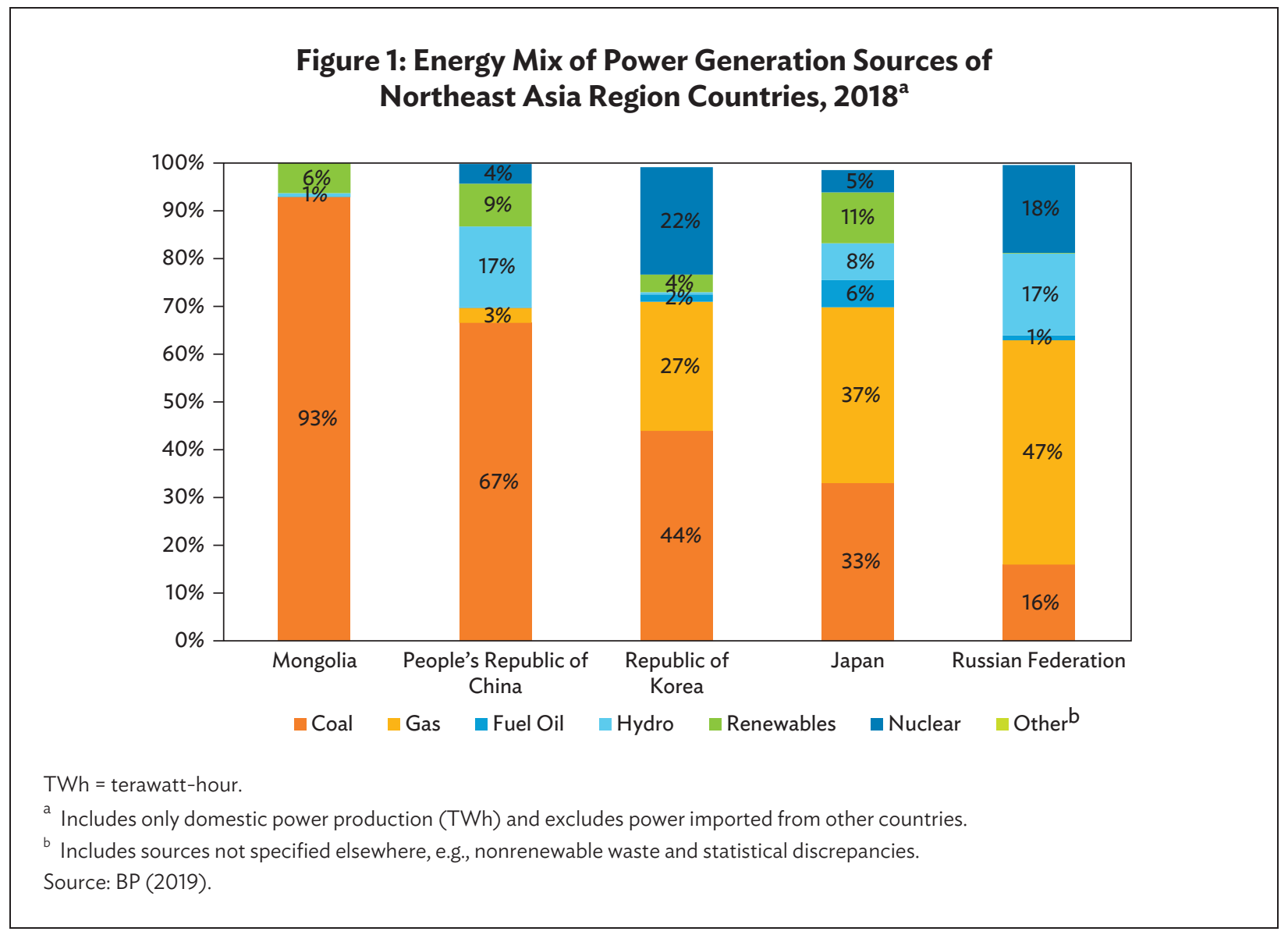


Figure 2: Tariffs of Electricity Consumption of Northeast Asia Countries, 2018

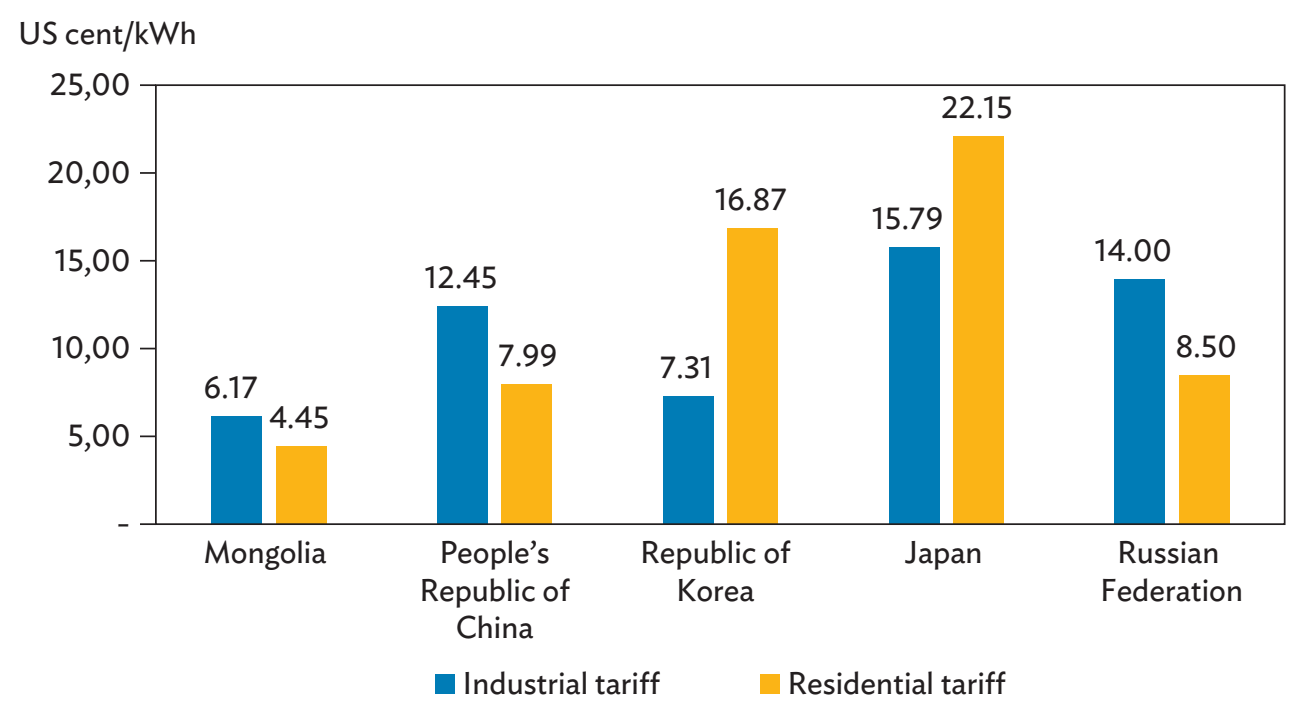

$\mathrm{kWh}=$ kilowatt-hour

Source: Energy Regulatory Commission (ERC) of Mongolia (2019).

In particular, it was said that Mongolia's renewable energy resources-mostly solar and wind powerwould be potentially abundant enough to support about $25 \%$ of the region's electricity needs beyond Mongolia's domestic power consumption (ADB, 2015). However, there had not yet been an assessment of the precise degree to which Mongolia's renewable energy resources can be exploited for regional-sharing purposes. In this regard, the NAPSI Study sought to first clarify how much wind and solar power would be eligible for power export from Mongolia to the neighboring countries based on techno-economic assessments. The NAPSI Study then compared the costs of wind and solar power generation in Mongolia with those in other countries. This section of the NAPSI Study also provides an overview of Mongolia and its neighboring countries in terms of each country's power sector situation and renewable energy development, to contextualize the claims concerning the potential for renewable energy and interconnection development in the NEA countries.

\section{B. Mongolia}

\section{Background}

The Mongolian power system is largely based on domestic coal and links power generation to the heating supply, as most of the major power plants are thermal generation of the combined heat and power (CHP) type. Three of these plants are in the capital Ulaanbaatar, and the others are in the provincial cities of Erdenet, Darkhan, Dalanzadgad, Dornod, and Ukhaakhudag. Regarding electricity transmission and distribution, the country is divided into four integrated grid systems: central, western, eastern, and Altai-Uliastai, of which the central region's integrated power grid is by far the largest. These four regional transmission grid systems are not integrated in operations and sufficed in the power transfer and supply capacity so that the power flow control is inflexible in the overall systems. ${ }^{5}$

5 ADB. 2020. Project Concept Paper for Proposed Loan for Mongolia: Supporting Renewable Energy Development Project. ADB initiated a technical assistance to prepare a transmission strengthening project. 
The installed electricity generation capacity of Mongolia is $1.2 \mathrm{GW}$. There are two 50-megawatt (MW) wind parks and three utility-scale solar photovoltaic plants in full operation with total solar photovoltaic capacity at $35 \mathrm{MW}$. The country's generation sector is open for private sector investments and a feed-in tariff system was introduced to encourage investments in renewable energy. There are proposals for some 18 thermal power plants; 6 hydropower plants, including 2 pumped storage plants; 4 wind farms; and more than 30 solar photovoltaic plants. These have been put forward for licensing by both domestic and foreign investors. In 2018, only $6 \%$ of the electricity generation was supplied by renewable energy facilities. In Mongolia, renewable energy output has already been curtailed since the systems are inadequate to control and absorb unstable power production of renewable energy. However, Mongolia has set a target of a $20 \%$ share of renewable capacity in the total installed capacity by 2023 (Energy Regulatory Commission of Mongolia, 2019). Mongolia's present electricity supply structure is in Figure 3.

\section{Figure 3: Electricity Supply Structure of Mongolia, 2018}

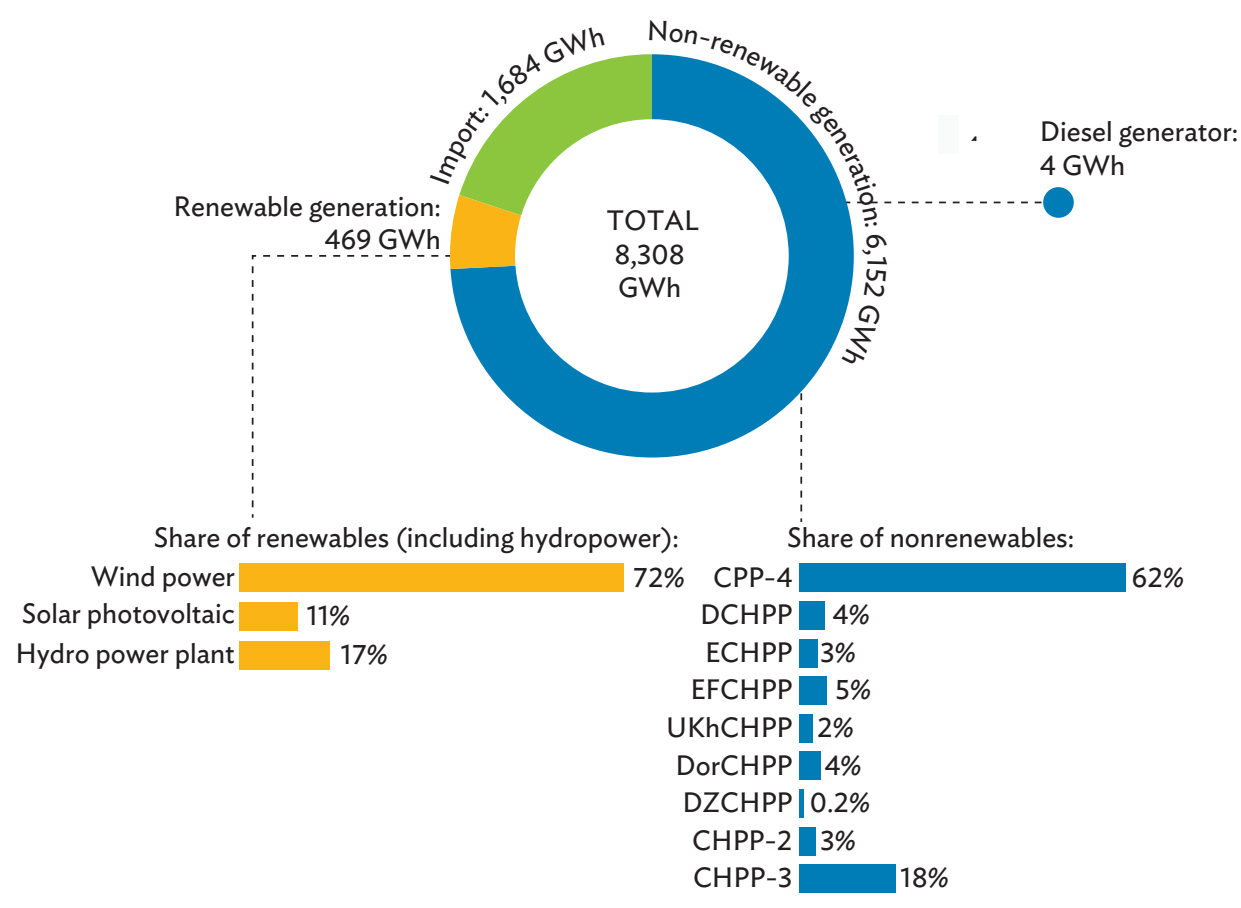

CHPP = combined heat and power plant, DCHPP = Darkhan combined heat and power plant, DZCHPP = Dalanzadgad combined heat and power plant, EFHPP = Erdenet Factory combined heat and power plant, GWh = gigawatt-hour, UKhHPP = Ukhaa Khudag combined heat and power plant.

Source: Energy Regulatory Commission Mongolia (2019).

A key component in Mongolia's cross-border interconnection is a 200-kilovolt ( $k V$ ) line from Selendeuna in Buryatia, Russian Federation that feeds electricity and provides grid services and frequency for Mongolia's Central Region Integrated Power Grid. The maximum capacity is 245 MW. The western region's integrated power grid is fed from the Russian Federation's Chadan-Handagaoly of the Siberian grid to Mongolia's Ulangom via a line built to the standards of $220 \mathrm{kV}$, but operated at $110 \mathrm{kV}$. In southern Mongolia, electricity is imported to the Oyu Tolgoi mining operation through a $220 \mathrm{kV}$ line from PRC, another line of major economic importance. However, this supply is isolated 
from the rest of the Mongolian grids because it is directly linked from the PRC grid to the Oyu Tolgoi mine. In addition, there are some medium- and low-voltage lines serving towns in the border areas with the PRC and the Russian Federation. The share of imported electricity is $20 \%$ of the total electricity supply of Mongolia. Cross-border interconnections have, therefore, been established, but are not currently being used at their full capacity and are used only for energy import.

Mongolia has the potential for the development of hydropower and substantial resources for wind and solar photovoltaic generation. There are, however, two key constraints for renewable energy development in Mongolia. First, the existing thermal power capacity of a CHP-type plant is not wellequipped to provide balancing power for variable renewable generation. Most of the CHP plants are aged, their operational efficiency is low, and were not designed for operational flexibility. Of the existing fleet, only CHP4 in Ulaanbaatar can demonstrate flexibility features. Its load-following capability is supported by many boilers and turbines, and has flexibility provided by turbine by-pass systems. However, its overall balancing capacity is limited because of the inherent properties of coalfired boilers, which have relatively high minimum loads and slow ramp-up rates, and thus cannot be expected to cope with a planned wind and solar photovoltaic expansion in the hundreds of MWs. Much of the balancing services, therefore, depend on the existing $220 \mathrm{kV}$ interconnection from the Russian Federation, and in case a large amount of renewable energy is generated in Mongolia, its current capacity will not be sufficient.

Second, the Mongolian system calls for additional fast-reacting balancing power, for which renewable hydropower with a reservoir would be ideal. However, Mongolia's current hydropower capacity stands at only $35 \mathrm{MW}$ from two run-of-river type stations (Fraunhofer ISE, 2018). There is much more potential for hydropower development in Mongolia; however, it is mostly linked to the Selenge river system, which is a transboundary water providing almost half of the riverine inflow to Lake Baikal in the Russian Federation: a UNESCO World Heritage site. While there are some potential schemes for developing hydropower on the Selenge river system-including the Eg-river hydropower plant (315 MW), Shuren hydropower plant (245 MW), and Orkhon (100 MW) - any plan to construct any of the above named hydropower plants potentially runs against the Russian Federation's lake protection policy. In the current situation, therefore, it is unrealistic to explore these hydropower schemes.

How could Mongolia overcome these constraints and develop its abundant renewable energy resources? To explore possibilities for overcoming these constraints to development of Mongolia's renewable energy resources, the NAPSI Study started its consideration of the Mongolian energy setting by carrying out two baseline studies:

(i) least-cost capacity expansion plan from 2020 to 2030 and 2036 using generation expansion simulation program (GESP), and

(ii) wind and solar photovoltaic resource estimation.

\section{Generation Expansion Simulation Program Analysis of Mongolia}

GESP is a generation least-cost expansion planning tool that minimizes total generation system costs over the planning horizon. It takes into account various parameters, including capital investments, emissions, renewable energy curtailments, reliability, production costs, technical constraints of different power generation types, and generation demands for electricity and heating purposes. The GESP analysis was based on a business-as-usual outlook over a period from 2020 up to 2036. It relied on the key targets of Mongolia's State Policy on Energy 2015-2030. The underlying electricity demand forecast of the analysis trebles the electricity demand from 2020 to 2036, with a compound average 
growth rate forecast by the NAPSI consultants at $10 \%$ in the $2020 \mathrm{~s}$ and $4 \%$ in the 2030 s. At the starting point, the level of Mongolia's reserve margin is critical, and the system in practice depends on the reserve provided by the Russian interconnection lines. Among the key constraints for the simulation stemming from the energy policy was that the domestic (i.e., excluding import capacity) reserve margin should be increased to $10 \%$ by 2023 and be no less than $20 \%$ by 2030 based on domestic expansion of installed capacity. Second, the policy aims to increase the share of renewable energy capacity to $20 \%$ by 2023 and $30 \%$ by 2030 , but not exceeding these shares because of inflexibility of the existing system and variability concerns of unstable renewable energy generation. Finally, concerning $\mathrm{CO}_{2}$ emissions, the policy aims to reduce $\mathrm{CO}_{2}$ intensity from the 2014 baseline by $10 \%$.

The results of the simulation clearly show that, as it stands, the Mongolian system is not able to balance out the variability of wind and solar photovoltaic generation without interconnections, even though the simulation assumed that part of the new coal-fired thermal power would have the flexibility to support some renewable energy generation. Following a business-as-usual model, the curtailment of the share of renewable energy within Mongolia will be unavoidable. These constraints in renewable energy capacity would likely result in Mongolia's continued dependence on coal. It should be noted, however, that the scope of the NAPSI Study did not include the assessment of other potential lowcarbon pathways. This is reflected in the relatively modest decline of the system's carbon intensity, even with the improved conversion efficiency of the new coal-fired fleet. The key assumptions of the least-cost generation expansion simulation is in Table 2.

To achieve the renewable energy capacity for 2036 would thus require significant development and upgrades in order to extend Mongolia's transmission network outside the country.

Table 2: Key Assumptions of the Least-Cost Generation Expansion Simulation

\begin{tabular}{lrrr}
\hline Item & $\mathbf{2 0 2 0}$ & $\mathbf{2 0 3 0}$ & $\mathbf{2 0 3 6}$ \\
\hline Peak demand (MW) & 1,388 & 3,470 & 4,338 \\
Total consumption (GWh) & 8,000 & 20,000 & 25,000 \\
Heat production (kGcal) & 9,540 & 14,683 & 18,920 \\
Total installed capacity (MW) & 2,150 & 5,920 & 7,120 \\
- Existing capacity (MW) & 1,120 & 1,120 & 1,120 \\
- Wind power (MW) & 215 & 900 & 1,100 \\
- Solar photovoltaic (MW) & 215 & 900 & 1,100 \\
- New CHP (MW) & 600 & 2,000 & 2,720 \\
- New non-CHP thermal (MW) & 0 & 1,000 & 1,080 \\
Share of renewable energy (\%) & 20 & 30 & 30 \\
$\mathrm{CO}_{2}$ intensity (tCO & $\mathrm{MWW})$ & 0.72 & 0.73 \\
$\mathrm{CO}_{2}$ emissions $\left(\mathrm{ktCO}_{2 \mathrm{e}}\right.$ ) & 0.86 & 14,319 & 18,155 \\
\hline
\end{tabular}

$\mathrm{CHP}=$ combined heat and power plant, $\mathrm{CO}_{2}=$ carbon dioxide, $\mathrm{GWh}=$ gigawatt-hour, $\mathrm{kGCal}=$ kilogram calorie, $\mathrm{MW}=$ megawatt, $\mathrm{MWh}=$ megawatt-hour, $\mathrm{tCO}_{2 \mathrm{e}}=$ metric tons of carbon dioxide equivalent.

Source: Électricité de France (2018b). 


\section{Solar Photovoltaic and Wind Resource Analysis of Mongolia}

The NAPSI Study investigates Mongolia's vast endowments of renewable energy resources in more detail than previous studies on the topic have done. It specifically focuses on solar photovoltaic and wind power development opportunities, thus excluding hydropower and other forms of renewable generation. The NAPSI Study aims to consider the following three key scenarios, which each support NEA power system integration along with development of solar photovoltaic and wind power generation:

(i) Scenario 1 includes $5 \mathrm{GW}$ of solar photovoltaic (2.5 GW) and wind power (2.5 GW) by 2026.

(ii) Scenario 2 includes $10 \mathrm{GW}$ of solar photovoltaic ( $5 \mathrm{GW}$ ) and wind power (5 GW) by 2036.

(iii) Scenario 3 includes $100 \mathrm{GW}$ of solar photovoltaic (50 GW) and wind power (50 GW) after 2036.

The base scenario, Scenario 0, is that of the GESP analysis, in which renewables develop according to Mongolia's domestic demand, whereas Scenarios 1 and 2 refer to the options of exporting most, if not all, electricity to neighboring countries. The study also analyzes Scenario 3 with $100 \mathrm{GW}$ installed renewable energy capacity in Mongolia for exports in the unspecified long term. Scenarios 1, 2, and 3 offer a prelude to analyzing regional interconnections.

The resource assessments were conducted in two phases to make the results more accurate and realistic than previous studies. The first phase of analysis collected the resource data-including wind speed $\left(\mathrm{m} / \mathrm{s}\right.$ ) and solar global horizontal irradiance ( $\mathrm{GHI}, \mathrm{kWh} / \mathrm{m}^{2}$ per year) - and mapped resultant power density and recoverable solar and wind resources as indicated (Figures 4 and 5).

In the second phase, the analysis excluded some areas with compelling geographic constraints for solar photovoltaic and wind development. These exclusions also reflected environmental and regulationbased restrictions, buffer zones of land use, and technological performance and limits (e.g., minimum space and availability of transport logistics). The comprehensive multicriteria analysis considered 30 criteria and constraints for development of renewables, from being near natural protection areas, to the proximity of roads and transmission infrastructure, and the slope or height of locations (Table 3). To select and identify suitable sites, all results were mapped based on a geographical information system (GIS) using a dedicated GIS tool developed by EDF and the European Institute for Energy Research, Karlsruhe, Germany, and applying ArcGIS and Python software.

The assessment approached the issue from viewpoints ranging from resources to technical capacity by considering the technical limits of solar photovoltaic and wind power generation. To do so, the assessment evaluated appropriate technical solutions, such as turbine models. The analysis then proceeded to rank and select preferred areas through a further multicriteria analysis, including parameters such as accessibility to roads and electricity transmission infrastructure (Table 4). Ranking was applied to minimum $10 \mathrm{MW}$ wind farms (10 square kilometers $\left[\mathrm{km}^{2}\right]$ ) and $5 \mathrm{MW}$ solar photovoltaic farms $\left(0.25 \mathrm{~km}^{2}\right)$. Finally, through a stepwise distillation process, renewable energy resources were ranked by applying scores. ${ }^{6}$ The selection was thus narrowed down based on a step-bystep assessment moving through gross resource data, technical feasibility, grid integration, site accessibility, and culminating with ranking evaluation and economic feasibility in a rigorous manner.

6 Explanation for scores: locations were provided a score from 1 to 5 , and only results scoring 4 or higher were considered for the feasible resource assessment. The highest scoring locations, (score 5) wind and solar photovoltaic yields, were only available in a total of $3 \mathrm{GW}$ and were considered to be too far away from other locations to be practical for exploitation.

Therefore, the score 5 areas were removed from the NAPSI Study scope and the score 4 areas were identified as preferred development sites. 
Figure 4: Wind Speed Values and Scores

Figure 5: Solar Radiation Values and Scores

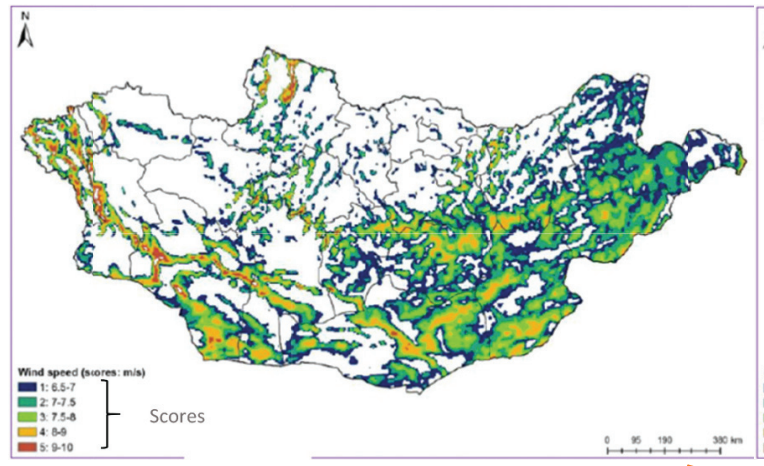

Source: Électricité de France (2018b).

Table 3: Sample Criteria of Constraints

- Elevation above 2,500 m

- Terrain slope $>20$ degree

- Waterland, river (200 m away)

- Permafrost area (Excluded)

- Quarry, mines (1-2 km away)

- Urban areas (1 km away)

- Railway, Roads (300 m and $100 \mathrm{~m}$ away)

- Protected areas with buffer (e.g., Ramsar sites, national parks, nature reserves, bird areas, monuments, sacred places, etc.

$\mathrm{km}=$ kilometer, $\mathrm{m}=$ meter .

Source: Électricité de France (2018b)

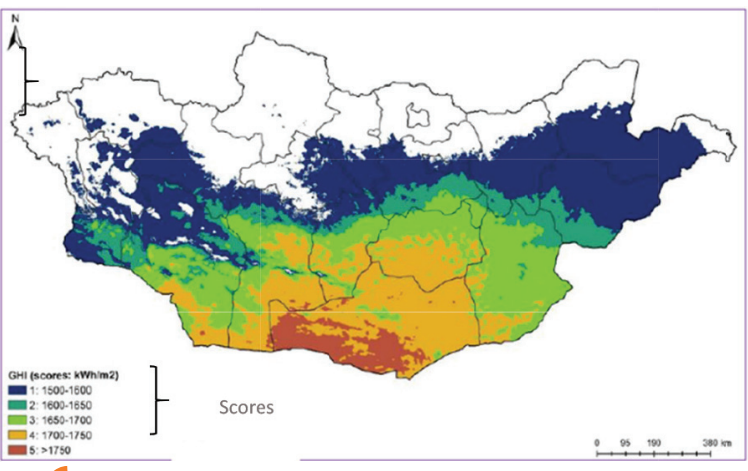

Source: Électricité de France (2018b).

\section{Table 4: Sample Criteria of Ranking}

- Wind speed

- Solar irradiation (GHI)

- Proxy to roads for logistics

- Proxy to railways for logistics

- Proxy to power lines

- Proxy to power substation

- Terrain slope

- Distance to cities and villages

- Available land areas

- Number of minimum size land areas

$\mathrm{GHI}=$ global horizontal irradiance.

Source: Électricité de France (2018b)

\section{Figure 6: Mongolia's Renewable Energy Potential, Including Wind (192 GW)} and Solar Photovoltaic (1,166 GW)

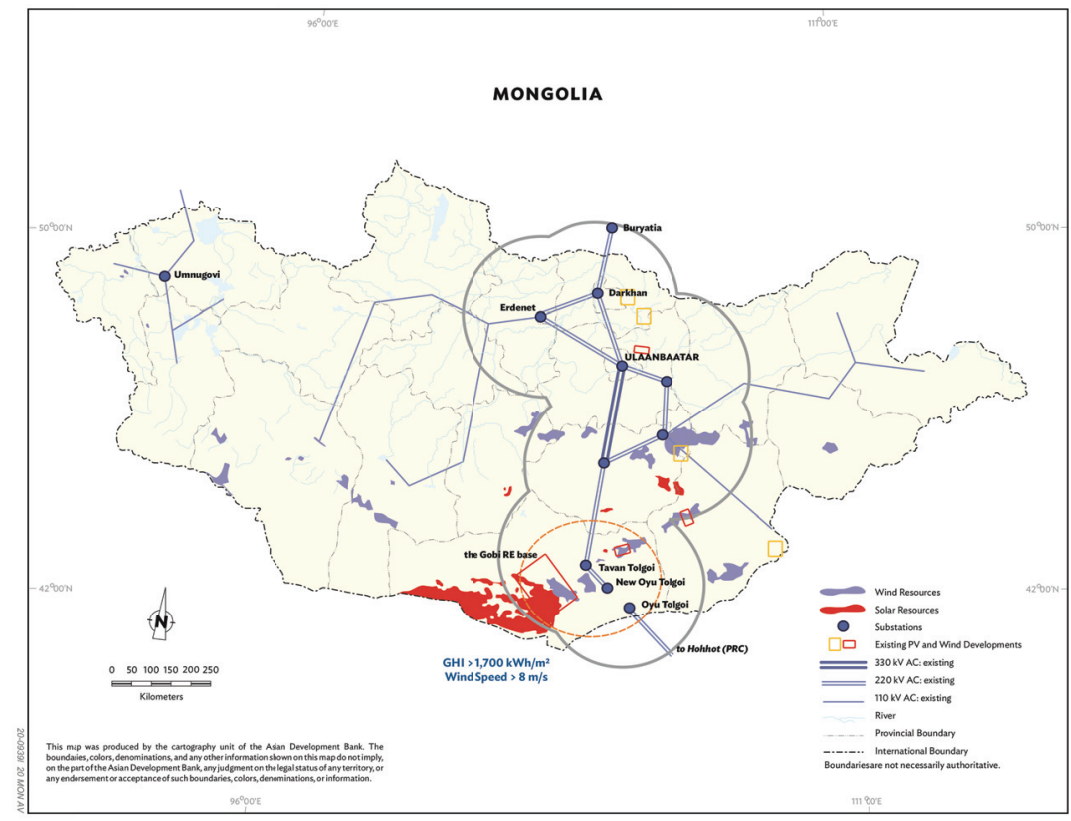

$\mathrm{GHI}=$ global horizontal irradiance, $\mathrm{GW}=$ gigawatt, $\mathrm{kV}=$ kilovolt, $\mathrm{PV}=$ photovoltaic, $\mathrm{RE}$ = renewable energy. Source: Électricité de France (2018b). 
As a result, the NAPSI Study confirms the huge potential for both wind and solar power, not only for Mongolia's domestic consumption but also for export purposes. The best economically exploitable resources can be estimated at $192 \mathrm{GW}$ of wind energy and 1,166 GW of solar photovoltaic (Figure 6). The total size of Mongolia's exploitable renewable energy resources for exportation is 1,358 GW, which is equivalent to 4,074 terawatt hours (TWh). This constitutes a significant resource potential, which represents 52\% of the 2016 NEA's whole electricity consumption and 37\% of the 2036 NEA's projected demand. These resources are found in abundance close to the intended location for export to PRC, in South Gobi of Mongolia. The resulting numbers are higher than previously estimated, but one must be cautious in the comparison because the set of criteria are not identical.

As to the costs of generation, the NAPSI Study provides an estimate for wind and solar photovoltaic technologies, and includes forecasts for the evolution of capital expenditures, operational expenditures, and capacity factors until 2036. It also calculates the levelized cost of energy (LCOE) by using both $5 \%$ and $8 \%$ discount factors. The estimates reflect conditions in the areas of Mongolia identified by the resource assessment.

In 2020, the LCOE estimates for wind power are lower than those for solar photovoltaic. The cost difference, however, reduces over the years because of the worldwide learning effect, as well as foreseen improvements in industrial capability in Mongolia for renewable energy installation and manufacturing so that step-by-step improvements and innovation lead to better capacity factors. While the NAPSI Study estimates LCOE at 4.9 US cents (cents)/kWh for wind power and at 6.8 cents/kWh for solar photovoltaic in 2020, the LCOE for both wind and solar photovoltaic are estimated to further reduce to the level of 2.7 cents $/ \mathrm{kWh}$ by 2036 . The NAPSI Study compares renewable energy's LCOE in Mongolia with those in other Asian countries, including the PRC and India. In its assessment Mongolia's costs are seen as highly competitive in the marketplace.

\section{Other Countries}

\section{People's Republic of China}

The PRC, as the largest energy consumer in the world, and as it is highly dependent on coal and imported fuels, has invested substantially in renewable energy development. On top of substantial coal and more limited natural gas resources, the country has abundant renewable resources for traditional hydropower, as well as wind and solar photovoltaic production. PRC is fully focused on becoming a key player in the world renewable energy market because of the intersection of strong motives, including improvement of energy independence, reduction in greenhouse gas emissions and air pollution, and promotion of the country's leadership position in the industry of manufacturing for renewable energy systems.

Consequently, from 2009 to 2018, the PRC's domestic renewable electricity capacity grew more than threefold, from $214 \mathrm{GW}$ to $712 \mathrm{GW}$, representing 37\% of the country's installed capacity and 23\% of generation production. This achievement is impressive, but the growth in the PRC's electricity demand remains robust, which will increase the pressure to further diversify the generation mix. In this regard, the country faces the challenge of the long distance between the sites of its best renewable resources and the areas with high demand. As with its natural gas fields, the regions with the best production characteristics for hydropower, solar photovoltaic, and wind are often far from the load centers in the PRC's eastern provinces. Therefore, the country has also expanded high-voltage (HV) electricity 
transmission lines, which have enabled long-distance electricity transmission from the country's northern, western, and southern electricity-producing areas to the east. It should also be noted that PRC has increased its worldwide market share in manufacturing and installing wind turbines and solar panels.

\section{Republic of Korea}

The ROK has the highest population density of the NEA countries, with 529 persons per $\mathrm{km}^{2}$, compared to 347 in Japan, 148 in the PRC, 9 in the Russian Federation, and 2 in Mongolia (World Bank, n.d.c). It is also a developed economy with a dedication to fight climate change and reduce dependence on imported oil, gas, and coal. Among renewable energy technologies, the country has focused mainly on solar photovoltaic. According to the ROK Renewable Energy 2030 Plan, as per energy targets for electricity generation, renewable energy sources will account for about $20 \%$ and $63.8 \mathrm{GW}$ by 2030, calling for a substantial increase from the $7.6 \%$ and $15.1 \mathrm{GW}$ in 2017 (Lee 2019). A scarcity of land, and its consequent high cost, among other factors, has motivated the ROK to consider the potential for offshore solar photovoltaic and wind electricity generation. The Ministry of Trade, Industry, and Energy has announced that a $2.1 \mathrm{GW}$ floating solar power plant will be built on a water surface close to Saemangeum, an estuarine tidal flat on the coast of the Yellow Sea.

The country will face a challenge with the renewable energy plan because its efforts to curb growth in electricity consumption through better energy efficiency are largely counterbalanced by the need to shift to electricity from direct use of fossil fuels. Electricity consumption per capita and direct use of fuels in industrial processes are high in the ROK because of its heavy industrial structure.

The ROK has few cost advantages to generate renewables in comparison to other countries, largely because of geographic characteristics due to the high cost of land with mountainous terrain, and its landlocked position as a substantial result of the political context of its relationship to the Democratic People's Republic of Korea (DPRK). The cost of imported fuels is also high, which, together with the other factors, may render the country open to considering imports of clean energy. Further, the ROK places much importance on developing distributed renewable energy coupled with smart grid solutions.

\section{Japan}

Japan is also a developed economy characterized by a high dependence on imported energy and high population density. It has a somewhat fragmented power system with 10 major vertically integrated electric power utilities for separate regions in Japan. Intensive efforts to improve energy efficiency and the saturating growth of the high-income economy have curbed the growth of electricity demand, while low-carbon solutions call for increased electrification. The country is reconsidering its high dependence on nuclear power. A strict commitment to the international targets in the fight against climate change has translated in Japan into various incentives for renewable energy, including feed-in tariffs, auctions, and various forms of carbon trading and certificates. 
However, Japan's generation capacity and transmission grid infrastructure are not flexible enough to absorb high shares of variable renewable power. The land is densely populated, intensively cultivated, and has well protected nature areas. Construction of renewable power, especially at utility scale, is a lengthy process requiring various permissions and authorizations related to land use and environmental protection, and the cost of land is high. Further, occasional typhoons cause stress to solar photovoltaic and wind installations.

Despite these constraints, an accumulated $59.5 \mathrm{GW}$ of solar photovoltaic capacity was installed in 2018. At the time, this capacity was on the higher side relative to other countries, whereas wind power capacity remained relatively small at $6.5 \mathrm{GW}$. The Ministry of Energy, Trade, and Industry has projected that by 2030 , renewables will cover $22 \%$ to $24 \%$ of total generation, based on hydropowerwhich has limited potential for further expansion-of 8.8\%-9.2\%, solar photovoltaic of 7\%, and wind energy of $1.7 \%$ with geothermal and bioenergy covering the balance.

\section{Russian Federation}

The Russian Federation has modernized its electricity generation sector over the last few decades, mainly thanks to an expanding fleet of natural gas-fired power plants. Currently, natural gas accounts for about half of the electricity generation, whereas the other half is covered in nearly equal shares by coal, hydropower, and nuclear. Expansion of gas use at the expense of coal has had a positive impact on the country's greenhouse gas and other airborne emissions.

The Russian Federation also has substantial renewable energy resources, including hydropower, solar, wind, geothermal, and bioenergy. Because of its vast land area, the Russian Federation has the largest wind potential in the world. However, the domestic electricity market provides limited commercial incentives to develop these energies.

In the country's energy strategies, the regions of East Siberia, the Far East, and Sakhalin belong to the "East" of the Russian Federation. With respect to administrative units, Mongolia is a neighbor with the Siberian Federal District, the PRC's northeast region also neighbors the Far Eastern Federal District, and Sakhalin has a border with Japan. In the context of the NAPSI Study and within the transmission grid structure of the Russian Federation, the east region grids are managed by various subsidiaries of the Russian grid company Rosseti. Generation, transmission, and distribution are unbundled, and the several power plant investment projects in the region are managed by companies such as Rushydro, InterRAO, Eurosibenergo, and others.

The installed capacity of the Siberian power system and the Far East power system at the start of 2019 reached $52 \mathrm{GW}$ and $11 \mathrm{GW}$, respectively. Hydropower is in a dominating position in the Siberian system, covering nearly half (49\%) of the generation, and holds a strong position (38\%) in the Far East power system as well. The Russian Federation's East is rich in energy resources including oil, natural gas, coal, geothermal, wind energy, and hydropower. However, the region-the Far East, in particularfaces several developmental challenges including demographic decline, outmigration, and a lack of infrastructure and industrial investments. The government has devised strategies to reverse some of the negative trends, including attracting foreign investments and expanding energy resource-based industries. 
Despite the economic issues, the demand for electricity is growing in the East by $2 \%$ to $3 \%$ annually. There is considerable capacity reserve, as measured by the difference between installed capacity and peak demand, of about $10 \mathrm{GW}$ in the Siberian and $5 \mathrm{GW}$ in the Far East system, which is, however, subject to the variability of the availability of hydropower. The installed capacity could be increased in the East by about $20 \mathrm{GW}$ by developing some of the power generation projects already identified in various strategies, which together with the current reserve margin of $15 \mathrm{GW}$, would provide a substantial reserve for trading electricity to the other NEA countries. The Russian Federation has expressed interest in exporting more hydropower, increasing its volume from the current 3.6 TWh per annum to the PRC and Mongolia to 45-50 TWh by 2030.

\section{CLEAN ENERGY-BASED INTERCONNECTED NORTHEAST ASIA REGION POWER SYSTEM}

\section{A. Method}

The NAPSI Study examined the techno-economic rationale behind the NEA regional interconnection scheme by applying a combination of analyses, including market assessment for power trade and a set of network planning studies. Following this, a cost-benefit analysis was conducted by (i) modelling all of the power systems that are part of the planned scheme and (ii) comparing the total system costs with and without cross-border interconnections. In the latter case, the system cost was the sum of the costs of all the national systems operating in isolation. In the former case, the least-cost yearly expansion and hourly dispatch were considered as if the cross-border interconnections-within transmission capacity limits - were part of the supply infrastructure of the national systems. The costs included both capital and operational expenditures to be annualized for cross-border transmission interconnections and renewable energy generation.

The NAPSI Study updated all assumptions for the least-cost expansion modeling, including demand forecasts, reserve margins, and other system reliability criteria, as well as technology and fuel cost estimates over the study horizon from 2020 to 2036. The overall NEA generation mix that results from the optimization model will be changed from 2016 to 2036 as indicated in Figure 7. Differences in national primary energy costs, capital and operational expenditures, and renewable energy capacity factors are taken into account on the basis of the specific energy-economic and geographic characteristics of the participating countries. These national differences include, among other things, that domestic mine-mouth coal is of low cost in North PRC, Mongolia, and the Russian Federation, whereas imported coal in East PRC, Japan, and the ROK follows world market prices; and that the capacity factors are higher and installation costs are lower for wind power and solar photovoltaic in South Gobi than in Japan or the ROK because of South Gobi's more favorable wind and solar irradiation (section III.E.2), as well as the low cost of land. 


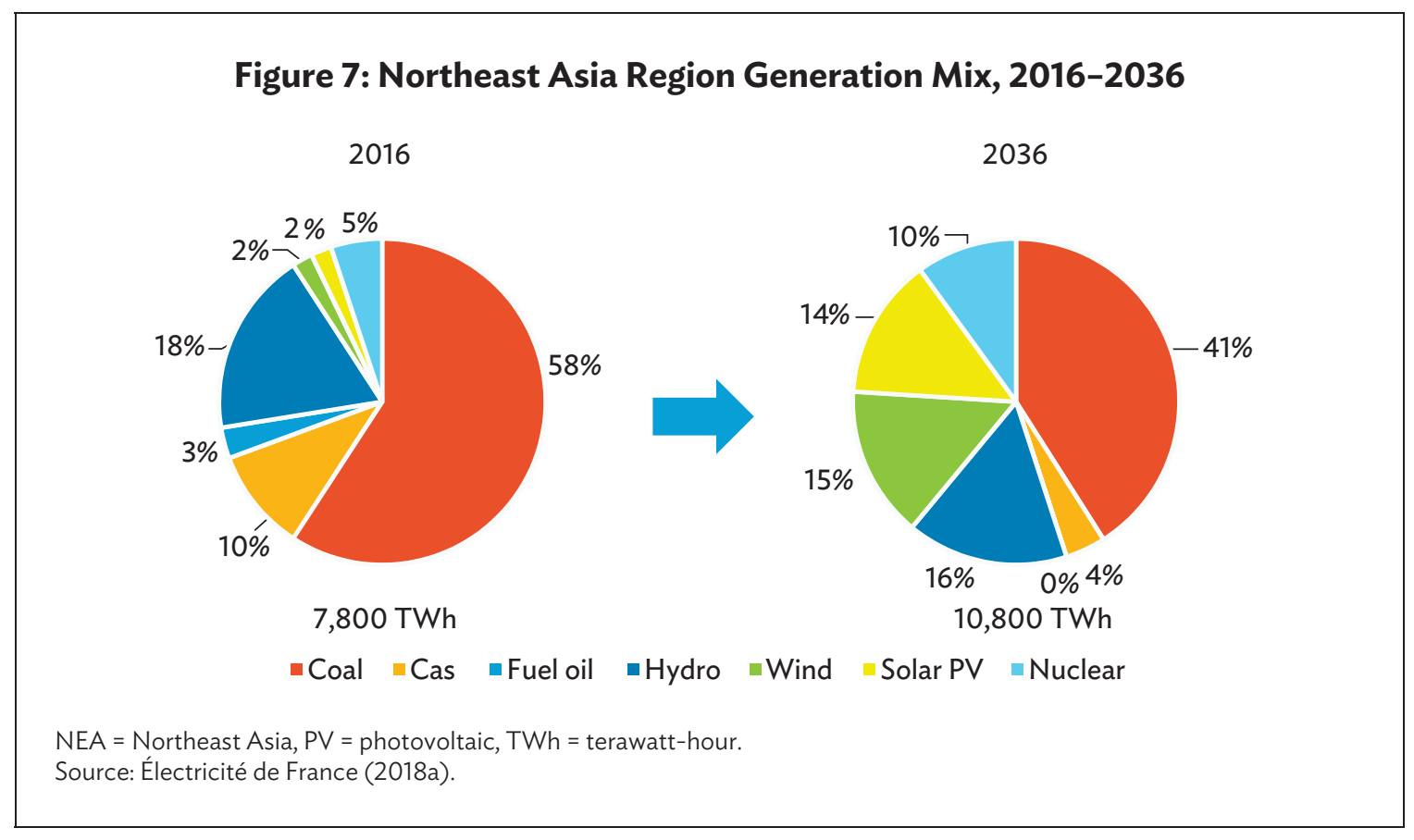

The analysis started by establishing an optimal generation portfolio and its least-cost annual expansion within each of the regional grid areas. The assumptions for the generation portfolio of each area are as presented in Table 5. The optimal dispatch of each generation capacity was calculated on an hourly level for selected years, and this exercise then produced information predicting generation by type of fuel and the use of transmission lines.

Table 5: Baseline Power Generation Assumption for Each Regional Grid System Area

\begin{tabular}{|c|c|c|c|c|}
\hline Country & \multicolumn{2}{|c|}{ Item } & 2020 & 2036 \\
\hline \multirow[t]{5}{*}{ Mongolia } & Demand & TWh & 8 & 25 \\
\hline & Peak Load & GW & 1.4 & 4.3 \\
\hline & Wind & GW & \multicolumn{2}{|c|}{ Depends on the scenario } \\
\hline & & Power factor & $42 \%$ & $48 \%$ \\
\hline & Photovoltaic & Power factor & $18 \%$ & $23 \%$ \\
\hline \multirow[t]{8}{*}{ China-West } & Demand & TWh & 1449 & 2050 \\
\hline & Peak Load & GW & 228 & 324 \\
\hline & Hydropower & TWh & 812 & 974 \\
\hline & \multirow[t]{2}{*}{ Wind } & GW & 104 & 220 \\
\hline & & Power factor & $42 \%$ & $23 \%$ \\
\hline & \multirow[t]{2}{*}{ Photovoltaic } & GW & 79 & 278 \\
\hline & & Power factor & $18 \%$ & $23 \%$ \\
\hline & Nuclear & GW & 0 & 0 \\
\hline
\end{tabular}


Table 5 continued

\begin{tabular}{|c|c|c|c|c|}
\hline \multirow{2}{*}{\begin{tabular}{|r|} 
Country \\
China-East
\end{tabular}} & \multicolumn{2}{|c|}{ Item } & \multirow{2}{*}{$\begin{array}{r}2020 \\
4839\end{array}$} & \multirow{2}{*}{$\frac{2036}{6847}$} \\
\hline & Demand & TWh & & \\
\hline & Peak Load & GW & 763 & 1079 \\
\hline & Hydropower & TWh & 406 & 487 \\
\hline & \multirow[t]{2}{*}{ Wind } & GW & 146 & 310 \\
\hline & & Power Factor & $23 \%$ & $33 \%$ \\
\hline & \multirow[t]{2}{*}{ Photovoltaic } & GW & 139 & 547 \\
\hline & & Power factor & $16 \%$ & $21 \%$ \\
\hline & Nuclear & GW & 57 & 135 \\
\hline \multirow[t]{8}{*}{ Japan } & Demand & TWh & 540 & 610 \\
\hline & Peak Load & GW & 158 & 166 \\
\hline & Hydropower & TWh & 84 & 95 \\
\hline & \multirow[t]{2}{*}{ Wind } & GW & 6 & 55 \\
\hline & & Power factor & $26 \%$ & $30 \%$ \\
\hline & \multirow[t]{2}{*}{ Photovoltaic } & GW & 64 & 100 \\
\hline & & Power factor & $15 \%$ & $19 \%$ \\
\hline & Nuclear & GW & 4 & 14 \\
\hline \multirow[t]{8}{*}{ Republic of Korea } & Demand & TWh & 540 & 610 \\
\hline & Peak Load & GW & 90 & 108 \\
\hline & Hydropower & TWh & 7 & 8 \\
\hline & \multirow[t]{2}{*}{ Wind } & GW & 3 & 31 \\
\hline & & Power factor & $21 \%$ & $30 \%$ \\
\hline & \multirow[t]{2}{*}{ Photovoltaic } & GW & 9 & 52 \\
\hline & & Power factor & $16 \%$ & $21 \%$ \\
\hline & Nuclear & GW & 25 & 20 \\
\hline \multirow[t]{4}{*}{ Russia-Siberia } & Demand & TWh & 260 & 331 \\
\hline & Peak Load & GW & 38 & 49 \\
\hline & Hydropower & TWh & 108 & 124 \\
\hline & Nuclear & GW & 0 & 2 \\
\hline \multirow[t]{4}{*}{ Russia-Far East } & Demand & TWh & 39 & 54 \\
\hline & Peak Load & GW & 6.3 & 8.8 \\
\hline & Hydropower & TWh & 14 & 18 \\
\hline & Nuclear & GW & 0 & 1 \\
\hline
\end{tabular}

GW = gigawatt, $\mathrm{TWh}$ =terawatt-hour.

Source: Électricité de France (2018a, 2019b). 
The model outputs included regional system costs, marginal costs, and revenues of each generation class, as well as resultant $\mathrm{CO}_{2}$ emissions. As an additional benefit, savings in the total costs can be counted together with the reductions in pollution and greenhouse gas emissions that result from the interconnections. These represent the societal benefits of interconnectivity for the entire region. The simulation estimated the emissions as outputs of different cases. However, the costs of emissions were not used as inputs so as to avoid affecting the dispatch simulation process, which was based solely on financial costs.

Precisely how the costs and benefits will be distributed among the participating countries is a subject for further studies. It is also a topic that is complicated by the fact that, in the globalized economy, the costs and benefits of the scheme are not distributed by the territorial location of assets. The participating countries may also join interconnection projects as shareholders, lenders, equipment suppliers and contractors, operators, and service providers, and in all these various roles they may tap into benefits from the joint scheme collectively.

\section{B. Modeling Power Trade and Interconnections in the Northeast Asia Region System}

Presently, the NEA region's transmission interconnection is quite limited. As of 2020, there are three transnational power trading connections: (i) the Russian Federation to Mongolia, (ii) the PRC to Mongolia, and (iii) the Russian Federation to the PRC (Figure 8). Mongolia imports power from the Russian Federation to cover $20 \%$ of its domestic electricity consumption, but there is only a grid-togrid connection point in the central region grid of Mongolia from Buryatia, the Russian Federation (through a $220 \mathrm{kV}$ AC transmission line). Other connections are only available to the border areas. They do not connect to the central grid system of Mongolia. These mainly include power supply to a border area in the western Mongolia. Likewise, Mongolia also imports power from the PRC for power supply directly to the Oyu Tolgoi mining (through a $220 \mathrm{kV}$ AC transmission line) without connecting the supply to Mongolia's grid systems. There is a missing link between the Oyu Tolgoi and New Oyu Tolgoi stations within Mongolia, as indicated in Figure 9. The Russian Federation's hydropower from Amur is exported to PRC's Heilongjiang Province through cross-border grid interconnections.

7 A transmission line has already connected the PRC (Inner Mongolia Autonomous Region) to the Oyu Tolgoi mining operation, but this line is not integrated into Mongolia's central grid systems. This transmission's ownership within Mongolia was transferred from the PRC to Mongolia, and there are plans to establish an interconnection and complete this missing link. Oyu Tolgoi mining company is now planning to develop its own coal thermal power plant for self-power consumption and domestic power supply to Mongolia. 
Figure 8: Cross-Border Power Trade in Northeast Asia Region, as of March 2020

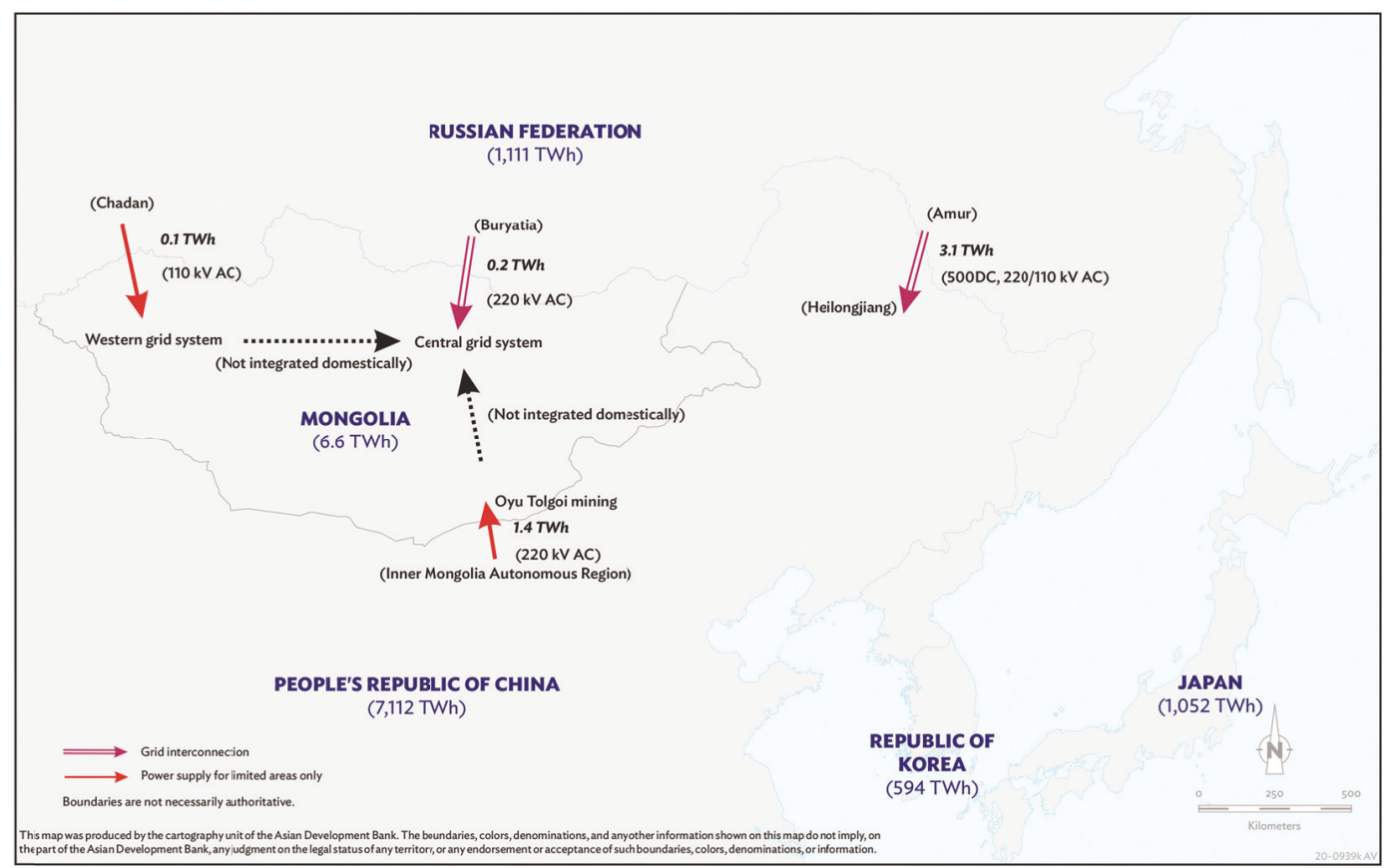

$\mathrm{AC}=$ alternating current, $\mathrm{DC}=$ direct current, $\mathrm{kV}=$ kilovolt, $\mathrm{TWh}=$ terawatt-hour.

Note: In addition to the above connection points, there are some medium and low voltage lines serving Mongolia's towns in the border areas by the PRC and the Russian Federation.

Source: BP (2019), Energy Regulatory Commission Mongolia (2019), Inter Rao (2020), Liu (2015), Oyu Tolgoi (2017), Renewable Energy Institute (2017).

The NAPSI Study considered adding more cross-border interconnections among grid systems in the countries, depending on some scenarios. Under the NAPSI Study, power system flows within the NEA region are assessed at the level of individual country systems for Japan and ROK, whereas the countrywide grid systems of Mongolia, PRC, and the Russian Federation are divided into subsystems operating within each country. The Mongolian grid system is assumed to divide into Ulaanbaatar's central region grid and the South Gobi area's separate grid. The PRC grid is similarly divided into PRC West and PRC East grids. For the Russian system, only the Siberian and the Far East systems are represented in the model. These are illustrated as nodes of the simplified model shown in Figure 10, which are connected by internal and cross-border transmission lines. ${ }^{8}$

8 The NAPSI Study acknowledges the political uncertainty related to creating a connection from the Russian Federation's Far East to the ROK through the Democratic People's Republic of Korea (DPRK), which did not participate in the NAPSI Study. Despite this, it was included as a transit route from the Russian Federation's Far East to the ROK. 


\section{Figure 9: Existing Grid Systems of Mongolia, as of March 2020}

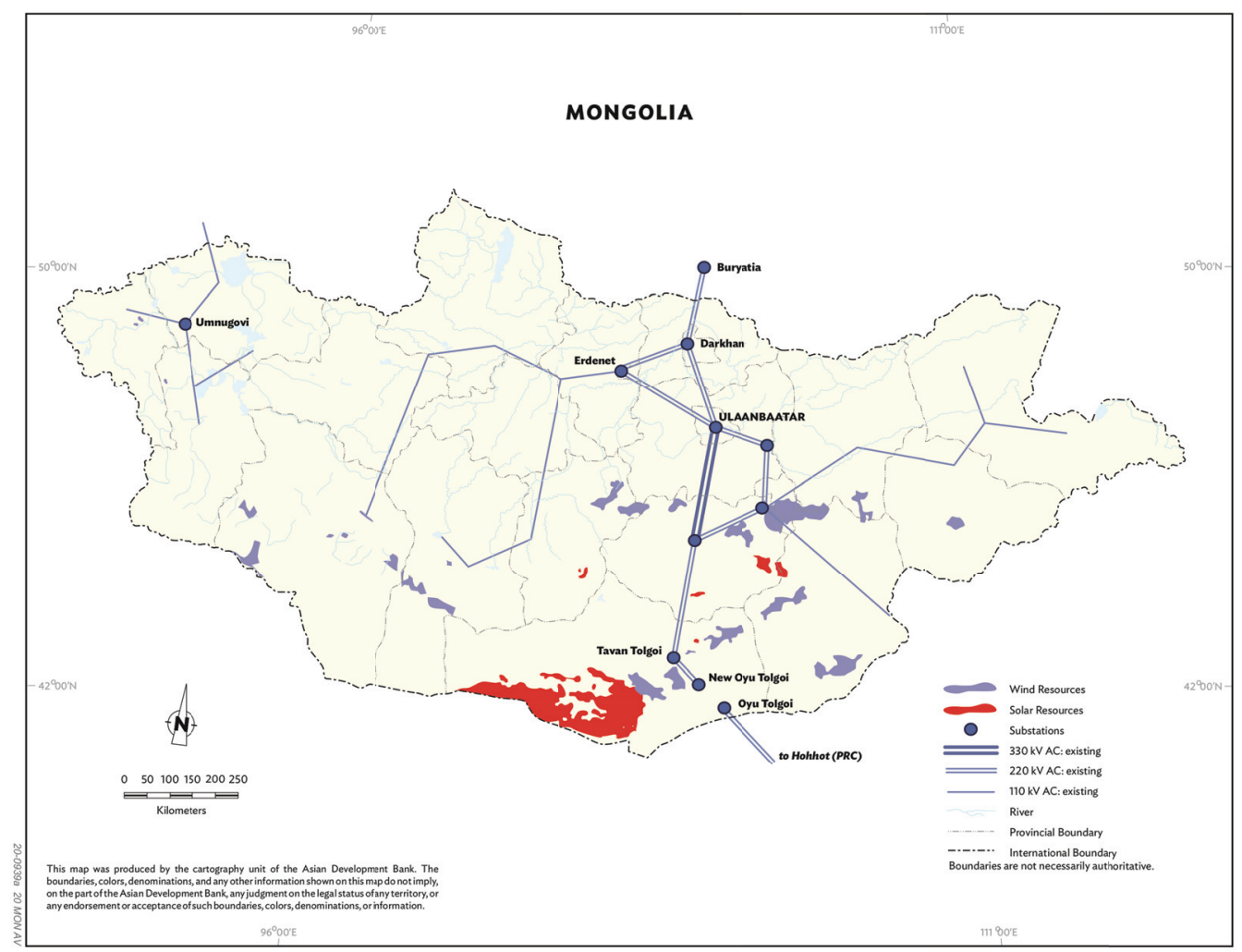

$\mathrm{HVDC}=$ high-voltage direct current, $\mathrm{kV}=$ kilovolt, $\mathrm{kW}=$ kilowatt, $\mathrm{PV}=$ photovoltaic, $\mathrm{RE}=$ renewable energy .

Source: Électricité de France (2018c).

Among the four scenarios for developing energy generation in the regional system, the NAPSI Study takes as a baseline Scenario 0 with no requirements for any new development scheme. This scenario anticipated that $0.3 \mathrm{GW}$ of renewable energy resources would be available within Mongolia for the year 2020. ${ }^{9}$ It also projected the corresponding transmission connections on the basis of an assumption that certain upgrades to the existing $220 \mathrm{kV}$ central grid in Mongolia would have already been completed. ${ }^{10}$

Under the NAPSI Study, the three other energy generation scenarios (section II.B.3) to be modeled are for the system configuration to be developed by (i) year 2026 with 5 GW renewable energy development in Mongolia (Scenario 1), (ii) year 2036 with $10 \mathrm{GW}$ renewable energy development in Mongolia (Scenario 2), and (iii) year 2036 with 100 GW renewable energy development in Mongolia (Scenario 3). These renewable energy resources can be exploited in the Mongolian Gobi Desert, where there are not, as yet, any active renewable energy developments.

9 As of March 2020, the tangible size of Mongolia's renewable energy production was 295 MW (i.e., about 0.3 GW), including $260 \mathrm{MW}$ from wind and solar power (ADB 2020) and 35 MW from hydropower (Fraunhofer ISE 2018).

10 The NAPSI Study assumed that the missing link between the Oyu Tologoi and New Oyu Tolgoi substations would be interconnected by 2020, and its cost was not reflected in the NAPSI Study. However, this assumption is not expected to be realized within 2020. Therefore, an additional cost for this alternating current interconnection was given to the investment costs of the integrated alternating current configuration, where this interconnection should be the base for the simulation, although other configurations (i.e., quarantined or integrated direct current configurations) would be relevant (section III.C) 


\section{Figure 10: Development Scenarios of Interconnections for Renewable Energy Production in South Gobi, Mongolia}
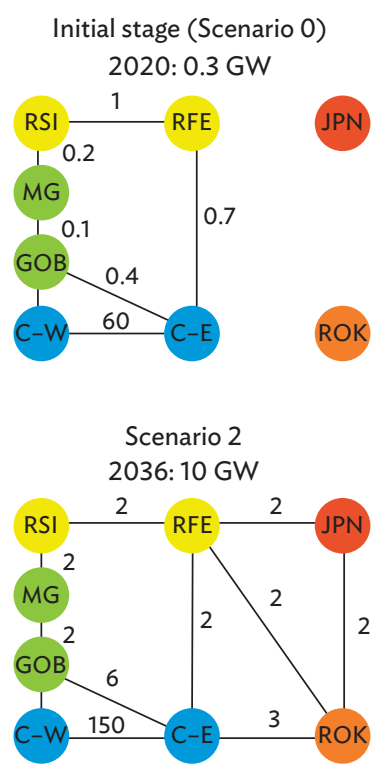
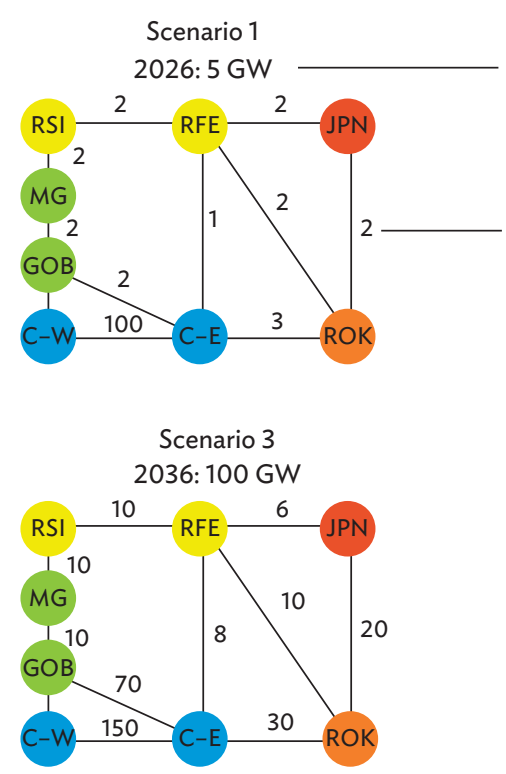

Renewable capacity $Y$

connected at the GOBI

node

Transmission capacity

in GW between countries

or areas

MG Mongolia-Ulaanbaatar

GOB Mongolia-GOBI

C-W China-West

C-E) China-East

RFE Russia-Far East

RSI Russia-Siberia

Republic of Korea

Japan

$\mathrm{GW}=$ gigawatt.

Source: Électricité de France (2018c and 2019b).

In Figure 11, load flow distribution is shown for each cross-border transmission line in the form of its annual load flow duration curve. It illustrates the power flows in Scenario 2 with $10 \mathrm{GW}$ (30 TWh) of renewable energy production capacity in South Gobi (the $10 \mathrm{GW}$ are comprised of $5 \mathrm{GW}$ of wind power [generating $21 \mathrm{TWh}$ ] and $5 \mathrm{GW}$ of solar photovoltaic [generating $9 \mathrm{TWh}$ ]). When the red duration curve is on the positive side of the vertical axis, power flows in the direction of the title of the curve, and the magnitude of capacity is shown by the vertical axis. When the red curve falls to the negative side of the vertical axis, the direction of electricity flow is the opposite. The horizontal axis represents the time (duration) over a year ( 8,760 hours).

The model is an idealized view of the interconnections, assuming a free regional electricity market with a priority dispatch of electricity. In this model, every differential in marginal costs between two nodes is utilized for transmitting electricity from a node with a lower marginal cost to a neighboring node with a higher marginal cost. Therefore, whenever the supply-demand balance allows, and when low- or nearzero marginal cost hydropower, solar photovoltaic, or wind energy is dominant, electricity will be transmitted. Such opportunities arise even because of differences in the time zones of different markets and because of differences in daily and seasonal load variation. Realizing such open and intensive trading would require that the trading processes be managed by national exchanges (e.g., such as Korean Power Exchange in the ROK), which cover most or all market participants of the country and in which any importer or exporter of electricity can be a party. These exchanges have proven successful at maintaining system reliability and selecting least-cost generating resources in various regions around the world, but would be more complicated to implement over the entire NEA region. It would also call for a standardized cost coverage mechanism for electricity interconnections. 


\section{Figure 11: Load Flow of Cross-Border Interconnections under Scenario 2: 10 GW Renewable Energy}

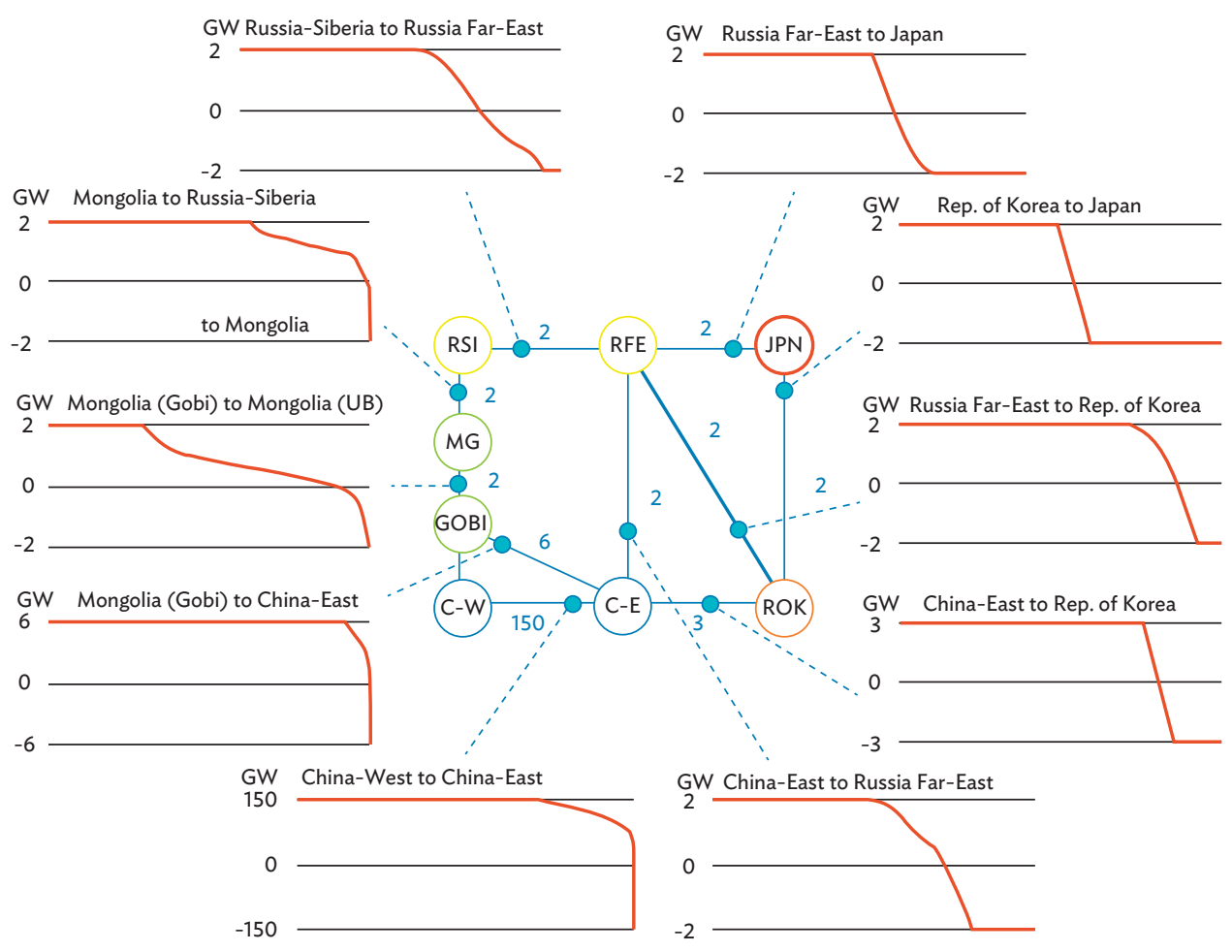

$\mathrm{C}-\mathrm{W}=$ China-West, $\mathrm{C}-\mathrm{E}=$ China-East, $\mathrm{GOBI}=$ Mongolia-Gobi, $\mathrm{GW}=$ gigawatt. JPN = Japan, MG = Mongolia-Ulaanbaatar, $\mathrm{RSI}=$ Russia-Siberia, RFE = Russia-Far East, ROK = Republic of Korea.

Source: Électricité de France (2018c).

It can be observed from the simulation that some lines are mainly used in one direction. These include electricity transmission from Western PRC to the East, from South Gobi to Eastern PRC, and, in general, toward the ROK, both from the PRC and the Russian Federation. Other lines are used in a more balanced bidirectional way. In the simulation, electricity trading with Japan is active and bidirectional. One can also observe that the lines are mostly fully loaded-on average at more than 90\% capacity factor-indicating that capacities are of about the right magnitude and that at nearly all times there are marginal cost differences present, thus triggering import or export. Because of the low marginal costs of Mongolia's renewable energy, unidirectional exports from Mongolia to the Russian Federation and the PRC prevails. Through onward trading from the Russian Federation to Japan, the PRC, and the ROK, it appears that the PRC and the ROK would be the largest off-takers for Mongolian electricity.

In the $10 \mathrm{GW}$ renewable energy case under Scenario 2, Japan has 2+2 GW interconnections, which equals to a theoretical maximum of annual trading of 35 TWh with the Russian Federation and the ROK. Despite the high fossil fuel costs, Japan's diverse generation mix, including nuclear and renewables, and differences in daily load variation-possibly helped by the 2-hour time difference with the Russian Federation-cause it to be an active trader in both directions. The time difference enables power trading horizontally across the countries, and the difference of daylight hours, subject to seasons, can increase further power trading opportunities horizontally and vertically across the 
countries. For example, Mongolia has 15 hours of daylight in the summertime, from 5:30 a.m. to 8:30 p.m. and thus solar photovoltaic generation can last longer than in countries at lower latitudes. This can help other countries meet the summer peak demand for electricity. Even after sunset, wind power generation can continue.

Overall, the model indicated that Scenario 2 included $19 \mathrm{GW}$ of the total capacity of cross-border interconnections, which equals the maximum potential of $166 \mathrm{TWh}$ annual export/import transactions, and about 150 TWh of simulated transactions." This is five times the renewable energy production of the planned South Gobi renewable energy base (i.e., $30 \mathrm{TWh}$ ), proving again the feasibility of interconnections as they allow for dispersal of clean energy and other low-cost generation over the NEA region.

\section{Options for Mongolian Grid Development}

The NAPSI Study scenarios give rise to key questions concerning how to begin developing regional interconnections and what development options should be considered to share Mongolia's renewable energy with other countries efficiently. In responding to these questions, the GESP analysis (section II.B.2) of the Mongolian energy system until 2036 clarified that the generation capacity considered for regional development would exceed the anticipated capacity of the Mongolian grid against the NEA interconnection scheme. Even with all currently planned grid reinforcing to be completed by 2020, including $220 \mathrm{kV}$ lines from the Mongolian central region surrounding the capital to the mining operations in the South, it is obvious that these lines will not be sufficient for the evacuation of power supplied by the planned South Gobi renewable energy base under the scenarios of 5 GW (2026), 10 GW (2036) and $100 \mathrm{GW}$ (long-term) as assumed in the modeling simulation (section III.B).

Given the constraints, there are three future network development configurations that could be used under any of the three energy development scenarios. One of them is to have a quarantined configuration, where the South Gobi renewable energy base network is to be physically segregated from the existing Mongolian $220 \mathrm{kV}$ transmission system. Alternatively, the South Gobi renewable energy base would be connected to the Mongolian national grid. In this case, the network configuration could be based on either AC or DC technologies.

The three options for future network configurations-(i) quarantined DC, (ii) integrated DC, and (iii) integrated AC-needed to be analyzed in the NAPSI Study. This means that a total of 9 grid configuration alternatives were analyzed through network and load flow analysis when each of the three configurations was coupled with each of the three scenarios (5 GW, $10 \mathrm{GW}$, and $100 \mathrm{GW}$ ). During the modeling process, the NAPSI Study checked if each configuration would be technically feasible and compared its cost and benefit relative to the other configurations subject to a given scenario. These in-depth analyses were conducted in Mongolia's context, and extended to each of other NEA countries in the regional context. For the purposes of briefly describing the three configurations, however, the data from Scenario 2 can be taken as representative.

1 Figure 11 Indicates annual power trading of $19 \mathrm{GW}$ (equivalent to about 166 TWh by multiplying by 8,760 hours), comprising Mongolia-Russian Federation (2 GW), Russian Federation-Japan (2 GW), ROK-Japan (2 GW), Russian Federation-ROK (2 GW), PRC-ROK (3 GW), Russian Federation-PRC (2 GW), and Mongolia (South Gobi)-PRC $(6 \mathrm{GW})$. Export and import transactions of this size should be reasonable to an aggregated power flow of $150 \mathrm{TWh}$, which is represented in annual load flow duration curves. 


\section{Quarantined Configuration}

In the quarantined configuration, the South Gobi renewable energy would be transmitted through two new high-voltage DC (HVDC) lines: (i) one to Baotou in PRC at $510 \mathrm{~km}$ distance of $500 \mathrm{kV}$ under Scenario 1, to be upgraded to $800 \mathrm{kV}$ under Scenario 2; and (ii) the other line linking directly to the Russian Siberia grid with a connection point to the Republic of Buryatia-which is part of the Russian Far East Federal District-at $900 \mathrm{~km}$ distance of $500 \mathrm{kV}$. These quarantined HVDC lines would operate independently and bypass the Mongolian grid. Scenario 2 transmission configuration is indicated in Figure 12.

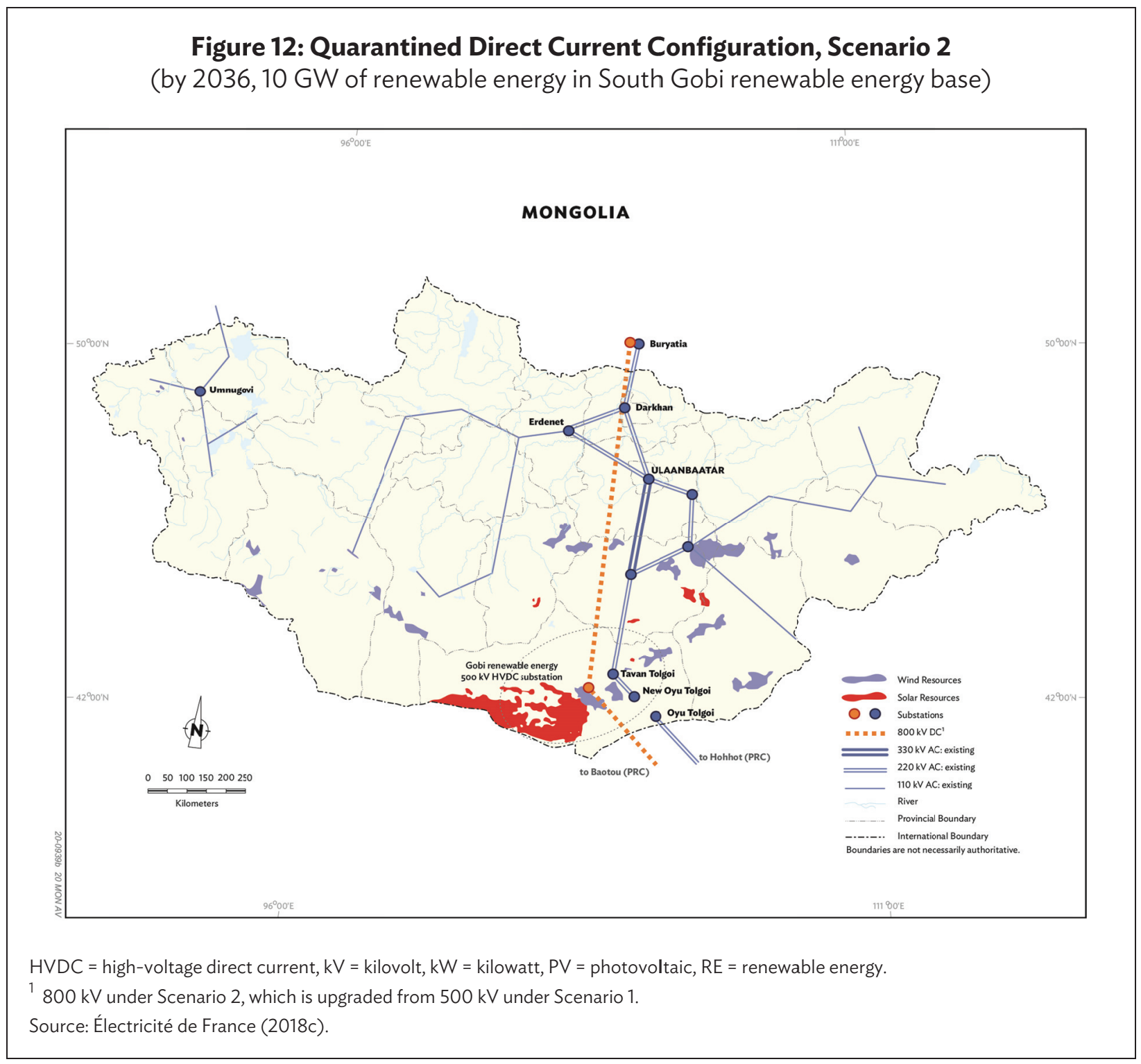


The above Figure 12's circled area is highlighted in Figure 13. As the predominant market is assumed to be in PRC under Scenario 2-10 GW renewable energy (5 $\mathrm{GW}$ of wind and $5 \mathrm{GW}$ of solar)-the connection to PRC (Baotou) would be of 6 GW capacity and the line to the Russian Federation would be of 2 GW capacity, totaling $8 \mathrm{GW}$. Despite the co-existence of two types of variable renewable energy production, wind and solar, the inherent variability of renewable energy generation would render the production of the full 10 GW capacity a very infrequent event. This enables the transmission capacity to be built lower than $10 \mathrm{GW}$ and thus allows operation to be more economical at a higher capacity utilization rate.

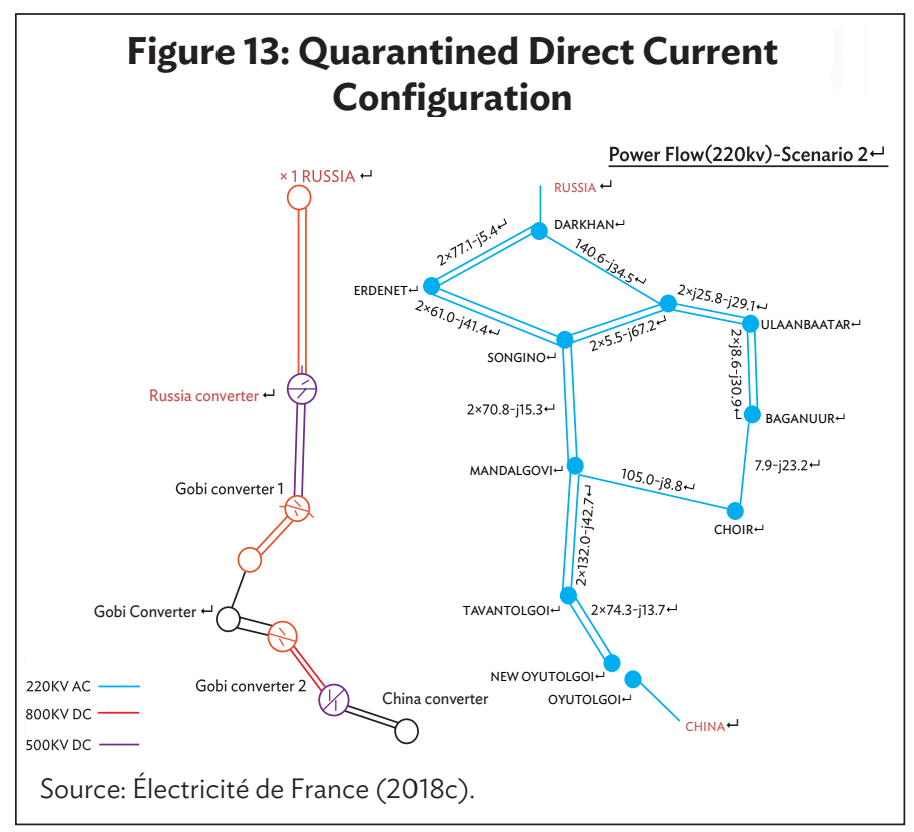

In this configuration, the South Gobi renewable energy base is not connected to the Mongolian grid at all. The DC line can be used for exports from Mongolia to PRC and the Russian Federation, but it can also serve as a transboundary connection between the PRC and the Russian Federation. Further, it will enable the Russian Federation hydropower to balance the variability of renewable electricity export from Mongolia to PRC. The Russian power system would become a natural storage and reserve capacity due the existing excess power capacity. In the event that Russian hydropower is affected by outages because of frozen rivers during the winter, then PRC's power could make up the difference. PRC has a power surplus in the winter, caused by lower electricity demand and excess supply as a result of thermal generation of CHPs for heat supply in the winter period (UN-ESCAP 2019).

\section{Integrated Direct Current Configuration}

The integrated DC configuration would follow the previous configuration (Figure 12), with the addition of a connection to the Mongolian grids. Distributed generation of the South Gobi renewable energy base would be led to a step-up transformer station (Figure 14). Three converter stations would then be needed. Two would be, as in the quarantined configuration, for exports through HVDC lines to the PRC and the Russian Federation. The third would connect the South Gobi renewable energy base to the Mongolian grid via a $220 \mathrm{kV}$ line to Tavan Tolgoi mining site, where it would connect to the national $220 \mathrm{kV}$ grid. This would be realized via a back-to-back (B2B) station. 


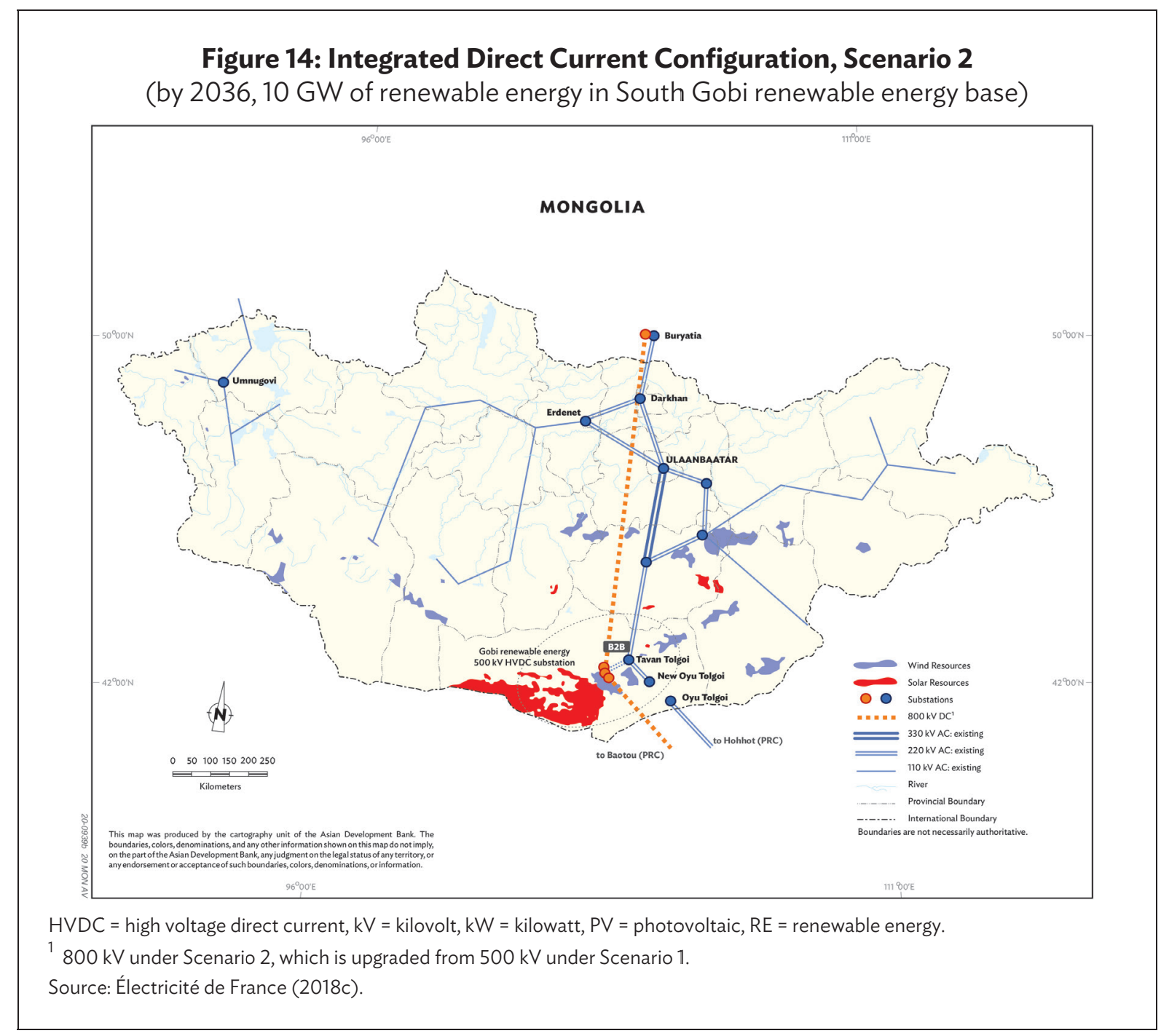

Figure 14's circled area is highlighted in Figure 15. In the Integrated DC configuration, a B2B station is used to interconnect two systems, the $500 \mathrm{kV} / 800$ $k V$ line from the South Gobi renewable energy base and the $220 \mathrm{kV} A C$ of the Mongolian Central Electricity System. B2B HVDC is used to connect independent transmission systems with incompatible electrical frequencies and/or different system dynamics and control principles. The rectifier units (conversion from $A C$ to $D C$ ) and inverter units (conversion from $D C$ to $A C$ ) are physically in the same station, and therefore called back-to-back. $\mathrm{B} 2 \mathrm{~B}$ is needed to meet system security

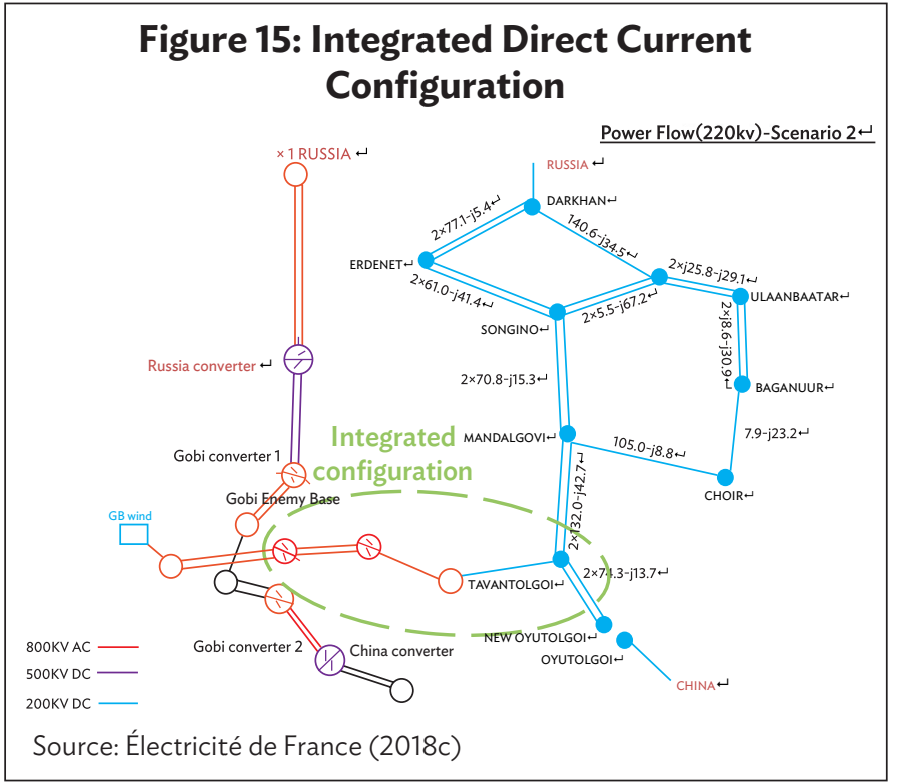


requirements as the supply capacity of the South Gobi renewable energy base is multifold that of the Mongolian demand. This poses a risk to system dynamics, especially if one of the two DC lines (to PRC and the Russian Federation) is blocked or faulted. In Scenario 2, the capacity of the B2B is set at 500 MW, and an HVDC transmission line-to be extended to Baotou in PRC for power export purposeneeds to be upgraded from $500 \mathrm{kV}$ to $800 \mathrm{kV}$.

\section{Integrated Alternating Current Configuration}

The integrated AC configuration has three aspects (Figure 16). First, it would provide a strong connection from the South Gobi renewable energy base to Mongolia's domestic grid. Second, it would incorporate a so-called bridge model proposed by Rosseti to Mongolia, which would develop a strong high-voltage AC (HVAC) connection to the Russian grid with a west-to-east transmission connection running from the western part of the Siberian grid, through Umnugovi in western Mongolia, through Erdenet and Darkhan in north to central Mongolia, and back to the Russian Federation's Buryatia. Third, this configuration would include the development of a $500 \mathrm{kV}$ transmission system that overlays the current $220 \mathrm{kV}$ system in Mongolia, also running from north to south, to connect the South Gobi renewable energy base to the bridge configuration in Erdenet.

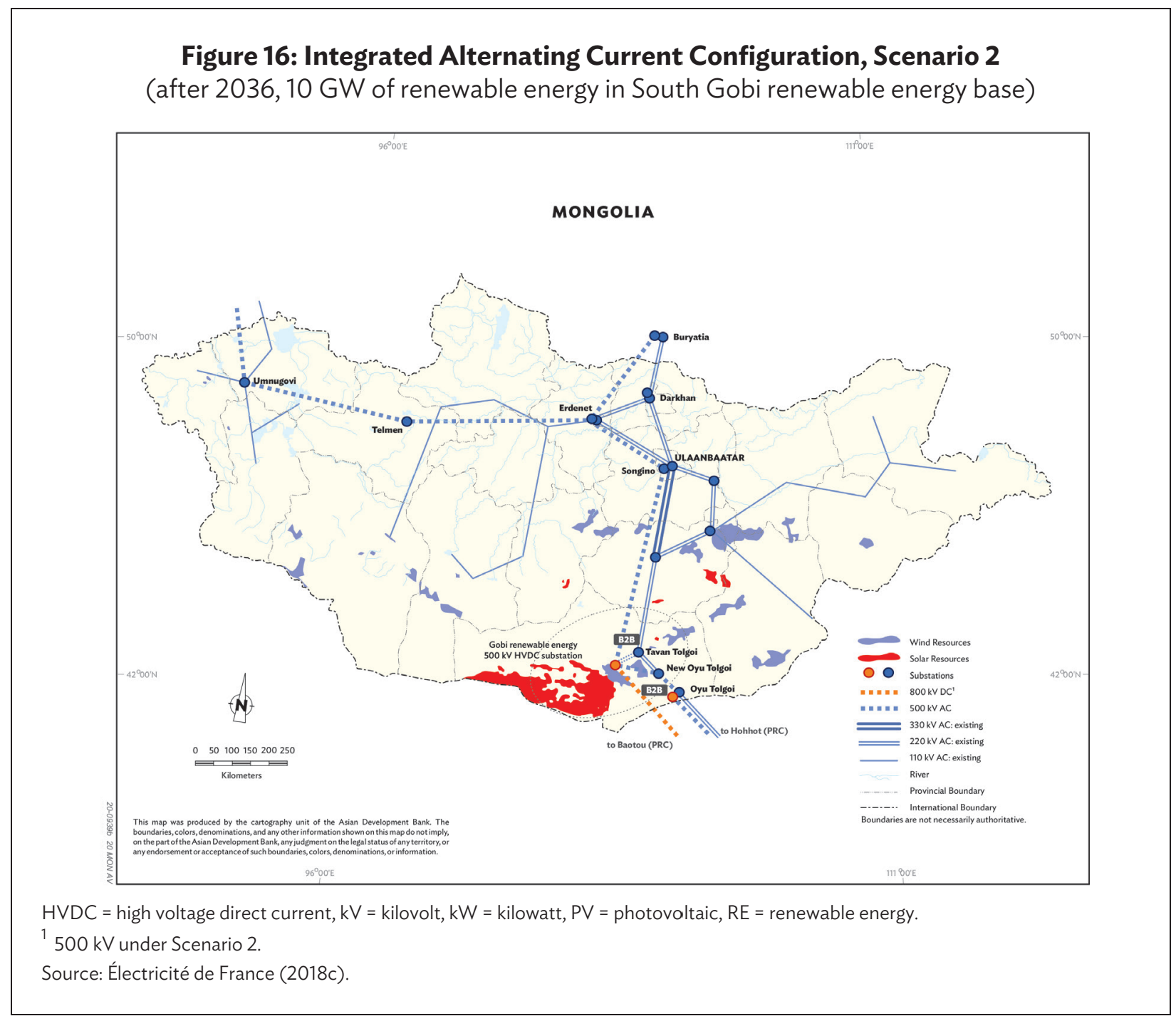


In this configuration, substations linking the $500 \mathrm{kV}$ AC system to the $220 \mathrm{kV} \mathrm{AC}$ system are planned for Oyu Tolgoi, Tavan Tolgoi, Songino (Near Ulaanbaatar), Erdenet, Darkhan, Telmen, and Umnugovi). The existing AC line from PRC to the Oyu Tolgoi mining complex would also be upgraded to $500 \mathrm{kV}$, having a 2 GW carrying capacity. Figure 16's circled area is highlighted in Figure 17. Although not considered in the NAPSI Study, a B2B station of 2 GW capacity in Oyu Tolgoi would be necessary for this line unless the PRC and the Russian Federation grids form a single wide-area synchronous grid, which is unlikely within the NAPSI Study horizon of 2036. The integrated AC configuration has a slightly higher transboundary

Figure 17: Integrated Alternating Current Configuration

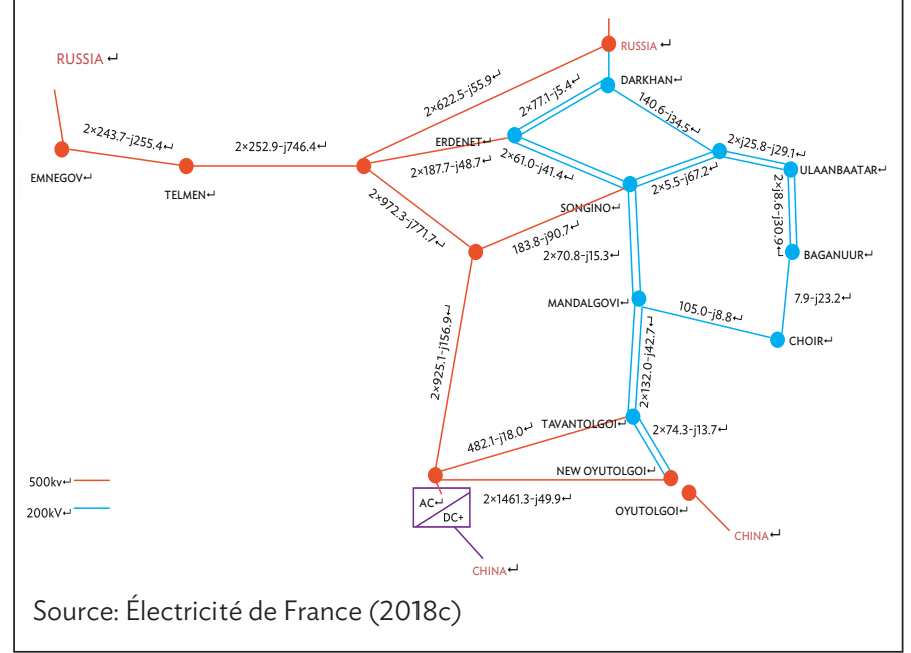
transmission capacity ( $9 \mathrm{GW}$ ) than the two other configurations ( $8 \mathrm{GW}$ ) because it includes an additional $1 \mathrm{GW}$ east-west transmission channel to the Russian Federation. This bridge model is motivated by a strategy to construct a strong import channel from the Russian Federation so that Mongolia would not need to construct large hydropower generators on the Selenge river system. This strategy would be in the Russian interest, as it would protect the flow of water into Lake Baikal.

On the Mongolian side, a strong transmission connection that would unite the country's central and western power systems into one strong national grid, has been on the energy policy agenda for years. However, the contemplated voltage and capacity of the bridge model of $500 \mathrm{kV}$ and $1 \mathrm{GW}$ would go beyond the actual total demand of Mongolian western region's power systems, which today remains well below $0.1 \mathrm{GW}$ (taking the Western Region and Altai Uliastai Integrated Power Systems together).

In this context, the economics of the AC lines will depend on two main factors. One is the potential and willingness of Mongolia to develop hydropower and CHP plants in the western and Altai Uliastai regions. This would then require the transmission line to evacuate excess power to the central region or for export to the Russian Federation. Such plans for generation investments exist, among others, for Erdeneburen hydropower plant and Ulaangom CHP plant. For the purpose of domestic consumption, however, Mongolia's generation development necessitates primarily the section between Mongolia's west and central regions. The second factor in providing load for the lines is the development of electricity trade with the Russian Federation. This could be either for export or import, but it would need to be beyond the $2 \mathrm{GW}$ that is already enabled by the Darkhan-Buryatia connection. Therefore, the increased potential of electricity imports from the Russian Federation rivals the domestic generation alternatives. However, the integrated $A C$ alternative may provide certain benefits for the local electricity generation arena, which may offset its slightly higher cost for Mongolia's domestic power system development.

\section{Comparison of Options for Mongolian Grid Development}

When comparing the three configuration options, there is one common transmission structure required. All three configurations require the building of a $500 \mathrm{kV} \mathrm{HVDC}$ interconnection from the 
Mongolia's South Gobi to PRC's Baotou under Scenarios 1 and 2, which would be upgraded to $800 \mathrm{kV}$ under Scenario 3. This new transmission line would enable evacuation of renewable energy power from Mongolia to PRC and is therefore essential under any option.

In the case of the quarantined DC configuration, this $500 \mathrm{kV} / 800 \mathrm{kV} \mathrm{HVDC}$ transmission would be physically segregated from the existing grid systems of Mongolia. This would allow for energy export but would not allow Mongolia to use the South Gobi's renewable energy for its own consumption within the country. Instead, this configuration would make no impact on the existing domestic power system of Mongolia. It should, therefore, be the lowest first-cost option. Following this, however, the NAPSI Study proposes to include the additional cost of another long distance 500 kV HVDC line, which would be extended from the South Gobi renewable energy base to the northern side to be connected to the Russian grid. The NAPSI Study explains that this would supply balancing power to stabilize the unstable and weather-dependent power supply of the South Gobi renewable energy. This would mean the construction of 900 kilometers of line and would therefore represent a significant additional cost.

In the case of the integrated DC configuration, the barrier to domestic supply of South Gobi renewable energy would be resolved by an interconnection from the South Gobi HVDC station to the existing AC substation of the central region grid of Mongolia. This conversion between AC and DC systems would require an additional cost over the quarantined configuration's cost.

In the case of the integrated AC configuration, both power export and domestic consumption would be available. This configuration would help Mongolia establish a single national grid system to cover across east to west and from south to north. This would improve the whole system's stability. Therefore, the NAPSI Study indicates that this option would have the flexibility to expand the power system in the most efficient manner. This solution sounds ideal but would also be the most expensive option.

The creation of an extension to the western area of Mongolia would allow some hydropower and renewable potential in the area to be developed, but it may be unnecessary for domestic consumption because this network configuration would also strengthen integration with the Russia Federation grid and enable electricity to be imported from the Russian Federation at more reasonable prices than the development of western Mongolia's resources. This configuration assumes the connection from the Mongolia's central region's grid to the PRC system by interconnecting the presently missing link between the Oyu Toligoi and the New Oyu Tolgoi substations. This was treated as a precondition in the NAPSI Study and, as a result, the study did not include the additional cost of this missing link's interconnection and the necessary converters between $A C$ and DC. This missing cost is estimated at $\$ 440$ million. To make an additional supply margin, one more additional HV line would also need to be extended to the Russian Federation.

The cost for each network configuration for Mongolia's grid development was revised by the author of this report and compared in Figure 18. It includes cross-border interconnections to their end points. The results indicate that the costs of the three alternatives are almost the same at about $\$ 2$ billion under scenario 1 for $5 \mathrm{GW}$ renewable energy supply. Under Scenario 2, the costs will be differentiated in the range of $\$ 2.9$ billion to $\$ 3.5$ billion, depending on the configuration options. To develop and transmit $10 \mathrm{GW}$ renewable energy from Mongolia's Gobi Desert, the lower cost configuration will be the quarantined DC configuration and the highest cost configuration will be the integrated $A C$. 


\section{Figure 18: Cost of Transmission Infrastructure Investments in Mongolia, Scenarios 1 and 2}

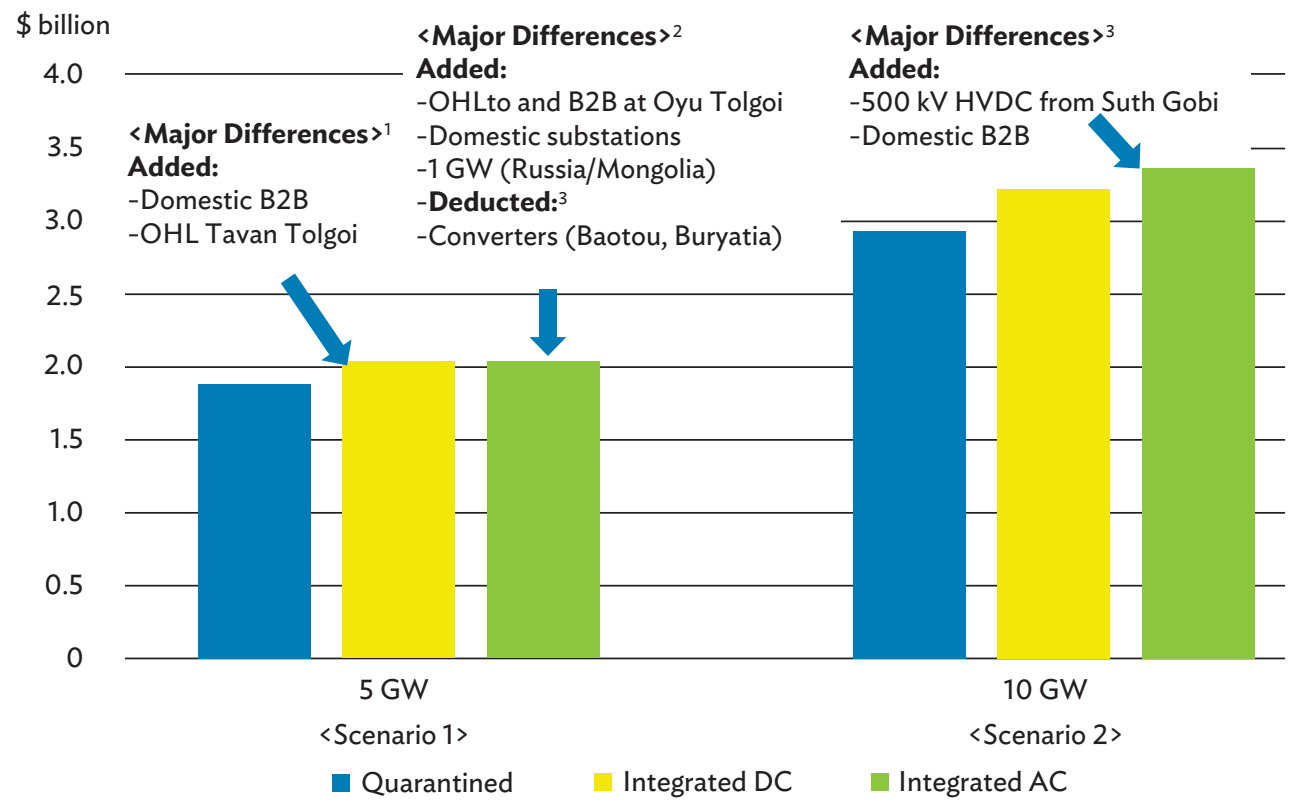

$A C=$ alternating current, $\mathrm{B} 2 \mathrm{~B}=$ back-to-back, $\mathrm{DC}=$ direct current, $\mathrm{GW}=$ gigawatt, $\mathrm{HVDC}=$ high-voltage direct current, $\mathrm{kV}=\mathrm{kilovolt}$, $\mathrm{OHL}=$ overhead line, $\mathrm{PRC}=$ People's Republic of China.

${ }^{1}$ The differential cost from the quarantined DC option is mainly based on the added costs of (i) an overhead AC line to be connected from the South Gobi substation to the Mongolia's Tavan Tolgoi substation (i.e., the central region grid) and (ii) its B2B convertor from DC to AC within Mongolia.

${ }^{2}$ The differential cost from the DC configurations is mainly based on the added costs of (i) an overhead AC line to be connected from the Oyu Tolgoi substation to the Mongolia's central region grid and its B2B convertor at the Oyu Tolgoi substation, (ii) other domestic AC substations along a new $500 \mathrm{kV}$ AC lines of the east-west transmission channel to the Russian Federation, and (iii) their additional $1 \mathrm{GW}$ capacity costs. However, the cost of converters to the PRC's Baotou and the Russian Federation's Buryatia is unnecessary for the AC integration since no HVDC interconnection is assumed under Scenario 1's integrated AC configuration in the study.

${ }^{3}$ The differential cost from the DC configurations is mainly based on the added costs of the $500 \mathrm{kV} H V D C$ interconnection from South Gobi to PRC's Baotou and its B2B convertor from DC to AC within Mongolia.

Source: Électricité de France (2018a and 2019b).

Setting aside the NAPSI Study, the author of this report also reassessed power supply costs including generation and transmission costs to be delivered from the South Gobi renewable energy base to the marketplace in PRC or the Russian Federation under the integrated AC option with Scenario 2 (10 GW renewable energy capacity in 2026). The resultant indicative LCOE was 4.5 to 5.7 US cents $/ \mathrm{kWh} .{ }^{12} \mathrm{As}$ renewable energy is capital-intensive, its supply cost will be sensitive to the weighted average cost of capital. The share of the transmission infrastructure cost is from 0.8 to 1.1 cents $/ \mathrm{kWh}$ (18\% to $20 \%$ of the total, respectively). The LCOE of renewable energy generation in Mongolia will be from 3.7 to 4.6 cents $/ \mathrm{kWh}$. This LCOE for generation is much lower than any equivalent prevailing LCOE of other countries including the PRC, India, the United States (US), and European countries. For example, the weighted-average LCOE of onshore wind farms commissioned in 2018 in the PRC and the US was identical at 4.8 cents $/ \mathrm{kWh}$, which is lower than 7.6 cents $/ \mathrm{kWh}$ in France, 7.5 cents $/ \mathrm{kWh}$ in Germany, 6.2 cents/kWh in India, and 6.3 cents/kWh in the United Kingdom (IRENA, 2019). Similarly,

12 The range was given based on two discount rates of $5 \%$ and $8 \%$ for a mixed $10 \mathrm{GW}$ portfolio of wind and solar photovoltaic generating 29.8 TWh annually with total installed cost of $\$ 9.8$ billion, weighted average operational expenditures of $\$ 40 / \mathrm{kW}$, curtailment of $3 \%$, transmission losses of $2 \%$, converter losses of $1.5 \%$, and transmission infrastructure cost of $\$ 3.2$ billion over the life of 30 years. 
the weighted-average LCOE of new utility scale solar photovoltaic plants commissioned in 2018 was 6.7 cents/kWh in PRC, 6.3 cents/kWh in India, and 8.2 cents/kWh in the US (IRENA, 2019).

\section{Northeast Region Interconnection Development Pathways}

\section{Technological Options for Cross-Border Interconnections}

In addition to Mongolia's development options for the grid systems, the NAPSI Study investigates the regional interconnection schemes in other countries, taking into consideration the prospects for energy exchange between the five NEA countries. Most of the interconnecting lines across the countries would be long and fall into the category in which HVDC technology, as opposed to HVAC, is more feasible. HVDC is able to transmit more power with smaller systems losses compared to HVAC. HVDC technology is also used to interconnect power systems of different countries since it avoids synchronizing the two systems which can, in turn, make one country's system failures or accidents affect another country's system. ${ }^{13}$

HVDC lines operating at $\pm 500 \mathrm{kV}$ and $\pm 800 \mathrm{kV}$ levels are thus proposed as the most typical solution for NEA interconnectivity. The respective capacities of HVDC lines are at about $3.5 \mathrm{GW}$ and $8 \mathrm{GW}$, and their economic transmission distances are less than $800 \mathrm{~km}$ and $800-1100 \mathrm{~km}$, respectively. Today, the majority of HVDC projects in the world are at or lower than $\pm 660 \mathrm{kV}$, but several HVDC projects recently commissioned in PRC and Brazil operate at $\pm 800 \mathrm{kV}$. The world's first, and so far only, HVDC project operating at $\pm 1,100 \mathrm{kV}$ was commissioned in the PRC in 2018. HVDC is advantageous in reducing technical transmission losses compared to HVAC.

The NAPSI Study further compares two types of HVDC lines: (i) line-commutated converter's highvoltage direct current (LCC-HVDC) and (ii) voltage source converter's high-voltage direct current (VSC-HVDC). It concludes that LCC-HVDC is a realistic solution for most interconnectors, which will be based on a point-to-point (P2P) transmission of a large amount of power from different places over a long distance. For undersea cables, however, the study recommends VSC-HVDC technology as a primary option for the links between the ROK and Japan to help enhance flexibility across multiterminal links.

The NAPSI Study also suggests advanced technology for a new undersea line routing between Japan and the Russian Federation. Such a technology is under development for deep submarine cables up to $3,000 \mathrm{~m}$ depth. It is currently prototyped and is expected to be qualified in the midterm. For this purpose, voltage levels of $525 \mathrm{kV}$ and $600 \mathrm{kV}$ for cross-linked polyethylene (XLPE) cables have been qualified or are in the qualification process by different manufacturers. Research is ongoing for $800 \mathrm{kV}$ XLPE cables. Cabling technologies will be critical for the NEA interconnection projects.

Finally, the NAPSI Study establishes a cost database for all equipment blocks per relevant unit $(\$ / \mathrm{kW}$, $\$ / \mathrm{km}$, etc.). It covers all relevant costs from project planning to the operational start. These include the costs of land use and permits, consulting, engineering, project management, equipment supplies, infrastructure, construction, and commissioning. The estimates were based on particular references to the experience of regional projects and contractors.

13 For example, a blackout in one location can spread across the entire system through synchronized alternating current systems. 


\section{Regional Interconnection Options Beyond Mongolia}

The assumptions for the NAPSI Study grid network analyses were provided by the techno-economic analysis of the interconnection systems based on each country's system expansion plan and power demand as well as generation fleet. For example, the NAPSI Study modeled the East PRC 1,000 kV transmission system in detail, as well as the Mongolian system. Simplified models were developed for the transmission systems in Japan, the Russian Federation, and the ROK. The NAPSI Study reviewed the characteristics of all the power grids of the NEA region and selected suitable landing sites and locations of converter stations for interconnecting lines, minimizing reinforcement needs around the end points of transmission lines and taking into consideration $\mathrm{N}-1$ criteria in setting the transmission capacities. ${ }^{14}$ The NAPSI Study did not include any detailed routing for lines or specify reinforcements that may be required within each of the NEA countries (e.g., impacts of interconnections on the system losses), but planned construction or upgrade of principal grid network under each scenario for each country beyond Mongolia.

\section{a. People's Republic of China}

The PRC has two wide-area synchronous grids: the State Grid and the China Southern Power Grid. The PRC is systematically developing internal interconnections for a strong national grid. The northern power grids were synchronized in 2005. Since 2011, all PRC provinces are interconnected. The two synchronous grids are joined by HVDC back-to-back connections. The PRC invests heavily in ultrahigh voltage (UHV) grid development, both UHV-DC and UHV-AC, and plans to have a grid operating synchronously at 1,000 kV by 2036. In December 2018, SGCC announced an ownership reform for UHV transmission to spur investments. This would allow new investors to include insurance companies, large-scale industrial funds, and investment platforms owned by local governments. In 2019, 9 AC and 10 DC UHV power transmission projects have been built, with a total line length of $27,570 \mathrm{~km}$ and a transforming (converting) capacity of nearly $300 \mathrm{GW}$. Two UHV transmission projects, one $\mathrm{AC}$ and one DC, are under construction (Figure 19).

HVDC interconnections from the South Gobi renewable energy base to PRC could be managed by two options of interconnections. First, HVDC lines from Mongolia could join the PRC's UHV-AC substations, which are closest to the border. From that connection, power would then be dispersed and transported to demand centers through the UHV-AC network. Second, P2P HVDC configurations could be used to transmit power from the South Gobi renewable energy base directly over long distances to the load centers in PRC, causing minimal disruption to the UHV-AC systems.

Under the NAPSI Study, the first interconnection between Mongolia and the PRC is planned to be from South Gobi to Baotou. This line holds a key role in Scenarios 1 and 2 (Figure 19). Baotou is a prefecture-level city and the largest city by urban population in the PRC's Inner Mongolia Autonomous

Region. In Scenario 1 (5 GW), an HVDC line of $2 \mathrm{GW}$ is planned from the South Gobi renewable energy base to Baotou, which can be expanded to 8 GW under Scenario 3.

14 The $\mathrm{N}-1$ criterion is a transmission network's minimum system security measure that addresses redundancy in order to avoid potential power interruptions and/or system failure (International Council on Large Electric Systems [CIGRE] Study Committee, 2017). 


\section{Figure 19: Ultra-High Voltage Projects in Operation and Under Construction by the State Grid Corporation of China}

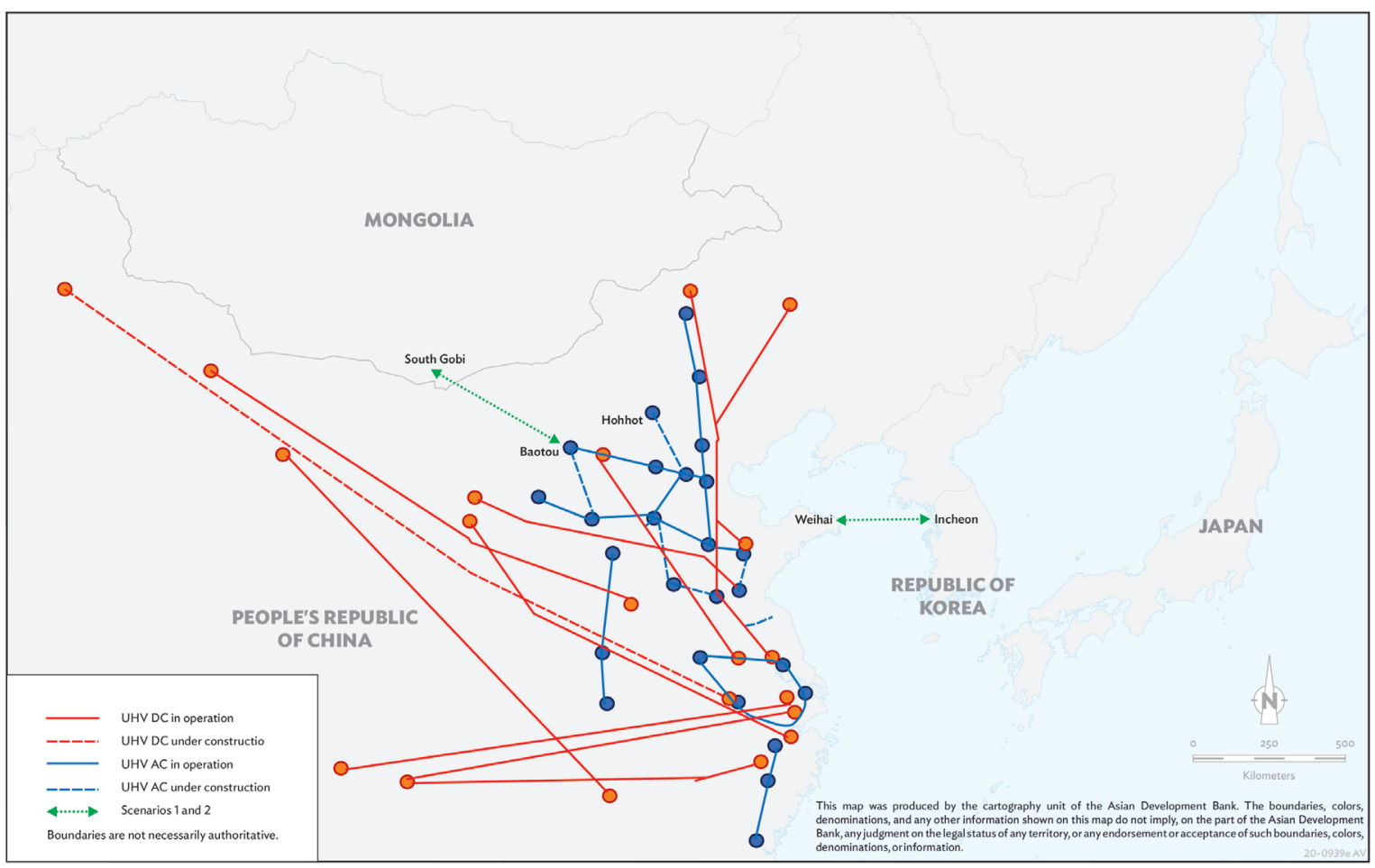

$A C=$ alternating current, $D C=$ direct current, $U H V=$ ultra-high voltage.

Source: State Grid Corporation of China (2020). Altered by the author.

However, the Inner Mongolia grid on the PRC side is currently, and in the near term, oversupplied. The wind energy capacity stood at about 29 GW and solar photovoltaic at 9 GW in 2018, together they offered $38 \mathrm{GW}$ of energy capacity. Wind curtailment is at 10\% and therefore new wind developments have not been encouraged in Inner Mongolia Autonomous Region during recent years. The development of the East PRC UHV grid is therefore of high importance, as it would allow more power to be evacuated to the Eastern PRC load centers. In the medium term (2026) and long term (2036), it is anticipated that the transmission de-bottlenecking will result in a better supply-demand balance, opening opportunities to export power from the South Gobi renewable energy base to the PRC and through the PRC to ROK.

The interconnection expansion plan under Scenario 3 includes three $\pm 800 \mathrm{kV}$ connections to UHVAC substations from Mongolia to Baotou, Ulanqab/Wulanchabu, and Huolinhe, all in Inner Mongolia Autonomous Region. However, considering the supply-demand situation, it is increasingly essential to develop P2P HVDC connections to efficiently bring electricity to the load centers. Therefore, there are four $\pm 800 \mathrm{kV}$ P2P HVDC connections planned to the major load centers of Bazhou (near Beijing), Tianjin, Tangshan, and Jinan. In addition, the plan includes one very long-distance connection to Nanyang in Southern Henan province at $\pm 1,100 \mathrm{kV}$. 
Currently, the PRC (SGCC) and the ROK (KEPCO) are in discussions to construct an HVDC interconnection between their two countries. The development is based on a memorandum of understanding (MOU) signed between the parties in 2017, which was followed by a review study in 2018 and negotiations on a joint development agreement. The plan is to have a special-purpose joint venture to own, construct, and operate the line. The interconnection is most likely to be an HVDC line with LCC-HVDC technology and a capacity of 2-2.4 GW operating at $500 \mathrm{kV}$. The converting station in the PRC is likely to be located at Weihai substation and in the ROK at Incheon or Siheung, located west of Seoul (Figure 19).

\section{b. Republic of Korea}

In terms of the regional electricity grid system, the ROK can be considered as "an island." Historical and political reasons have not allowed the country to connect to the DPRK or through its areas to the PRC's Northeast or the Russian Federation's Far East. In this sense, it should be more feasible to consider the proposed submarine cable interconnection between Incheon, ROK and Weihai, PRC (Figure 19), rather than alternative routes to go through DPRK. This is partly because the ROK's electricity load is mainly concentrated in the coastal regions. The main power stations are also located in the coastal towns and cities near the coal and natural gas import facilities. The country's terrain is hilly, and the power transmission corridors are tight. The domestic transmission voltages are $765 \mathrm{kV}$, $345 \mathrm{kV}, 154 \mathrm{kV}$, and $66 \mathrm{kV}$.

The upcoming renewable energy development within the ROK focuses on its southern parts. The supply-demand balance is, and will be, in surplus there. This surplus can be transmitted to the north, especially to the Seoul area. The planned interconnection from the PRC to the ROK's Incheon, will alleviate the transmission congestion by bringing $2-2.4 \mathrm{GW}$ of power to the metropolitan area. Under Scenario 2, the capacity is expected to increase to $4 \mathrm{GW}$. The grid reliability in the ROK is very high. Nevertheless, cross-border interconnections will help to further enhance reliability and balance the variability of the country's growing production of renewable energy.

Under Scenario 3, a $30 \mathrm{GW}$ interconnection capacity with the PRC is seen as feasible. The converter stations on the PRC side are planned in Weihai, Weifang, and Lin Yi. The landing points on the ROK's side are Incheon, Hwasung, and Seosan. Having such capacity built on the basis of 2-3 GW cables is regarded as uneconomic, and therefore the proposal is to have $3 \times 10 \mathrm{GW}$ submarine HVDC cables. Such a solution will not comply with the N-1 criterion, but it would not encounter the same issues of availability and cost of land for converter stations and corridor problems as would be caused by a more significant number of cables.

The NAPSI Study also makes a consideration for a connection from the Russian Federation through DPRK to the ROK as, at the time of the study's commencement, the regional foreign policy climate took steps for the better. The NAPSI Study chose Donghe in the northeast of the ROK as the end point for this HVDC line. Two converter stations would be placed in Japan, the first in Hadong in the south of the Korean peninsula and the second in Yasan. In the event that DPRK was fully included in the NEA interconnection schemes, the ROK would not be treated as an island but could easily be connected to the continent as the grid networking hub and to Japan as a power transit.

\section{c. Japan}

Japan is in the middle of restructuring its power industry, which is operated by 10 (previously) vertically integrated companies. The country's national grid is quite fragmented. Eastern and northern areas 
operate at 50 hertz $(\mathrm{Hz})$ whereas western and southern areas operate at $60 \mathrm{~Hz}$. Therefore, there are ample examples of AC/DC converter stations in operation. Yet, inter-utility trade has been limited in relation to overall electricity consumption. Wind energy resources are most abundant in the north, in Hokkaido as well as in Aomori and Akita prefectures, and solar resources intensify toward the south.

The 2013 Policy on Electricity System Reforms established a three-phase reform process to be implemented in the following order: (i) expansion of cross-regional grid operation, (ii) full liberalization of retail market entry, and (iii) legal separation of transmission and distribution from the vertically integrated business. The country completed full deregulation of the electricity retail market (including the residential sector and other small-scale customers) in 2016. The power industry has been further transformed by the legal separation of transmission and distribution from the vertically integrated business in April 2020.

Regarding the nation's power generation mix, Japan's policy target for the 2030 energy mix is to reduce fossil fuel dependence through energy conservation, but also to increase the share of renewables in Japan's power generation mix to about 22\%-24\% by the year 2030 (Japan Electric Power Information Center 2019). For comparison, in 2018 the total share of renewables in Japan's energy mix stood at $17.4 \%$, an increase of $1 \%$ from the previous year (Institute for Sustainable Energy Policy 2019). This seems to be an ambitious target considering ongoing policies and sector frameworks.

Nevertheless, Japan has limited contemporary interest in cross-border transmission. The current goal is that within-country electricity trading should be commercially interesting for the 10 regional companies, which is given a higher priority than cross-border interconnections. High-level policies also do not mention electricity imports as part of the future energy mix, and the related sector regulations are silent as to possibilities for importing power from other countries (Nakayama, 2019). In Japan, there has been some caution surrounding dependence on power imports in terms of security concerns. However, Japan presently relies to a large extent on imported primary energy of oil and natural gas at relatively high cost, and the resultant generation mix is largely dependent on fossil fuel generation. Therefore, it could potentially be one of the major beneficiaries of the NEA region interconnectivity to increase clean renewable energy, while reducing fossil fuel imports and associated $\mathrm{CO}_{2}$ emissions.

In the case of the cross-border interconnectivity, because of the high cost of land and constraints with wayleaves, the landing points should come as close as possible to the load centers. Under the NAPSI Study, the first HVDC cross-boundary connection is planned from the ROK to land at Hino in Fukui prefecture within the service territory of Hokuriku Electric Power Co. The second one would be from the Russian Federation, through landing in Hokkaido and continuing to land at Minami substation in Iwaki in Fukushima prefecture, which is about $200 \mathrm{~km}$ north of Tokyo under the territory of Tohoku Electric Power Co. Both connections are planned at 2 GW capacity.

Under Scenario 3, more transmission capacity will be needed in these two principal routes first. The NAPSI Study then proposes to design multi-terminal HVDC systems, considering cost savings and supply areas' characteristics. It is not considered possible for any region in Japan to accept a $20 \mathrm{GW}$ import at a single location. It is therefore necessary that it be dispersed to many different regions for connection points. VSC-HVDC technology allows for multi-terminal configurations in order to distribute power flows in an optimal manner. Specifically, a three-point terminal would end at Hino, Takahama, and Ooi for $8 \mathrm{GW}$ capacity from ROK, and a 2-terminal HVDC would connect to ROK at Hokubu and Nishi-Gunma with $12 \mathrm{GW}$ capacity. The model showed frequent power exchanges in two directions between Japan and both the ROK and the Russian Federation. VSC-HVDC technology offers the operational flexibility necessary for such operations. 
The interconnection from the Russian Federation is often expected to go from Sakhalin through routes via Mamiya Strait and Soya Strait, where the water depth is typically not more than $500 \mathrm{~m}$. The NAPSI Study preliminarily explored a route from the Russian Federation's Far East to Southern Hokkaido, which could avoid the very deepest parts of the Sea of Japan, yet may pass depths from 1,500 $\mathrm{m}$ to $2,500 \mathrm{~m}$. As described earlier, technology is under development for deep submarine cables of up to 3,000 $\mathrm{m}$ depth, and a technological advance could give an opportunity for a new undersea line routing for a Japan-Russian Federation interconnection.

\section{d. Russian Federation}

The Russian power system, called the Unified Electricity System (UES), includes several integrated power systems and territorially isolated power systems. Two main subsidiaries of Rosseti manage the regional grids, which neighbors Mongolia and the PRC. The two are the Federal Grid Company (FGC UES) and Interregional Distribution Grid Company of Siberia (IDGC Siberia). Counting from west Mongolia to Primorsky in the east, the respective regional grids are Altay (IDGC Siberia), Tyiva (FGC UES), Buryatia (IDGC Siberia), Zabaikalskiy (IDGC Siberia), Amur region (FGC UES), Jewish autonomous province (FGC UES), Khabarovsk region, and Primorsky region. The grids are managed by various subsidiaries such as Altai Energo, Buryatia Energo, Chita Energo, etc.

The East UES currently has a maximum voltage rating at $500 \mathrm{kV}$. The next level below in importance is the $220 \mathrm{kV}$ system. The high-voltage grid ( $330 \mathrm{kV}$ and higher) of Siberia does not reach the Far East as there is a section connected via $220 \mathrm{kV}$ lines only (Figure 20). Under the NAPSI Study, this section from Chita city in the eastern part of the Siberian grid to Zeyskaya in the Far East region would be upgraded for Scenario 3 with a $\pm 800 \mathrm{kV} \mathrm{HVDC}$ line of $10 \mathrm{GW}$. It would be essential to close the loop connecting Japan, Mongolia, and the Russian Federation in the future.

There is potential for electricity surplus in both the Siberian grid and the Far East grid systems, which indicates good prospects for the construction of new hydropower capacity in the latter system. However, while the Siberian grid can transmit surpluses to the west, the area served with $220 \mathrm{kV}$ (Figure 20) and the Far East have less opportunity for inside-the-country transmission, and therefore cross-border interconnections would allow a more imminent opportunity for additional electricity supply and project development in the Far East.

The Russian Federation is already exporting power to both Mongolia and the PRC. Export from the Russian Federation's Selenduma 220 kV substation (Buryatia of Russia) to Mongolia's Darkhan (Central North Mongolia) with a maximum capacity of $245 \mathrm{MW}$ is of importance for Mongolia, as this line provides frequency and balancing services to the Mongolian grid. In addition, the $110 \mathrm{kV}$ line from the Russian Federation's Chadan, which is built to the standards of $220 \mathrm{kV}$, provides the bulk of the demand to the western region grid of Mongolia. There are also several $10 \mathrm{kV}$ and low-voltage connections feeding power to remote towns in Mongolia near the Russian border.

In the event that Mongolia chooses the bridge configuration (section III.C.3), it will bring with it new $500 \mathrm{kV}$ HVAC connections along the existing directions from Darkhan to Buryatia and Umnugovi (West Mongolia) to Chadan/Kyzylskaya substations in the Russian Federation. In the case of other configurations for Mongolia's grid, Mongolia would connect from the South Gobi renewable energy base to Buryatia via an HVDC line, which could be upgraded from the initial $2 \mathrm{GW}$ for Scenarios 1 to 9 GW for Scenario 3. 
Figure 20: Structural Diagram of East Siberian and Far East Trunk Transmission Grid in the Russian Federation

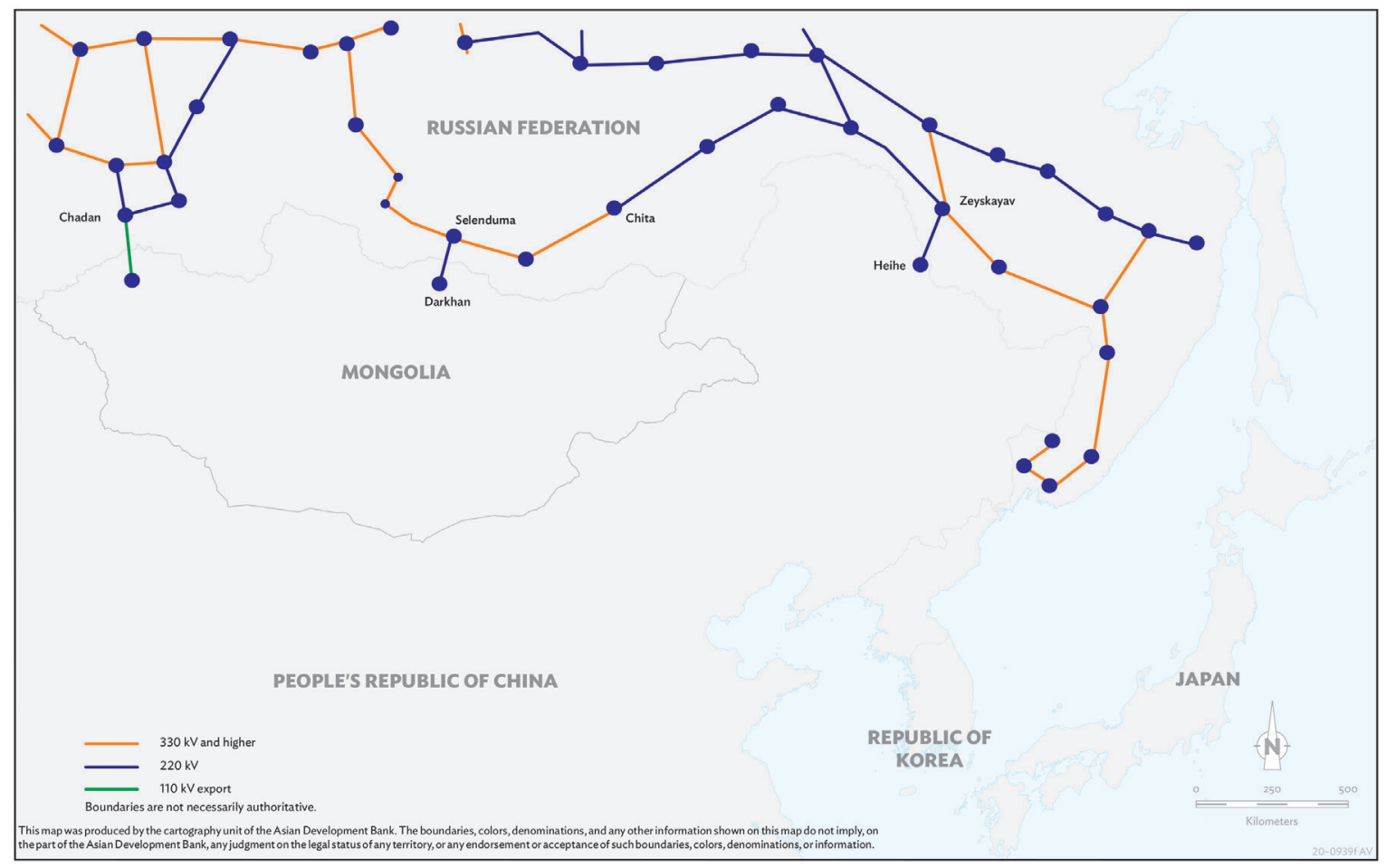

$\mathrm{kV}=$ kilovolt.

Source: Électricité de France (2018c). Altered by the author.

The Russian Federation also exports more than 3 TWh of power annually to the PRC via a few existing interconnecting lines. The $220 \mathrm{kV}$ line connected to a B2B station in the PRC's Heihe town in northern Heilongjiang is the most important export/import station of these interconnecting lines. Under Scenarios 1 and 2, no interconnection investments are foreseen in this region. However, under the NAPSI Study Scenario 3, there is a plan to strengthen the Russia-PRC connection in NEA from Primorsky via a 7 GW east-to-west HVDC line to Harbin, the capital of Heilongjiang province and the biggest load center of the PRC's northeast.

\section{E. Technical and Economic Assessments of the Simulation Results}

\section{Interconnection Network Configuration}

The principal network configuration remains the same when the capacity of renewable energy production increases from $5 \mathrm{GW}$ to $10 \mathrm{GW}$, moving from Scenario 1 to 2, but the capacities of individual lines must be increased accordingly. Under Scenario 1, the transmission capacity from south Mongolia to the PRC would need to increase from $2 \mathrm{GW}$ to $6 \mathrm{GW}$ in both the quarantine and integrated DC configurations for the Mongolian grid. Scenario 2 would also mean increasing the transmission capacity from the PRC to the ROK from $2 \mathrm{GW}$ to $4 \mathrm{GW}$. The network configurations under Scenarios 1 and 2 are shown in Figure 21 and scenario 3 in Figure 22. 


\section{Figure 21: Northeast Asia Region Interconnection Scheme under Scenarios 1 and 2}

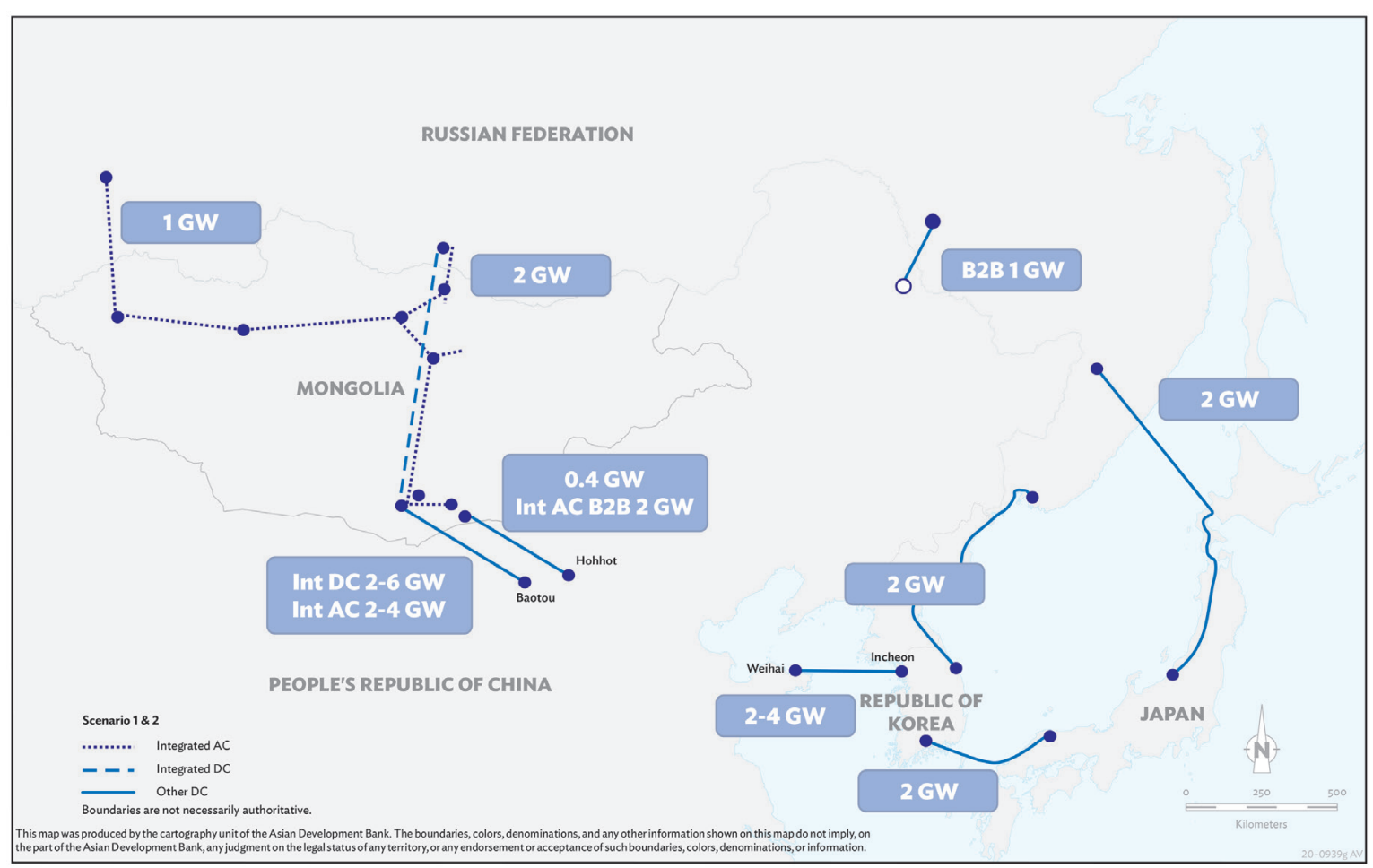

$\mathrm{AC}=$ alternating current, $\mathrm{B} 2 \mathrm{~B}=$ back-to-back, $\mathrm{DC}=$ direct current, $\mathrm{GW}$ = gigawatt .

Source: Électricité de France (2018c).

Scenario 3 looks at the long term with its $100 \mathrm{GW}$ wind and solar photovoltaic target, as shown in Figure 22. New HDVC interconnections would be developed from Mongolia to PRC resulting in a total of eight lines, one line from Russian Primorsky to Harbin, two more connections from Shandong to the ROK, a second line route from the ROK to Japan, and the Russian Federation's internal grid is strengthened by the $\pm 800 \mathrm{kV}$ line between the Siberian and Far East systems.

The line voltages would mostly be increased from $500 \mathrm{kV}$ to $800 \mathrm{kV}$. The exceptions are the very long line from Mongolia's South Gobi to the PRC's Nanyang and the line from Sin Yasan in the ROK to Hokubu to Nishigunma in Japan, which are designed at 1,100 kV. Multiterminal VSC-HVDC technology would be used for the lines from the ROK to Japan. 


\section{Figure 22: Northeast Asia Region Interconnection Scheme under Scenario 3}

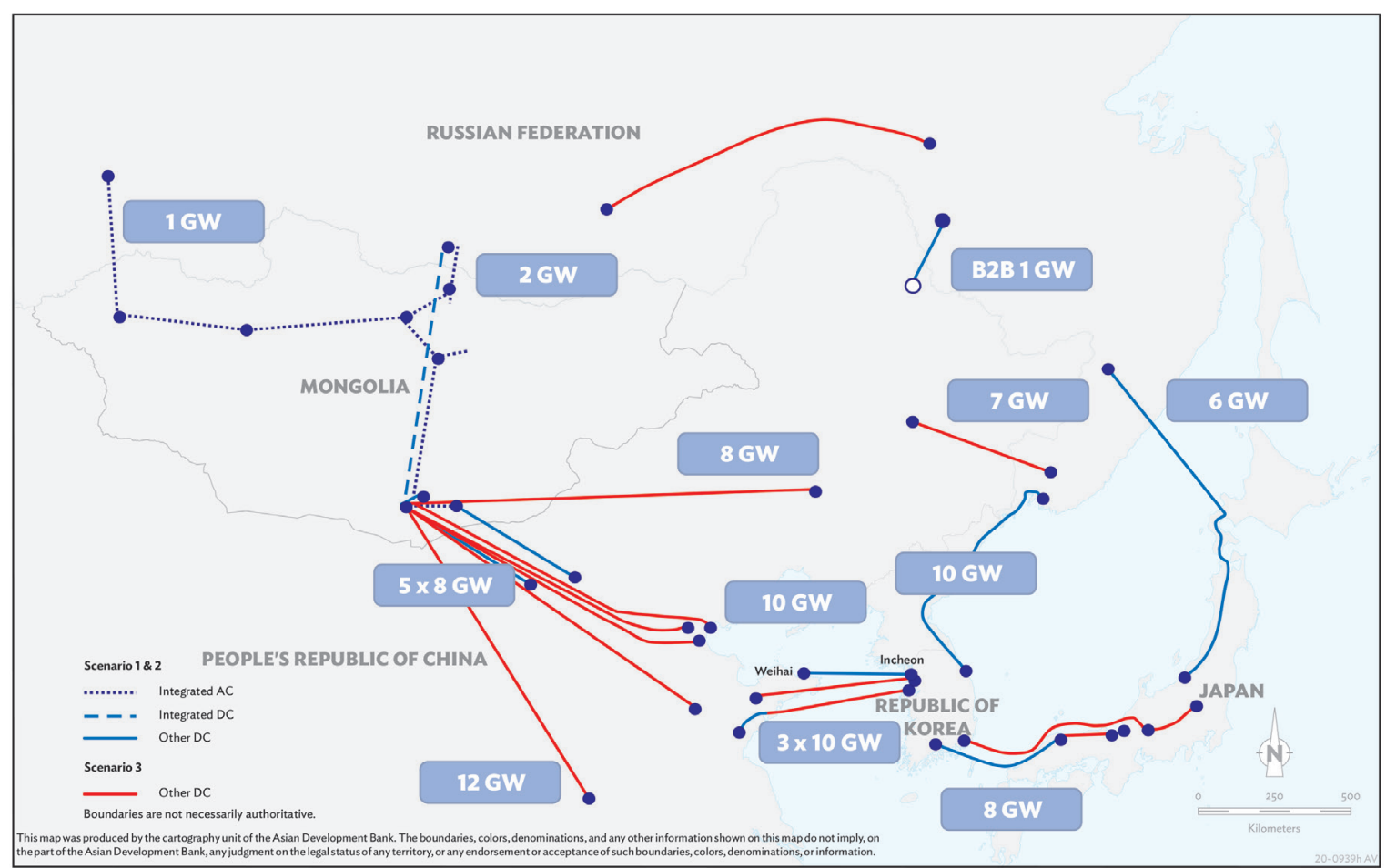

$\mathrm{AC}=$ alternating current, $\mathrm{DC}=$ direct current, $\mathrm{GW}=$ gigawatt.

Source: Électricité de France (2018c).

\section{Cost and Benefit Analysis}

The NAPSI Study's schemes include the costs of additional network reinforcement and development in Mongolia as well as those of the new line linking Russian Siberia and the Far East regions. However, the NAPSI Study did not include additional costs that may be caused by the need to reinforce the transmission networks of individual countries as a direct or indirect consequence of the NEA region interconnections. For example, the NAPSI Study did not include the PRC's costs for upgrading the grid inside the country.

The total costs of the interconnection schemes do not develop proportionally to the renewable energy capacity in South Gobi. This is because much of the cross-country electricity trading is not directly dependent on the renewable energy production in South Gobi, but is driven by marginal generation cost differences between the countries. The interconnections, once developed, can serve to both transmit renewable energy and facilitate cross-country electricity trading. Overall, the costs are divided rather evenly by country under the NAPSI Study. 
As indicated in Figure 23, the NAPSI Study estimates that it will cost $\$ 7.8$ billion to implement Scenario 1's interconnections between the participating countries. ${ }^{15}$ This is assuming the use of Mongolia's integrated AC option, which is the most expensive option to Mongolia. The cost of interconnecting the South Gobi renewable energy base of $5 \mathrm{GW}$ to the PRC and the Russian Federation is about $\$ 2$ billion under Scenario 1. The other costs of the scheme stem from the submarine cable from the Russian Federation's Primorsky to Kashiwazaki-Kariwa in Japan of $\$ 1.9$ billion; the submarine cable from the PRC's Weihai to Incheon in the ROK of \$1.7 billion; and the politically highly uncertain transmission project from Vladivostok via DPRK to the ROK of $\$ 1$ billion. Finally, the cost of the line from Hadong in the ROK to Hino in Japan is estimated at $\$ 1.3$ billion. Scenario 2 includes a second line to the PRC and increases the capacity of the PRC to the ROK connection, bringing the costs up to $\$ 9.6$ billion to see the project through.

\section{Figure 23: Northeast Asia Region Countries' Interconnection Costs-Scenarios 1, 2, and 3 (Integrated Alternating Current Option)}

Scenario 1 - Renewables 5 GW

$\$ 7.8$

billion

Scenario 2 - Renewables $10 \mathrm{GW}$

GW = gigawatt, $P R C=$ People's Republic of China, ROK = Republilc of Korea.

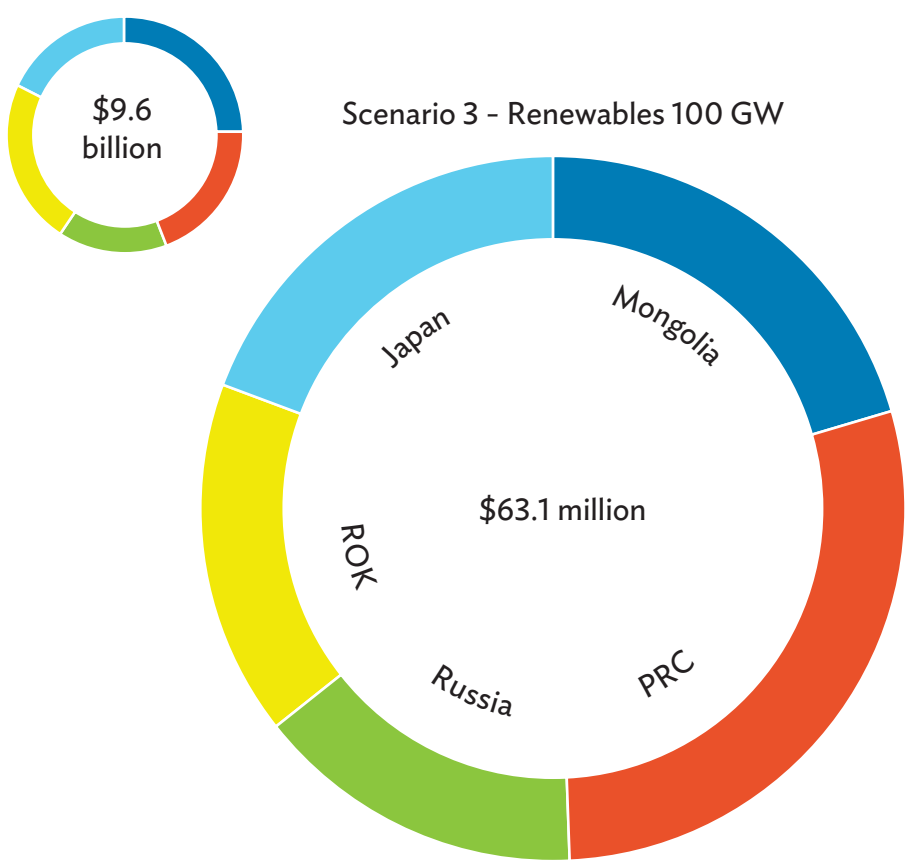

Source: Électricité de France (2018c)

15 The NAPSI Study's reports did not include the cost of the B2B connection between Mongolia's Oyu Tolgoi and New Oyu Tologi substations, estimated at $\$ 440$ million. This cost was added and revised in this document. 
Scenario 3 will cost $\$ 63.1$ million to be realized. The two multi-terminal lines from the ROK to Japan are the costliest individual investments, at $\$ 6.0$ billion and $\$ 6.7$ billion. The deep-sea cable from the Russian Federation's Primorsky to Japan will cost $\$ 3.7$ billion. Submarine cable connections from the PRC to the ROK will cost from $\$ 3.6$ billion to $\$ 3.7$ billion. The eight connections from Mongolia to the PRC have estimated costs from $\$ 1.8$ billion to $\$ 3.4$ billion. Of these connections, the $\pm 1,100 \mathrm{kV}$ and $1,500 \mathrm{~km}$ line to Nanyang in southern Henan will be the costliest, and the lowest cost will be for the line from the South Gobi renewable energy base to Baotou in Inner Mongolia Autonomous Region.

Figure 23 indicates the cost estimates of the NEA interconnection for the integrated AC configuration under Scenarios 1, 2, and 3. Figure 24 summarizes the NAPSI Study's cost estimates of (i) the NEA interconnection and (ii) South Gobi's renewable energy generation, for each of the three network configurations and each of the three scenarios. This indicates that it will cost at least about $\$ 19$ billion for Scenario 2 and about $\$ 130$ billion for Scenario 3 to develop the South Gobi's renewable energy and its power supply through the NEA interconnection. However, when the cost is distributed over the projected time period of construction and the shares attributed to individual countries (Figure 23), the cost should be economically viable for the region.

\section{Figure 24: Investment Costs for Northeast Asia Region Interconnection and Mongolia's Renewable Energy Generation-Scenarios 1, 2, and 3}

(\$ billion)

Scenario 1 (5 GW Renewable) by 2026

\begin{tabular}{|l|c|c|c|}
\hline & $\begin{array}{c}\text { NEA } \\
\text { Interconnection }\end{array}$ & $\begin{array}{c}\text { Renewable } \\
\text { Generation }\end{array}$ & Total \\
\hline Option 1 Quarantined DC) & 7.7 & 5.6 & 13.3 \\
\hline Option 2 (Intergraded DC) & 7.8 & 5.6 & 13.4 \\
\hline Option 3 (Intergraded AC) & 7.81 & 5.6 & 13.4 \\
\hline
\end{tabular}

Scenario 2 (10 GW Renewable) by 2036

\begin{tabular}{|l|c|c|c|}
\hline & $\begin{array}{c}\text { NEA } \\
\text { Interconnection }\end{array}$ & $\begin{array}{c}\text { Renewable } \\
\text { Generation }\end{array}$ & Total \\
\hline Option 1 (Quarantined DC) & 9.0 & 9.8 & 18.8 \\
\hline Option 2 (Intergraded DC) & 9.3 & 9.8 & 19.1 \\
\hline Option 3 (Intergraded AC) & $9.6^{1}$ & 9.8 & 19.4 \\
\hline
\end{tabular}

Scenario 3 (100 GW Renewable) after 2036

\begin{tabular}{|l|c|c|c|}
\hline & $\begin{array}{c}\text { NEA } \\
\text { Interconnection }\end{array}$ & $\begin{array}{c}\text { Renewable } \\
\text { Generation }\end{array}$ & Total \\
\hline Option 1 (Quarantined DC) & 62.8 & 67.1 & 129.9 \\
\hline Option 2 (Intergraded DC) & 63.0 & 67.1 & 130.1 \\
\hline Option 3 (Intergraded AC) & $63.1^{1}$ & 67.1 & 130.2 \\
\hline
\end{tabular}

$\mathrm{AC}=$ alternating current, $\mathrm{B} 2 \mathrm{~B}=$ back-to-back, $\mathrm{DC}=$ direct current, $\mathrm{GW}=$ gigawatt, NAPSI = NEA = Northeast Asia Power System Interconnection, PRC = People's Republic of China.

${ }^{1}$ The NEA interconnection cost includes the costs of transboundary interconnections to the end points in the PRC and the Russian Federation as well as associated transmission system development (i.e., B2B converter station in Oyu Tolgoi) in Mongolia. These costs were not included in the NAPSI Study, but it is necessary to add them to capture all the relevant costs required.

${ }^{2}$ Over its course the NAPSI Study provides two different amounts for Scenario 3's renewable generation costs. The module 4 report (2018a) indicates costs of $\$ 67.1$ billion, and the draft final report (2019b) indicates costs of $\$ 85.4$ billion. The former amount was based on reduction of capital expenditures of solar photovoltaic and wind power projects beyond 2036 until 2051 . However, the latter amount applied if the assessment includes all capital expenditures used by Scenario 2 until 2036.

Source: Électricité de France (2018b, 2018c) 
As to the cost-benefit analysis, the NAPSI Study indicates that, under Scenario 1, a smaller development of $5 \mathrm{GW}$ of renewable energy in Mongolia by 2026 would not actually be the least-cost option. Through interconnections, low-cost alternatives in the Russian Federation and the PRC could meet the regional demands more economically than renewable energy in Mongolia.

However, under Scenario 2, the benefits are weighted toward regional interconnection with development of $10 \mathrm{GW}$ of renewable energy in Mongolia. The regional interconnection itself can have a significant impact that would increase gross and net benefits compared to the situation without its existence. As indicated in Figure 25, the model for the existing situation of power trading indicated that (i) the gross benefit of the cross-border interconnection scheme is $\$ 4.0$ billion annually, including savings in terms of investment and operational expenses but excluding investments in interconnection infrastructure; and (ii) the investment cost of interconnection infrastructure amounts to $\$ 1.0$ billion annually and therefore the net benefit of the interconnection scheme is $\$ 3.0$ billion annually, on its own and without any renewable energy investments in Mongolia. ${ }^{16}$ If $10 \mathrm{GW}$ of solar and wind power are developed in South Gobi, it would add $\$ 0.2$ billion to the net benefit. But this net gain looks limited compared to the corresponding cost ( $\$ 1.9$ billion).

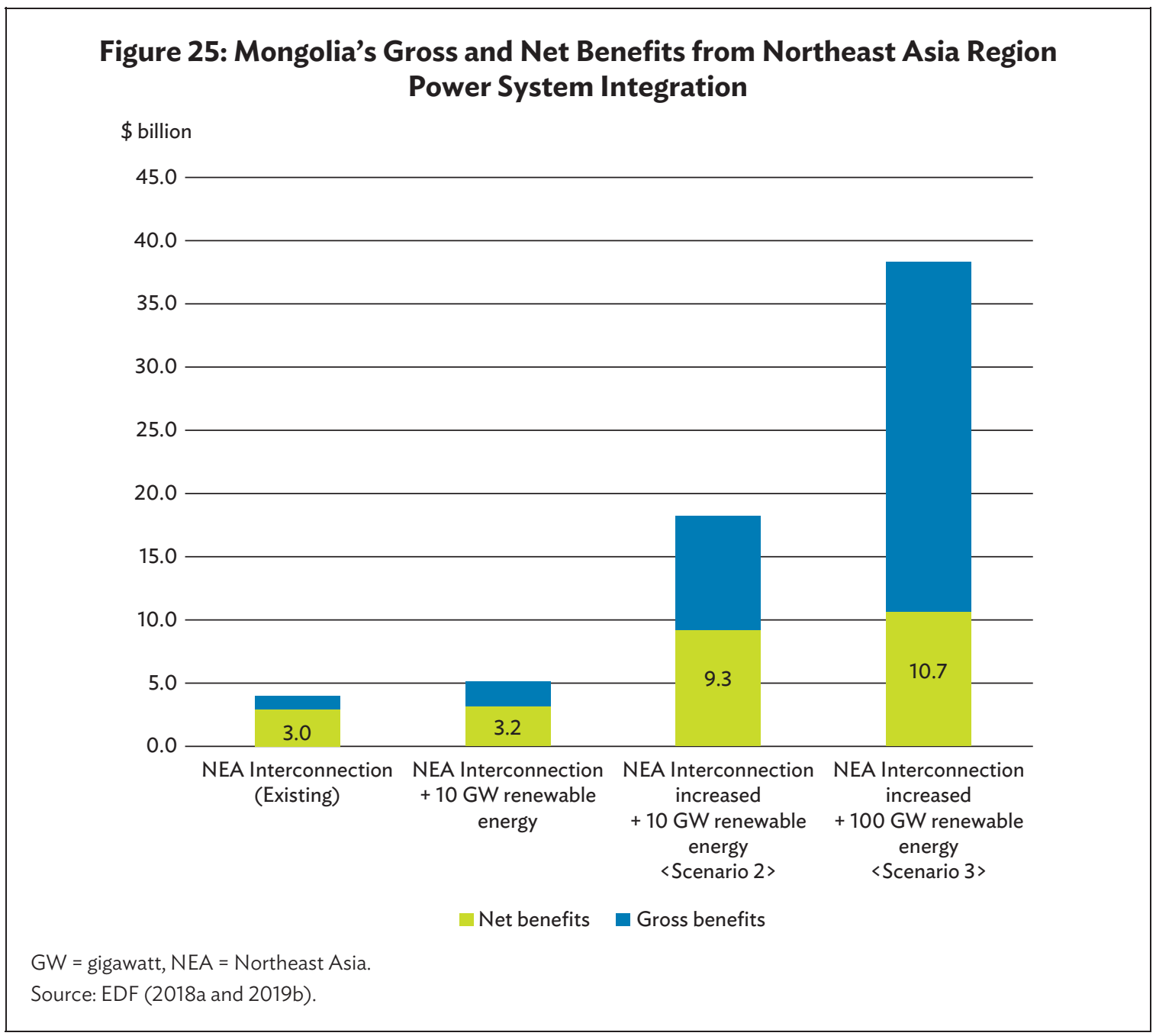

16 The numbers mentioned represent median results. The analyses result in a range of costs as a consequence of uncertainties in cost estimations, leading us to present the unit costs in ranges. 
The costs and benefits from $10 \mathrm{GW}$ solar and wind power development in Mongolia can be maximized in the event that the regional interconnection is also significantly expanded in the NEA as is assumed in Scenario 2. Under these circumstances, the net benefits can be almost tripled to $\$ 9.3$ billion. The significant increase in the net benefit as a result of the NEA regional interconnection expansion demonstrates that Mongolia's renewable energy development can be considered the least-cost option in Scenario 2, when the regional interconnection reduces the cost of an optimized system and increases Mongolia's competency of solar and wind power development. Both the benefits and costs further increase if renewable energy development is increased to the level of $100 \mathrm{GW}$ under Scenario 3 , providing a gross benefit of $\$ 27.6$ billion and a net benefit of $\$ 10.7$ billion annually.

A least-cost option that assumes regional interconnection is also critical in order to maximize the benefits and efficiency while identifying most effective renewable energy development sites. The NAPSI Study clarifies that Mongolia would be more cost-effective and efficient in developing wind and solar power compared to the ROK and Japan. Mongolia has advantages in terms of both cost and quality of wind and solar resources, which can be measured by cost and capacity factors, as indicated Figure 26 for wind power and Figure 27 for solar photovoltaic. The NAPSI Study confirms that, because of the higher cost and lower capacity factor, a similar injection of renewable energy generation would not be the least-cost case if it was to be built in the ROK or Japan. In other words, the benefits of producing renewable energy in Mongolia are higher than those of producing the same amount of renewable energy in ROK and Japan.

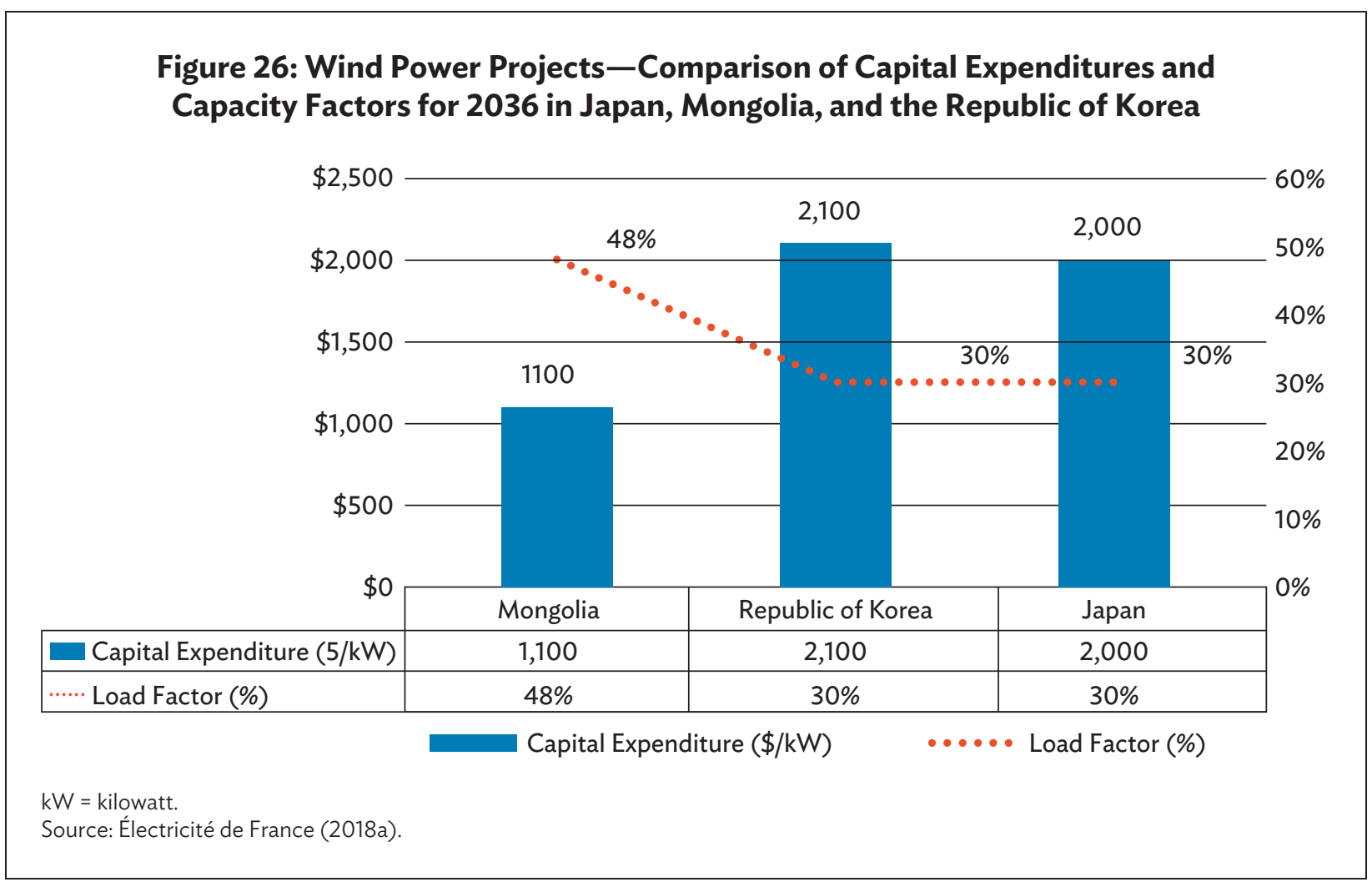


Figure 27: Solar Photovoltaic Projects-Comparison of Capital Expenditures and
Capacity Factors for 2036 in Japan, Mongolia, and the Republic of Korea

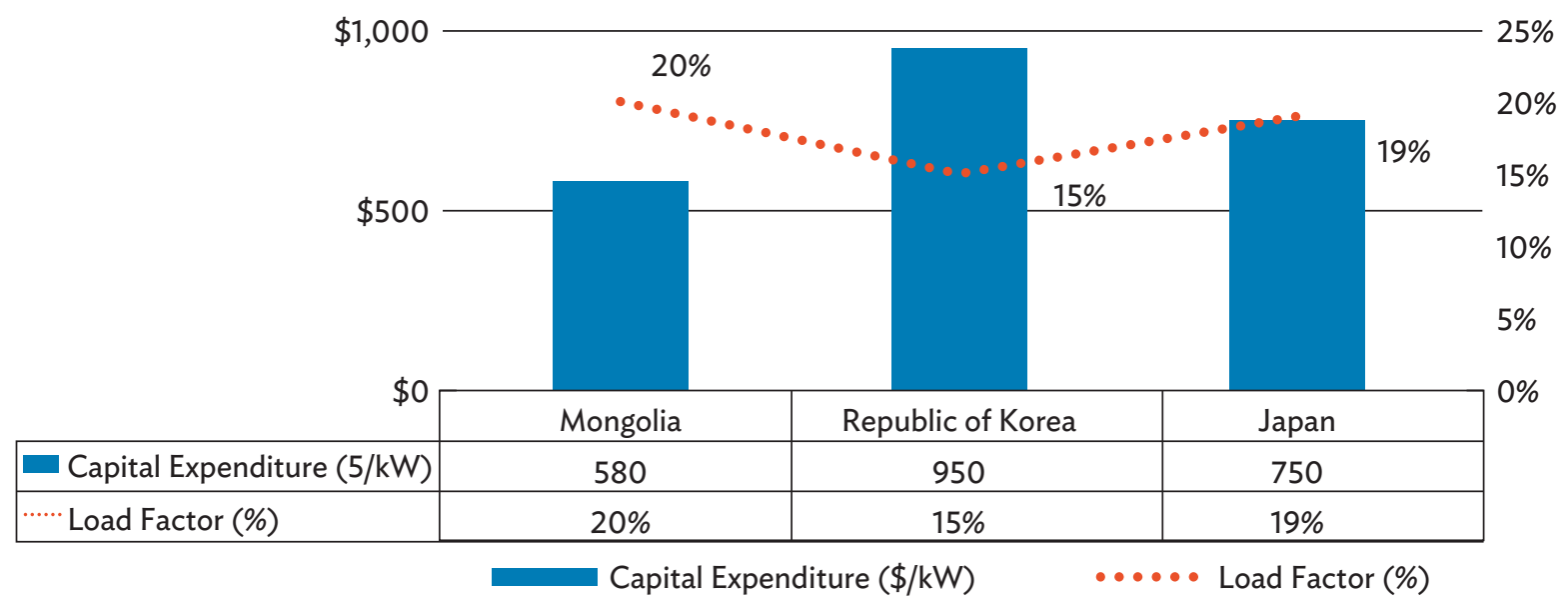

$\mathrm{kW}=$ kilowatt. $\mathrm{PV}=$ photovoltaic.

Source: Électricité de France (2018a).

Under Scenario 2, Mongolia's renewable energy of $10 \mathrm{GW}$ (generating about $30 \mathrm{TWh}$ ) will decrease coal generation by 8 TWh and gas generation by 22 TWh. Under Scenario 3, Mongolia's wind and solar power of $100 \mathrm{GW}$ (generating $300 \mathrm{TWh}$ ) would replace $170 \mathrm{TWh}$ of coal generation and $130 \mathrm{TWh}$ of gas generation. In terms of carbon impacts, renewable energy supply from South Gobi would offset first gas-based electricity generation and then coal-based generation as indicated in Figure 28. A capacity of $10 \mathrm{GW}$ would replace predominantly gas-based generation, which has a higher generation cost, but with a higher scale of renewable energy generation the replacement effect would have an increasing impact on coal-fired generation. Under scenario 2, the emission factor for capacity substitution of $10 \mathrm{GW}$ (30 TWh) of Mongolian renewables is $0.57 \mathrm{tCO}_{2} / \mathrm{MWh}$, with the effect that renewables replace coal by about one quarter and that gas replaces the remaining three quarters. Under Scenario 3, Mongolian renewables of $100 \mathrm{GW}$ (300 TWh) would have more significant effects. It would replace both existing coal and gas generation, with the emission factor for capacity substitution of $0.70 \mathrm{tCO}_{2} / \mathrm{MWh}$.

The resultant volume of $\mathrm{CO}_{2}$ reduction is estimated at 17 million tons annually under Scenario 2 (in the $10 \mathrm{GW}$ renewable energy alternative), and 210 million tons under Scenario 3 (100 GW renewable energy alternative). In terms of carbon reduction impacts, Figure 29 demonstrates the merits of scale for both the regional interconnection and Mongolian renewable development, as compared to a business-as-usual scenario with no regional interconnection with Mongolia and no use of Mongolian renewables for regional purposes. If $\mathrm{CO}_{2}$ reduction was valued at $\$ 30$ per ton reduced (for reference, Korea Emissions Trading Scheme [KETS] valuation was about $\$ 25$ per ton reduced in February 2019), it would provide an additional project benefit of $\$ 510$ million under Scenario 2 and $\$ 6,300$ million under Scenario 3. This would represent a significant addition to the net benefits. The ROK already has an operational KETS, which is the third-largest carbon market in the world. In addition, cap-and-trade programs are emerging in Japan and the PRC. Therefore, the opportunity to reduce $\mathrm{CO}_{2}$ emissions will probably play an ever-increasing role in future interconnectivity planning for the NEA region. 
Figure 28: Changes in the Energy Generation Mix of Northeast Asia Region

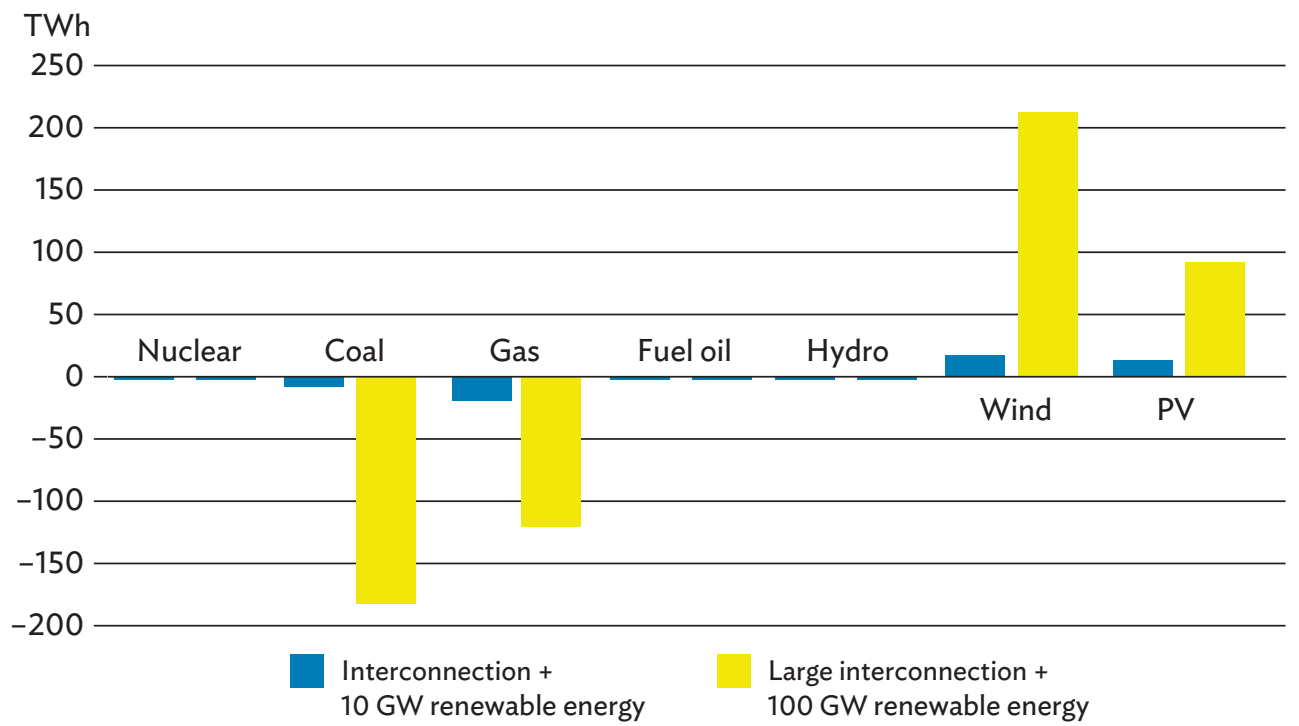

$\mathrm{GW}=$ gigawatt, $\mathrm{PV}=$ photovoltaic.

Source: Électricité de France (2018a).

Figure 29: Carbon Reduction Impacts of Mongolia's Renewable Energy and Northeast Asia Region Interconnection

Mt

4,200

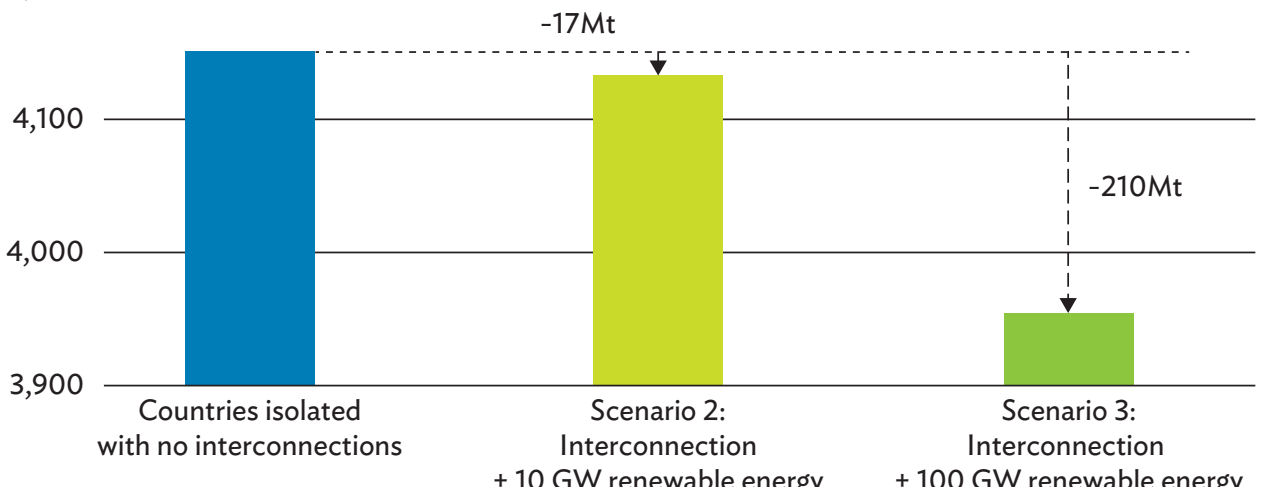

$\mathrm{Mt}=$ million tons, $\mathrm{GW}=$ gigawatt

Source: Électricité de France (2018a). 


\section{DISCUSSIONS ON ISSUES AND CONCERNS}

The NEA's dependency on fossil fuels is quite high, with $70 \%$ of its power generation currently obtained from fossil fuel sources. In particular, high coal usage has generated massive quantities of $\mathrm{CO}_{2}$ and air-polluting substances. Ulaanbaatar, Beijing, and other cities in both Mongolia and the PRC currently suffer from severe air pollution. It is said that the air pollution has spread out as far as Seoul, worsening the existing air quality problems in wider areas. The level of fine dust has been soaring in Seoul over the past decades. The cities have nearly the worst air quality among advanced economies, particularly in the winter season. Thus, climate change and pollution come with security issues beyond a country's borders.

Energy security also provides an important motivation for the interconnection of the NEA region. In addition to the problems surrounding fossil fuels, nuclear power has been viewed with uncertainty since Japan's Great Earthquake caused a nuclear disaster in March 2011. This has caused a shift in focus to resilient power systems and renewable energy. The ROK's power shortage and rolling blackouts in September 2011 also highlighted the power supply system's vulnerability and responsive flexibility. While Japan and the ROK, as well as the PRC, have responded by increasing their dependence on imports of fossil fuels, there is not currently a means to also import a substantial quantity of clean renewable energy.

Mongolia and the Russian Federation, on the other hand, rely on exports of excess fossil fuels (i.e., coal and gas, respectively). However, they suffer from the price fluctuations of these exports, including a recent sales price reduction in 2020. They also have few ways to export their abundant hydropower and renewable energy potential instead of coal and gas. The Mongolian South Gobi's significant solar and wind power resources particularly, cannot be deployed and absorbed in Mongolia alone. They should therefore be exported to neighboring countries to diversify the sources of Mongolia's foreign exchequers. In the event that these resources can be partly used for Mongolia's domestic electricity consumption in the future, it will help create generation margin and improve the reliability of the domestic power supply. These overarching energy security issues at the level of each country are all related to rationales for power trading opportunities among the NEA countries.

With these holistic motivations, the NAPSI Study analyzed and planned the necessary building blocks to move towards the creation of an NEA region interconnected power system from both technical and economic points of view. The modeling simulation provided technical options to be considered by the policy makers of Mongolia and other NEA neighboring countries. The techno-economic assessments indicated what the least-cost option would be, depending on the scale of development and investment in Mongolia's Gobi Desert base renewable energy and its related interconnections with other NEA countries. The NAPSI Study concluded that regional economic benefits could be increased by investments in Mongolia's renewable energy export and its supporting regional interconnections. The question then becomes, why such vast renewable energy potential has not yet been exploited, and the creation of cross-border interconnections has been sluggish. The NAPSI Study's results can further be discussed and reassessed with critical reviews, considering other impactful factors of political (policy), commercial, and regulatory issues that can either promote or hinder the development of the NEA's interconnectivity. In this section, the author departs from the NAPSI Study's recommendation with regards to Mongolian development priorities, particularly with concern to the grid configuration options and transmission interconnections. 


\section{A. Political Aspects}

In many countries, the national energy policies often cite energy independence aspirations and security concerns, which can trigger debates and arguments against the prospect of energy imports. The ethos of energy sovereignty may also translate into investment restrictions for foreign participants. Further, changing public opinions and political sentiments between the countries can create significant barriers for policy makers and developers trying to confront regional interconnectivity. The NEA countries also have specific political sensitivities that need to be addressed because of their historical relationships and international diplomacy. DPRK's position in the region, for instance, continues to be uncertain to the international and regional community. The NEA region has one of the world's most complex geopolitical dynamics. Each of the bilateral relationships have moved back and forth over the decades. Under the current situation, Mongolia is in a relatively neutral position with an equal distance to each of the other NEA countries.

It is unsurprising, therefore, that Mongolia takes the central position in the NAPSI Study's plan for regional power system interconnection. However, Mongolia is landlocked between two neighboring giant countries: the PRC and the Russian Federation. This might raise concerns in Mongolia over the strong political influences from its neighboring countries when exploring power export to or through these countries. These concerns may be able to be alleviated through mutual power trade opportunities on commercial terms, which will create a win-win situation in the power system interconnection. Consequently, there is some consensus in Mongolia at political and industrial levels that supports exporting its renewable energy and enabling cooperation for this purpose (EDF, 2017b). On an official level, the Mongolian Parliament already approved the policy vision to become an energy exporting country in 2015.

In considering Mongolia's grid development configuration-quarantined DC, integrated DC, or integrated AC-in relation to South Gobi's renewable energy (section III.C), however, Mongolian stakeholders' opinions might well be divided by the pros and cons of various options. Mongolia's decision-making process should not be straightforward in this regard. This may not be an issue for the first 5-10 GW power export, but the long-term perspective should be different among the stakeholders. The key point, when considering a long-term direction, will be whether Mongolia's renewable energy should be used only for export business, or should also be used partly for domestic consumption. Some policy makers may hesitate to have the integrated AC system, which would allow Mongolia's small power system to be integrated with the Russian Federation's large grid systems. Under this situation, being more dependent on the Russian Federation's systems, Mongolia's system might be more easily affected and disrupted in the event of any serious blackout accidents in the neighboring country's large systems. ${ }^{17}$ This option may also conflict with Mongolia's own energy policy, which pursues development of domestic power generation capacity to increase energy sovereignty.

The integrated AC option may set Mongolia free from concerns over renewable energy's inherent variability or other project requirements for domestic CHP or hydropower generation plants, by enabling the Mongolian grid as part of the Russian synchronized grid systems. While the NAPSI Study assumes power export from Mongolia to the Russian Federation, this option is likely to drastically increase Mongolia's dependency on power imports and system operations for the future. On the other hand, others may expect the integrated AC option to bring the western region's hydropower resources

17 For example, Bhutan is interconnected with India through a synchronized alternating current system. When India was faced with an extensive system failure, it immediately brought down Bhutanese hydropower generation. Fortunately, one hydropower plant was quickly restarted with no blackout problems within Bhutan. Bangladesh adopted the direct current interconnection with India. 
to the central region of Mongolia. Any dependence on power import from the Russian Federation could then be reduced because of increased domestic generation that could be exploited widely. In addition, the national grid system could finally be established from the west to the east and from the north to south. This option would thus require huge internal and external investments, even in Mongolia's remote regions with small energy demand. The AC integration would be the most expensive option and its resultant economic and financial viability should be questioned in a Mongolian analysis of stand-alone costs and benefits, unless its renewable energy export revenues were collectively counted for the entire benefits from investment saving in other domestic power generation. Therefore, this assumption will need to be clarified based on a more in-depth feasibility analysis.

How about the quarantine and integrated DC options? The NAPSI Study indicated that South Gobi's renewable energy intermittency issue could be balanced by backup power through another grid extension to the Russian Grid on the northern side, while solar and wind power could be exported to the PRC on the southern side. In the event that the grid extension on the northern side to the Russian Federation is not constructed as the NAPSI Study's DC options recommend, it may be possible to rely on the PRC's backup power resources to stabilize variability of solar and wind power. The PRC originally proposed to provide its electricity to several mines and towns in southern Mongolia and integrate them in the PRC grid. This would require three $220 \mathrm{kV}$ lines from the PRC's GuoHe, Mandula Port, and YuLong. Another route for power supply from the PRC could be a B2B interconnection between the Oyu Tolgoi and New Oyu Tolgoi substations within Mongolia. Under each of these situations, the Mongolian grid may be attached as part of the PRC synchronised system, instead of as part of the Russia Federation's. However, this DC configuration would allow Mongolia's grid system to be protected from disruption by the PRC's grid accidents, unlike the AC configuration. In any cases, it will be necessary to perform a more precise study to assess the use of the PRC power resources to deal with the intermittency issue.

Another political aspect in Mongolia may be related to severe domestic air pollution in Ulaanbaatar and other cities, particularly in the winter season because of the use of coal for heating purposes. Some people think that this should be replaced with clean energy, i.e., renewable energy. Realistically, it may be necessary to clarify what the cost estimate would be to replace coal heating with electric heating systems based on advanced renewable energy technologies. Alternately, the Mongolian heating problems could be resolved by using natural gas for heating; if Mongolia was able to make partial use of a natural gas pipeline, which is presently being discussed, running from the Russian Federation to the PRC through Mongolia. There are as yet, however, too many uncertainties to be able to predict what solutions for heating may be feasible and economical. It is necessary to wait and see what outcomes may occur over an uncertain time frame and what options may become practicable.

Under such a variable situation, with many open-ended options and scenarios, it is impossible to compare the costs and benefits of all possible outcomes in order to identify the best outcome. However, the NAPSI Study clarified the two fundamental points: (i) the exact size of Mongolia's solar and wind resources will be feasible for development and export, and (ii) these resources will require an HVDC transmission link from Mongolia's South Gobi to the PRC. Identifying these points is a first step required by any of the three grid options. Although it will eventually be necessary to consider and resolve how to stabilize the renewable energy generation using backup power from the PRC, the Russian Federation, or Mongolia itself, this is not the right time. This issue should be revisited after seeing how further investment and implementation of grid systems in the Russian Federation and the PRC develops. Stabilizing renewable energy generation can be considered in designing a specific pilot project (2-5 GW renewable energy export) for interconnecting South Gobi and the PRC without 
committing to a final holistic landscape. There is still time to discuss and consider which grid options to explore, AC or DC, while moving forward to prepare this first specific project. It is not constructive to spend any more time on extensive market studies and grand design activities for subsequent relevant activities.

While the NAPSI Study provided three grid options, in reality, choosing one option among these three will not be an immediate issue. The NAPSI Study recommended the integrated AC as the best option from a viewpoint of NEA-wide technical and economic costs and benefits. However, considering the high investment costs and a step-by-step development, it would be unpragmatic and unwise to take the integrated AC option from the beginning, even though it appears to be the ideal design.

Taking a view based on current political realities, it is suggested that the first step in development should be through the quarantined DC option connected to the PRC's grid. This aims to bring in investments to both South Gobi renewable energy and transmission development, lay down the basic infrastructure for power export, and start earning power export revenue for Mongolia. This approach will make the least impact. Some renewable energy projects could continue in a distributed fashion to connect with the Mongolian domestic grid. Considering Scenarios 1 and 2 to develop up to $10 \mathrm{GW}$ power export from South Gobi by 2036, this capacity size is not small, but should not become an insurmountable problem since the actual development would take place step by step. This development would be supported by the fact that PRC is promoting the transmission of the sizable renewable energy resources of PRC's Inner Mongolia Autonomous Region to East PRC and an additional $10 \mathrm{GW}$ could be absorbed in this plan. By the time all of this has come into effect, the holistic and long-term energy development vision of Mongolia will have become clearer. A discussion can then be had over which option - the integrated AC or integrated DC-should be followed to best allow Mongolia to deal with its many relevant domestic and international priorities, such as diplomacy as well as the air pollution and natural gas issues in the context of renewable energy development over time.

In launching a specific power export project in Mongolia's South Gobi with any investors and financiers, however, it will be necessary to remove any concerns about renewable energy export from Mongolia toward the PRC and the transmission capacity expansion in the PRC to its demand centers and/or the ROK. This is because the PRC's Inner Mongolia Autonomous Region also has large renewable energy projects, but they are already faced with curtailment because of lack of transmission capacity to evacuate power. This issue may not be able to be easily clarified in a bilateral deal, since many different agendas will be brought together. Therefore, the ROK may be involved in a strategic position as the third-party country. The ROK has been in discussions with the PRC to promote a grid interconnection between the two countries (sections III.D.2.a, III.D.2.b, III.E.2). However, there are those within the ROK who are cautious concerning the import of power from the PRC that may be sourced from coal burning. Given the two interconnections, between the ROK and the PRC and between Mongolia and the PRC, Mongolia's renewable energy would be accessible to the ROK physically through the PRC grid systems. This would help to allay the ROK's concerns over the import of the PRC power into the ROK, as it would increase the balance of renewable energy in the transmission mix.

Both the ROK and the PRC have further political motivations to pursue these connections. The ROK promoted the NEA's regional grid concept earlier in the 2000s and set up an ambitious target to reduce $\mathrm{CO}_{2}$ emissions for climate change. In 2018, the PRC launched the Belt and Road Energy Partnership, which was aligned with the One Belt One Road Initiative. The PRC's solar and wind power manufactures have an advantage in the worldwide share. Given this background, the two 
interconnections would be highly relevant and beneficial to the tripartite parties among the ROK, the PRC, and Mongolia. Of course, political hurdles are not so simple to remove. While the discussion frameworks with the ROK and the PRC are being explored by Mongolia, technical feasibility should, in the meantime, be checked through further load flow analysis and specific cost and benefit analysis. This tripartite interconnection might eventually help change the political will of Japan, which has officially been indifferent to cross-border power trade. Recently, Kazakhstan's parties also expressed their keen interest to export renewable energy to the ROK and the PRC under the Silk Road Super Grid concept. Since Kazakhstan also has vast renewable energy potential, its participation in subsequent dialogue might be a game changer for regional frameworks in the subsequent deal discussions.

From a domestic political angle, attention should also be paid to Mongolia's own policy framework. It will be recommended that Mongolia clarify how to treat the power export business in the policy. Particularly, it is necessary to explain how to use the power export revenues domestically to avoid triggering the "resource curse" paradox (Murshed, 2018). ${ }^{18}$ The government will need to make a sustainable policy framework to make the export revenue flow transparent. It will also need to set up any benefit sharing mechanism that is allowed to redistribute part of the revenues to domestic electricity consumers in the form of a transparent subsidy. ${ }^{19}$

\section{B. Commercial Aspects}

In addition to $\mathrm{CO}_{2}$ reductions arising from renewable energy, the difference of electricity costs among the NEA countries provides a valid economic rationale for cross-border power trading through interconnections between countries. The NAPSI Study's economic analysis is based on the free flow of electricity driven by differences in the marginal costs between the national systems. Their results showed that the financial and $\mathrm{CO}_{2}$ benefits of free cross-border power trading are substantial. Based on the underlying assumption about free and competitive electricity markets, it was indicated in the past regional workshop that the power will flow from a country with higher tariffs country to a country with lower tariffs (Figure 30).

However, these flow directions are quite indicative and illusive. This assumption does not make any sense unless all the retail tariffs were determined on the cost base principle. In the NEA region, however, the tariff structure has been distorted between residential and industrial tariffs. The tariff structure has also been subsidized or politicized and has not reflected the cost structure reasonably. Therefore, power trading should be considered on the basis of competitiveness of generation and ongrid costs. However, the NAPSI Study has not highlighted such a pricing value chain analysis and resultant consumer's benefits from power trading.

18 The resource curse, also known as the paradox of plenty, refers to the observation in development economics that countries rich in natural resources, particularly minerals and fuels, perform less well economically than countries with fewer natural resources. In other words, resources are an economic curse rather than a blessing. Discussion of the causes of this paradox involve the nature of resource booms, the benefits and costs of export-led growth, the problems of de-industrialization and manufacturing base erosion, rent-seeking behavior and corruption, and the empirical evidence of the effects of natural resource dependence on growth. This issue may not be relevant to Mongolia's wind and solar power as long as the business is not highly profitable. However, there has been no research that clarifies this possibility.

19 For example, Bhutan residential tariffs were cross-subsidized by revenues of hydropower export to India. As a result, Bhutan maintains the lowest electricity prices in the South Asia region. The regulator announces to electricity consumers the required cost of power supply, subsidy amounts, and resultant electricity prices in a transparent manner. 


\section{Figure 30: Northeast Asia Region Countries' 2018 Electricity Tariffs and Potential Power Flow under the Free Power Trading Market}

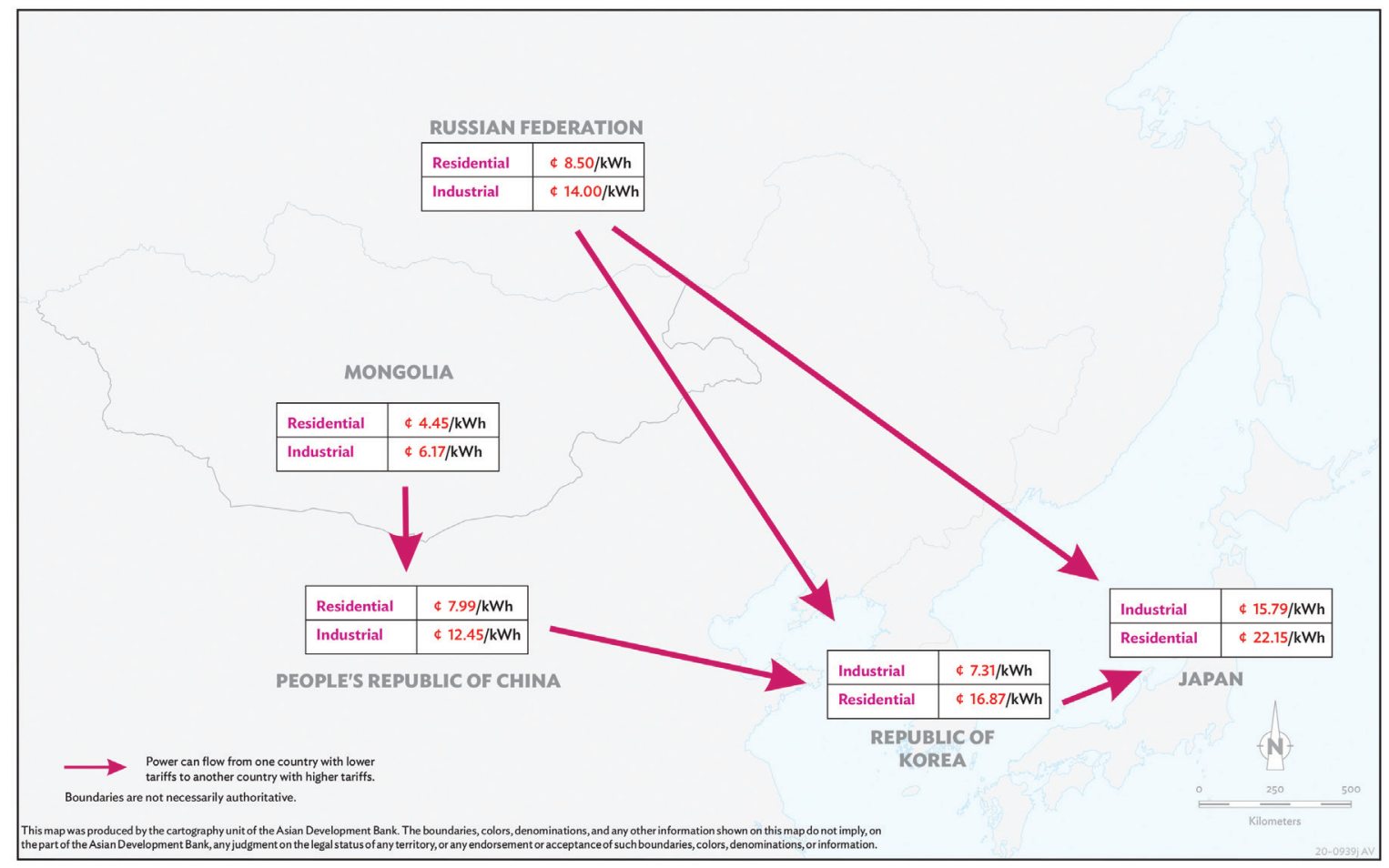

$\Phi=$ US cent, $\mathrm{kWh}=$ kilo watt-hour, NEA = Northeast Asia region.

Source: Energy Regulatory Commission of Mongolia (2019).

To set aside differential pricing effects of power supply costs, each country can be both an importer and an exporter of electricity between each of the other countries considering bidirectional power flows in the technical nature of cross-border power trading. However, Japan, the PRC, and the ROK are likely to be more import-oriented considering potential demand for clean energy. On the other hand, the Russian Federation and Mongolia are likely to be export-oriented because of their untapped sizable renewable energy potential. Therefore, power export from Mongolia to the Russian Federation may not be feasible in a commercial manner for the short and medium term. However, the power could flow from Mongolia to the PRC and the ROK. Eventually, power from Mongolia and the Russian Federation could reach Japan, in the case of Japan's interconnection to the free power trade market that allows renewable energy to be prioritized in the merit order systems as the least marginal cost of generation. The NAPSI Study assumes for Scenarios 1 and 2 that the maximum import for each NEA country would not exceed $20 \%$ of the peak demand of the regional system. This cap will be subject to each government's policy decision, but $20 \%$ is considered a tolerable level in practice, based on Europe's cross-border power exchange (Renewable Energy Institute 2017).

Since all of the power trading opportunities cannot take place at the same time, it should be realistic to explore the bilateral and/or tripartite power trade among Mongolia, the PRC, and the ROK at the first stage. For the two interconnections between Mongolia and the PRC, and between the PRC and the ROK, the corresponding power purchase agreements (PPAs) will be required. Their PPAs have not been conceptualized, but the back-to-back arrangements between the two PPAs can be explored to 
substantiate a trilateral PPA. Such PPA drafting studies may be able to clarify concrete issues that need to be resolved. For example, the PPA may address a backup power issue to stabilize the weather dependent fluctuating solar and wind power generation in Mongolia's South Gobi. This issue may be resolved by arranging backup power from the PRC. For the first step to develop 2-5 GW under the Scenario 1, this capacity size may be managed with the quarantined DC option. However, In the event that the size of power export eventually grows substantially, either the integrated AC or DC option can be considered as the second step to build balancing capacity for the variability of renewable energy. At this stage, it will be necessary to decide whether or not to (i) stabilize the South Gobi's renewable energy production using additional power supply from the Russian Federation or the PRC, and (ii) enable part of the South Gobi's renewables for Mongolia's domestic consumption. In exporting renewable energy projects, backup power arrangements will be unavoidable to secure a certain level of power supply. Also, PPAs should consider how to reflect the backup power costs in pricing of power purchases and sales. These matters should be clarified in further studies.

In the current realm, however, there are fundamental issues that ought to be solved so that the market participants will be commercially motivated to move forward with the interconnection investments. One such issue is that the northern and northeastern parts of the PRC have had positive supplydemand balance (i.e., oversupply) for about a decade. The domestic wind power development in northern PRC has therefore led to curtailments to the extent that a temporary freeze of wind power development in Inner Mongolia Autonomous Region was introduced. Since there is a high degree of domestic interest in exporting electricity from Inner Mongolia Autonomous Region to Eastern PRC within the PRC, there may be less economic incentive to import more power to the PRC's northern and northeastern regions from Mongolia or the Russian Federation. The positive supply-demand balance is reflected in the low on-grid prices of electricity in the PRC's northern and northeastern regions, neighboring Mongolia, and the Russian Federation. However, on-grid prices are generally higher in the Eastern coastal areas of PRC. The market access to the demand centers in Eastern PRC will therefore be crucial for power export from Mongolia to the PRC. In fact, Inner Mongolia Autonomous Region's curtailment of renewable energy will be improved by the PRC's ongoing schemes to build large capacity grid connections from Inner Mongolia Autonomous Region to eastern load centers. These schemes will also mobilize inherent flexibility resources from thermal power plants to stabilize the renewable energy intermittency. Therefore, there is a good prospect to remove a barrier for energy exports from Mongolia to the PRC in the midterm, say in 2026.

The regional cost difference can motivate relevant parties of power export and import to build grid interconnections. For example, the PRC's Shandong indicates lower cost of electricity production than the ROK. This cost difference creates a situation that supports exports from Shandong to the ROK. Such regional issues may also appear in Japan, where different regional utilities' economic interests will vary in acting as the receiving end of imported electricity. It is necessary to further study pricing value chains and the tariffs on grids and consumers on a case-by-case basis. There should be a specific project study designed to attempt renewable energy power flows from Mongolia's Gobi Desert to the ROK through the PRC grid interconnections. This study will be required to clarify pricing cost value chains of power flows considering load flow studies of line losses and congestions.

Another commercial analysis will be required to assess market competition. Mongolia's renewable energy projects may need to compete with the PRC Inner Mongolia Autonomous Region's renewable energy, which can be expected to have cheaper pricing finance within the PRC. The PRC's projects, therefore, may be more viable than Mongolia's Gobi Desert projects. The wind and solar conditions in the PRC's Inner Mongolia Autonomous Region are not significantly different from those in Mongolia's South Gobi. To make South Gobi's renewable energy development viable, Mongolia's first project 
should be developed with a low cost of debt from bilateral or multilateral finance to demonstrate the potential impact of subsequent projects and encourage their financing by other parties from Mongolia, the PRC, and international societies. Further, Mongolia's cost disadvantage compared to Inner Mongolia Autonomous Region may also be offset by higher load factors, economies of scale, and back-to-back PPAs with the PRC and the ROK. If renewable energy development can be scaled up to the gigawatt range, it is likely that the project unit cost can be reduced following the international best practice.

The coal industry is also quite important to Mongolia. Through the NEA interconnections, coal-fired power may also come into the system for power trading, subject to its cost competitiveness. This possibility can be included in further commercial analysis. The NAPSI Study's simulation, under Scenarios 2 and 3, indicated that if the NEA interconnection was substantially extended and power export from Mongolia exceeded its renewable energy capacity, the low cost of Mongolian coal could trigger partial export to its neighboring countries.

The development of NEA regional interconnections might also produce situations where the cost burden between the contracting countries is deemed unbalanced in the short or medium term. This can especially be the case if the international interconnections increase the costs of strengthening domestic transmission lines, which serve as de facto cross-border infrastructure. Another example would be if the cost burden for building balancing capacity for the variability of renewable energy falls to an unrelated market participant in another country. Therefore, it will be essential for the national transmission system operators (TSOs) to coordinate power imports and exports, as well as their backup arrangements in the case of any gaps, in order to make tradable electricity accessible in the wholesale markets beyond national boundaries. In the case of the NEA, however, the development of such a regulatory regime has a long way to go.

\section{Regulatory Aspects}

The NAPSI Study made recommendations for the NEA countries on free regional electricity markets, institutionalization of competitive mechanisms, standardization of power trade contracts, regional grid codes, and equal priority for domestic demand and export commitments, all of which align with the European power trading market practices. In an advanced marketplace-such as within Nordpool, which operates mainly in the Nordic and Baltic countries-trading is based on electricity and renewable energy always has access to the market. TSOs in these countries have concluded system operation agreements that determine the obligations for maintaining and using different kinds of reserves and balancing power so that market disturbances, such a renewable energy curtailment, are minimized.

As the NEA countries do not currently share a unified set of regulatory systems, the recommended market mechanism of the NAPSI Study seems premature for the NEA power trade. The requirement for such extensive regulatory reforms, however, should not hold back cross-border interconnectivity plans. It is considered more realistic and beneficial for the regional scheme to start developing interconnectivity under the existing regulatory environments based on bilateral and tripartite PPAs, in which transmission rights should be agreed on in transmission agreements between the power sellers and purchasers as well as TSOs.

As to the cost coverage of cross-border transmission and regional interconnections, the NAPSI Study proposes the use of transmission rights auctions. The marginal cost difference between two countries - the lower price belonging to the country exporting and the higher to the one importingthat enables profitable trade transactions is called the economic congestion rent. In this model, TSOs

of the two countries sell transmission rights to the market participants through auctioning. The winning 
party implements the transaction, buys and sells a block of electricity through the interconnector based on the congestion rent, and then pays out of the sales margin to TSOs for the transmission cost at the final price of the auction.

A pre-requisite to the transmission rights auction is third-party access (TPA), which is a transparent and nondiscriminatory access to interconnection guaranteed for all players in electricity generation and wholesale trading. However, transmission rights cannot be effectively auctioned off if there are too few market participants competing for the prospect of importing a block of energy. TPA, as with some other regulatory aspects recommended by the NAPSI Study, is not yet fully in place in all NEA countries. The short- and medium-term steps in building regional interconnectivity must, therefore, be based on the prevailing or more near-term realities of the relevant trading countries.

Japan, the PRC, the ROK, and the Russian Federation are large countries and economies, and their organizational, institutional, and regulatory systems are significantly different. However, all five NEA countries, including Mongolia, have accelerated their power sector reforms and are moving gradually towards more competitive generation markets. However, the pursuit of NEA interconnections is not a matter of such significance that it could, by itself, drive regulatory developments in these countries.

Generation and transmission businesses have been unbundled in most of the region's countries, with Japan completing this process in 2020. In Mongolia and the PRC, the TSOs act according to a singlebuyer principle, which allows generation competition, but not a multitude of buyers and traders that could by-pass the central marketplace through one-to-one PPAs. PRC is experimenting with spot markets. Eight regional spot-markets have already been established, and the latest simulation was launched in Inner Mongolia Autonomous Region in 2019. The country is moving rapidly with the evolution of its electricity market.

Even when countries have competitive wholesale electricity markets, subtle differences in sector regulations can create barriers to the development of regional interconnectivity. For example, the Russian Federation has a well-functioning and competitive marketplace for wholesale electricity. However, there are few players in the market, so the market is not very dynamic. Some features, such as obligatory purchase of capacity (under the Russian Federation's capacity market) by the market participants, may turn out to be issues that must be solved in order for dynamic cross-border electricity trading involving the Russian Federation to take place.

Although marginal generation cost differences exist, it will be a challenge to create mechanisms to harness all or most of them in day-ahead, or hour-ahead, cross-border trading under the various national/regional power dispatch regimes. Many currently existing cross-border interconnections, between Mongolia, the PRC, and the Russian Federation, operate simply by separating a border area from the importing country and supplying it from the exporting country, without the area being connected to the national grid. Therefore, most connections are unidirectional. However, the direction of regulatory development in the five NEA countries is generally favorable to the development of regional interconnectivity.

The first phase of NAPSI could start with PPAs and transmission services agreements (TSAs) between the market participant. These could possibly be governed by a framework agreement between the three or four participating countries. In Figure 31, three alternatives are outlined as an example. In all three alternatives it is assumed that the variability of renewable electricity production in Mongolia is balanced by the Russian Federation through a contract that relies either on a regulated contract between the two respective TSOs or power purchase from the Russian Federation's electricity dayahead marketplace. 
(i) The PRC as purchasing country,

(ii) the ROK as purchasing country, and

(iii) the PRC as purchasing country and seller to the ROK.

In option (iii) there may or may not be a back-to-back agreement coupling the PPAs between Mongolia and the PRC and between the PRC and the ROK.

\section{Figure 31: Alternative Commercial Arrangements for the First Phase}

(i) The PRC as a purchaser

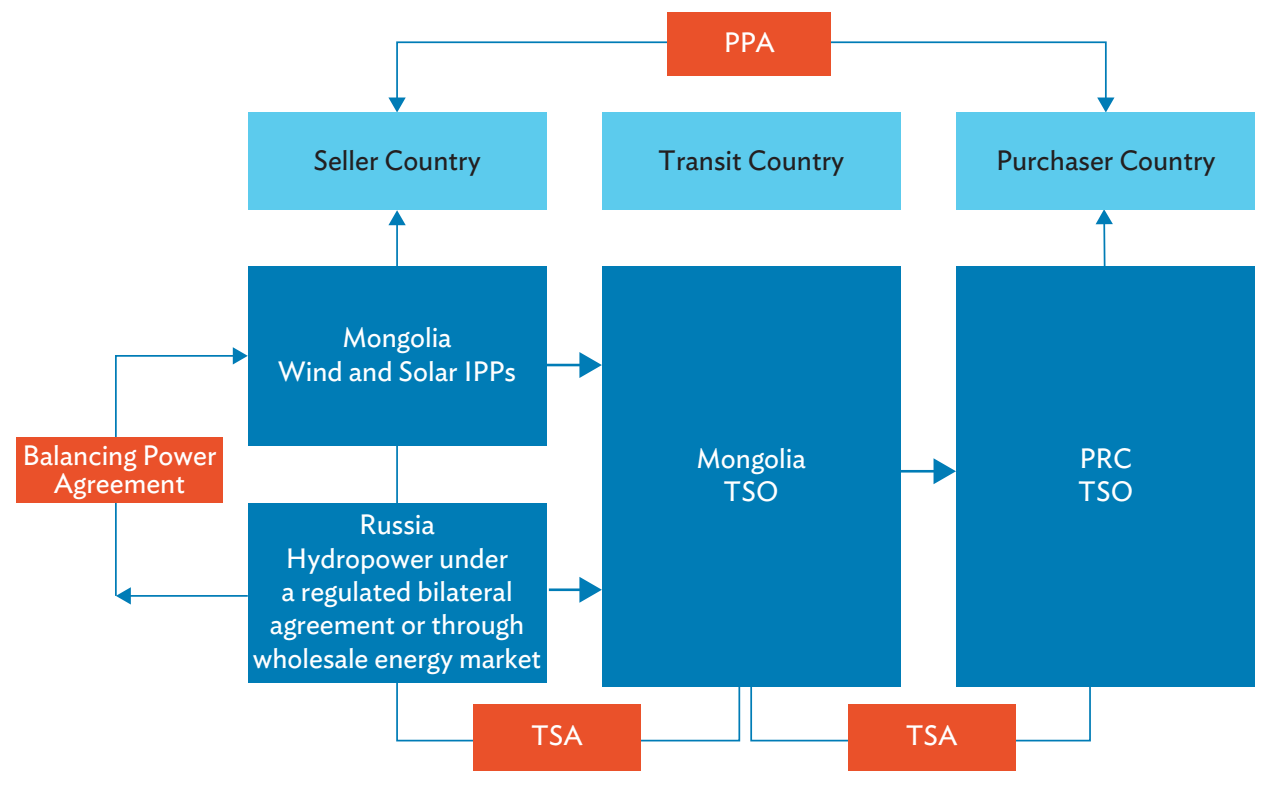

(ii) The ROK as a purchaser

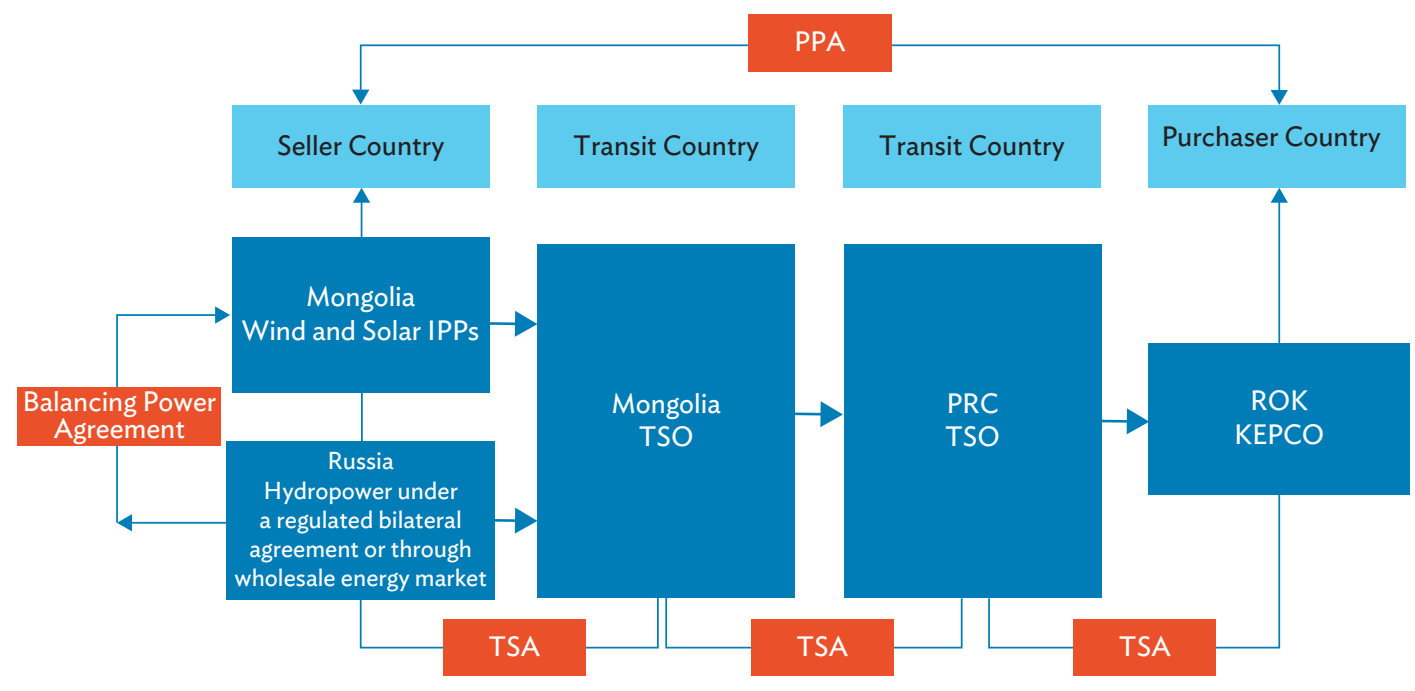


Figure 31 continued

(iii) The PRC as a purchaser from Mongolia and a seller to the ROK

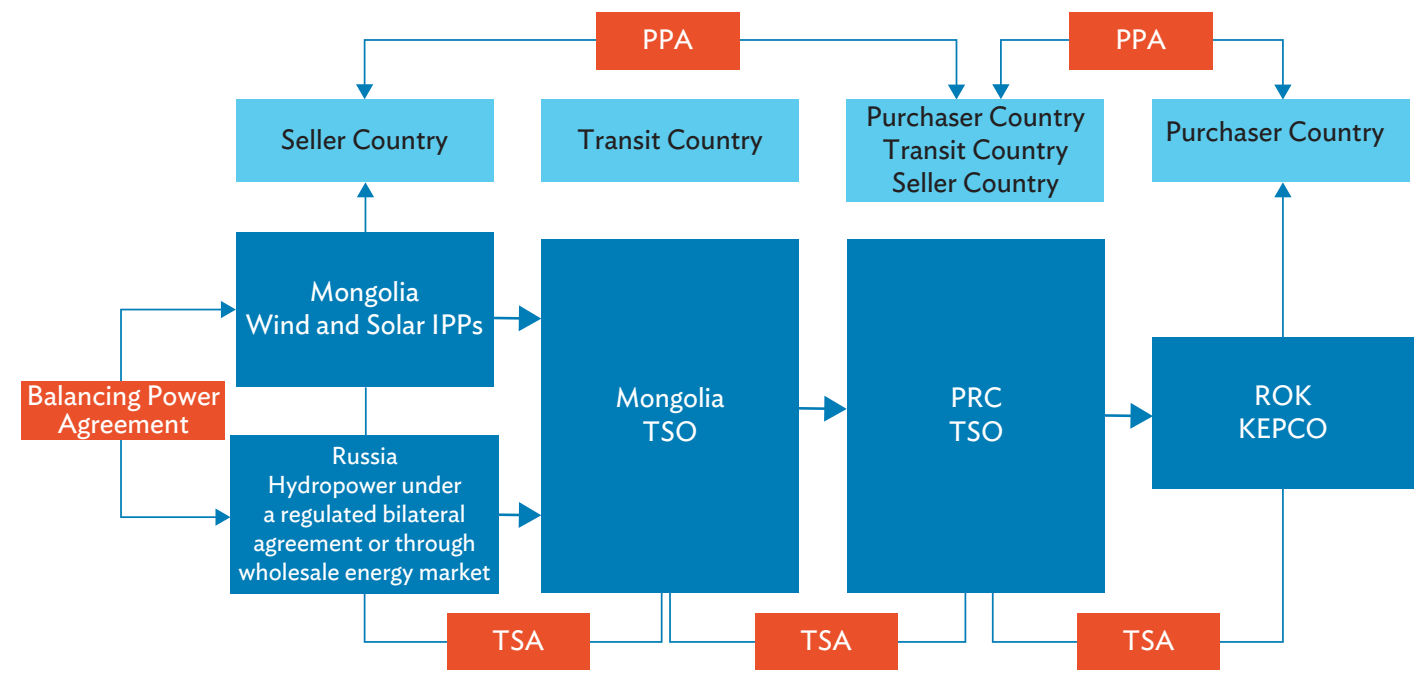

IPP $=$ independent power producer, $\mathrm{KEPCO}=$ Korea Electric Power Corporation, PPA $=$ Power Purchase Agreement, $\mathrm{PRC}=$ People's Republic of China, ROK = Republic of Korea, TSA = transmission services agreement (wheeling agreement), TSO = transmission system operator (single-buyer system operator).

Source: Author.

The mechanism proposed by the NAPSI Study largely follows that which has been developed in Europe by ENTSO-E (the European Network of Transmission System Operators for Electricity), which represents 43 electricity TSOs from 36 countries across Europe. Based on this practice, the NAPSI Study recommends the creation of "the NAPSI Authority" for managing the development of interconnection infrastructure and for guiding the processes to harmonize national regulations so that they promote regional cooperation for electricity trade. However, the establishment of this authority will require clarifying operational budgetary sources, institutional structure, operational procedures, regulatory details, staff training programs, and agreements among the relevant countries. Realizing this authority will therefore be a long process. These issues may require further discussion and additional necessities may be identified in a transition from Scenario 2 (10 GW renewable energy) to Scenario 3 (100 GW). Regional power trading mechanisms should subsequently be discussed in a common multilateral platform in parallel towards a shared long-term vision.

In relation to the other Mongolian grid configuration options, the quarantined DC would have less impact on relevant regulatory requirements. Since this option would segregate the grid from South Gobi to the PRC, it would be managed separately from the Mongolian domestic grid systems. However, some new regulations might need to be introduced in detail for this purpose. The integrated $A C$ option, on the other hand, would require complex coordination of regulatory requirements with regulators in the other interconnected countries, and operational safety in the grid systems would require additional contingent costs in terms of both physical and human resource capacities.

\section{Conclusion of Grid Configuration and Transmission Interconnection}

The three proposed network configurations should not be considered as pre-fixed all-or-nothing solutions, instead they provide building blocks for stepwise development of interconnectivity. It is not 
straightforward to compare the costs and benefits of all possible outcomes in order to identify the best option, given many open-ended scenarios and many variables that may impact the future picture of Mongolia's power sector. The integrated AC configuration recommended by the NAPSI Study, however, seems the least reversible and most risky. Therefore, the author thinks that the first step in development should be through part of the quarantined DC option that would connect from Mongolia only to the PRC's grid line without connecting to the Russian grid to bring the balancing capacity to stabilize renewable energy. This could target evacuating renewable energy of only 2-5 GW while addressing the issues of stabilizing the variability and intermittency within the PRC's systems. As Mongolia's South Gobi renewable energy base can further be expanded up to $10 \mathrm{GW}$, the decision among the three options should be made based on further analysis as the situation develops. In the meantime, Mongolia can decide the extent to which its national grid systems should be connected to the Russian Federation grid, the PRC grid, or both grids, taking into consideration where to get backup power sources to stabilize renewable energy's inherent variability and intermittency. It is crucial to demonstrate the first step of development to make further development opportunities expand.

In addition to the interconnection between Mongolia and the PRC, the possibility of back-to-back arrangements with the interconnection between the PRC and the ROK should be explored. The latter interconnection scheme is advanced. However, one of the arguments in the ROK is that the country should not import coal-based electricity generation from the PRC, considering climate and local pollution concerns. Therefore, the interconnection planned between the PRC and the ROK should be linked to the import of clean energy from Mongolia. Such a linkage, trading exclusively in clean energy, might also eventually help change the political sentiments in Japan, which has officially been very cautious or indifferent to cross-border power trade.

\section{WAYS FORWARD WITH DEVELOPMENT PRIORITIES}

Based on the NAPSI Study's results and consideration of the issues and concerns they raise, this review will suggest subsequent actions and directions to be taken for renewable energy cooperation and power system interconnection in the NEA. These recommendations are approached from four angles: (i) specific project investment studies, (ii) financial structuring studies, (iii) legal and regulatory frameworks for enabling investment environment, and (iv) institutional development and creation of a regional interconnection authority.

\section{A. Specific Project Investment Plans}

To start building the NEA power system interconnections, specific investments will be needed by 2026 . These can be initiated and grouped into the three following specific investment projects (Figure 32):

(i) Wind and solar photovoltaic investments in the Mongolia's South Gobi renewable energy base to 2-5 GW capacity on an initial stage towards $10 \mathrm{GW}$.

(ii) Interconnections linking Mongolia's South Gobi renewable energy base with the PRC and/or the Russian Federation (500 kV HVDC).

(iii) Interconnection between PRC and the ROK (i.e., Weihai and Incheon with $500 \mathrm{kV}$ HVDC). 


\section{Figure 32: Specific Investment Priority Projects}

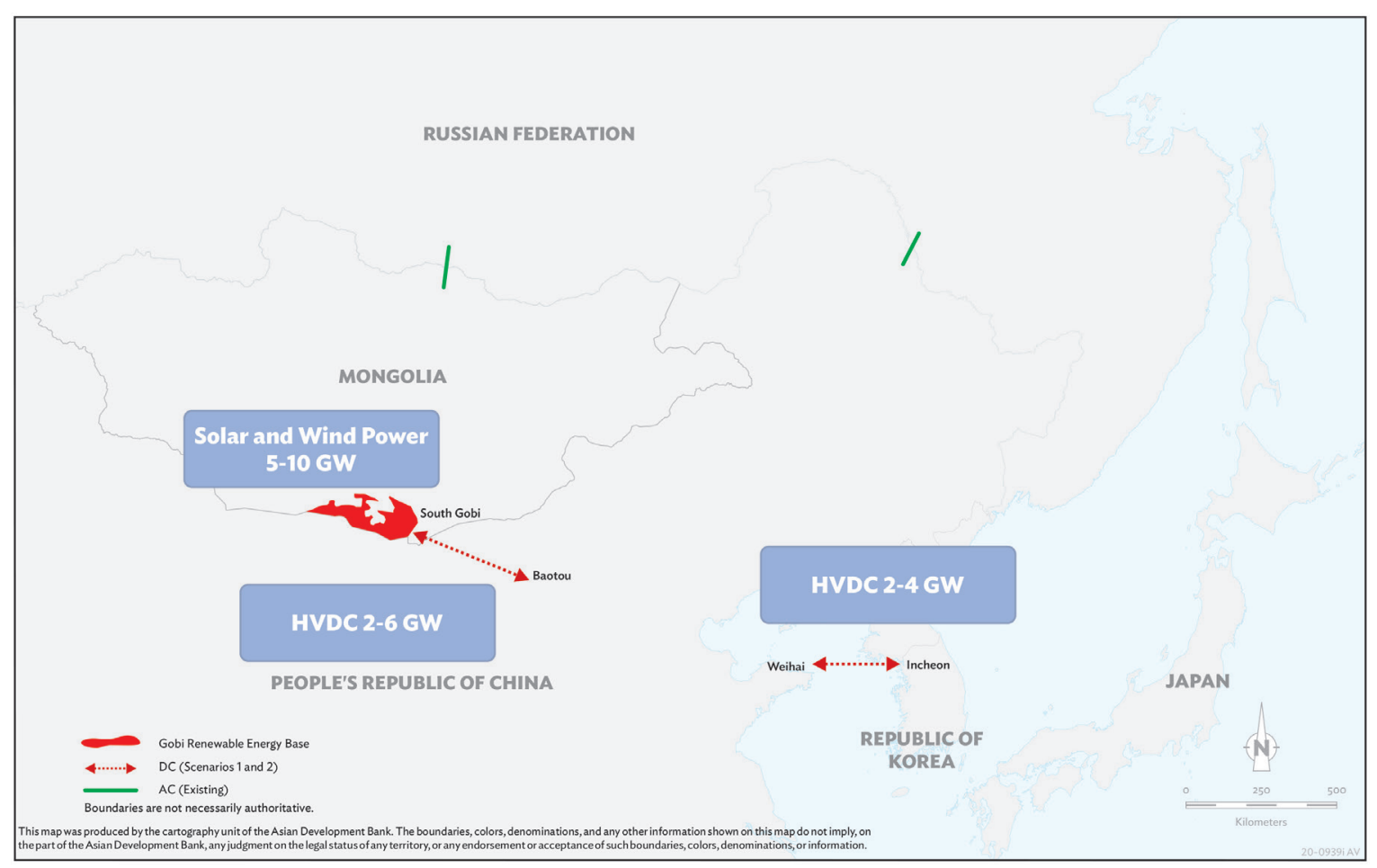

$\mathrm{GW}$ = gigawatt. HVDC = high voltage direct current.

Source: Électricité de France (2018c). Altered by the author.

Investments in (i) renewable energy generation in South Gobi and (ii) Mongolian interconnections with the PRC and the Russian Federation are, naturally, inextricably linked. The reason why these investments are placed in different categories is that the parties taking commercial interest in each are different, even though all parties need to work together in a coordinated manner in realizing them. Wind and solar photovoltaic investments can be made by the NEA region's big power generation companies, but also by private sector investors, who focus on renewable energy generation regionally or globally. The interconnections require a different set of investors that may include TSOs and/or government owned companies.

To see the development opportunities for the South Gobi renewable energy base, it may be relevant to start to look into international references of the recent wind and solar power development. Currently there are more than 20 mega size wind farms (each with a capacity of more than $0.5 \mathrm{GW}$ ) in the world. Two-thirds of these are in the US. The largest wind farm in the world is Jiuquan Wind Power Base in Gansu (the PRC) with an $8 \mathrm{GW}$ capacity. Its development continues with a planned total capacity of $20 \mathrm{GW}$. The wind power base is built mostly in $200 \mathrm{MW}$ blocks. All farms are operated in a coordinated manner with the grid systems. However, some projects have encountered transmission capacity bottlenecks beyond any technical matters of wind power generation and have therefore not reached their full operational potential. As to solar photovoltaic in the world, the biggest solar parks in operation have now reached the $1 \mathrm{GW}$ range, but many of them are expanding to the $2 \mathrm{GW}$ range. The largest parks currently under planning or tendering aim for capacity of up to $5 \mathrm{GW}$. The Tengger Desert Solar Park in PRC's Ninxia is the one of world's largest operating solar farm, with a capacity of 1.5 GW. 
The 1.2 GW Noor Abu Dhabi solar photovoltaic park in Sweihan started commercial operations in 2019. Other large-scale parks are in operation in the PRC, India, Morocco, Mexico, and the US. Massive projects are also under development in Saudi Arabia.

Considering this international experience, the challenges for developing renewable energy in South Gobi to export to neighboring countries are not primarily technical. Economies of scale for the interconnection infrastructure demand that significant renewable energy generation capacity be developed quickly to at least 2-5 GW in the first phase so that the $500 \mathrm{kV}$ level substation, converter stations, and at least one HV interconnecting line can be appropriately loaded. The development focus ought to be placed more on commercial and business prerequisites rather than technical aspects. To realize the first step of the NAPSI concept, the key activities will be (i) creation of a business model and consequent commercial structure with confirmed off-take arrangements by export and import parties, and (ii) simultaneous development of the transmission infrastructure with committed partners comprised of public companies with support from each government.

Of the three important projects, the PRC-ROK interconnector is the most topical and of the highest priority for making a breakthrough for South Gobi's renewable energy and the subsequent HV transmission link between Mongolia and the PRC. As of early 2020, negotiations between KEPCO and SGCC are progressing toward a joint development agreement. Following that, the parties will negotiate a shareholders' agreement for a joint venture to own and develop the project. Given the central role of this link in the regional plans, it would be desirable that the parties consider the option of SGCC channeling renewable energy from the South Gobi renewable energy base through this line in the future. It may take time to ink a joint development agreement-subject to agreement on the optimal joint venture business structure and each government's support and decision-making-but it is useful to note (i) that the PRC plays a pivotal role in developing interconnections from Mongolia because of its proximity to South Gobi and its market size for power trading, and (ii) that the ROK is in a strategic position to incentivize the power demand and initiate investments in the vast potential of wind and solar energy to be brought from Mongolia through the PRC to the ROK. This tripartite interconnection can be extended to Japan and the Russian Federation later or simultaneously.

The subsequent actions for specific project investments can be the production of studies on (i) backto-back PPAs of power trade between the ROK and the PRC and between Mongolia and the PRC, (ii) individual and collective financial and economic analysis to investigate pricing for electricity and transmission services, and (iii) load flow and other techno-economic analysis to clarify possibilities to balance variable solar and wind power and to verify availability of transmission capacity from the PRC's Inner Mongolia Autonomous Region to Eastern PRC so that renewable energy projects developed in Inner Mongolia Autonomous Region and Mongolia would not obstruct each other.

The regional interconnections recommended by the NAPSI Study include also the following routes:

(i) Vladivostok (Russia) - DPRK-Donghe (ROK) 500 kV, LCC-HVDC, 2 GW

(ii) Hadong (SK) - Hino (Japan) 500 kV LCC-HVDC, 2 GW

(iii) Primorsky (Russian Federation FE) - Kashiwazaki-Kariwa (Japan), 500 kV, LCCHVDC, 2 GW

The above two interconnecting lines to Japan are crucial to completing the ring structure for the NEA region. However, in the short term, the priorities of the Japanese energy administration and transmission operators may not be in international cross-boundary lines. The 10 major utility companies still hold dominating positions in their separate supply areas as de facto regional 
monopolies, and they have traditionally taken little interest in the electricity import option. The implementation of unbundling is ongoing, with completion expected in 2020. Regarding the line from the Russian Federation to the ROK via DPRK, the political climate is yet to be supportive of the pursuit of that initiative.

\section{B. Project and Financial Structuring}

Mongolia has successfully attracted more than $\$ 500$ million of private sector investment in wind and solar energy projects in since 2012. These investments rely on Mongolia's feed-in-tariffs based on the Renewable Energy Law. However, the scale of investments contemplated under the NAPSI Study scenarios considerably exceeds Mongolia's past investments in the power sector.

The total cost of developing NEA regional grid connections and $10 \mathrm{GW}$ of renewable energy installments in South Gobi (Scenario 2 [Integrated AC] selected here only as an example) is estimated at $\$ 19.4$ billion. Of this total, $\$ 9.8$ billion is for the renewable energy generation capacity. The grid development cost directly linked to Mongolia, including the costs of interconnections added to the cost for strengthening the grid within its territory, is $\$ 3.5$ billion. If the combined $\$ 13.3$ billion of Mongolian projects with its neighbors is to be developed within 16 years from 2020 to 2036, the investment evenly distributed as annual installments is about $\$ 0.8$ billion.

This investment cost would not be insignificant for Mongolia. In 2018, Mongolia's GDP was \$13 billion (Table 1), and the gross fixed capital formation, including investment in fixed assets - such as roads, municipal and energy infrastructure, industry, and buildings-totaled $\$ 3.8$ billion. The estimated annual requirement of $\$ 800$ million for the NAPSI investment would represent $6 \%$ of GDP and $21 \%$ of annual fixed asset formation in the country. Although the level of investment is high in the Mongolian context, its share of GDP and investments does not appear unbearably high.

However, the investment size can also be weighed against the financial capacity of the power sector entities in the country, which would typically be the parties for such investments. In this context, the share of the utilities sector is estimated at about $2 \%$ of the GDP, and the total revenue of energy sector companies is just more than $\$ 300$ million. The revenues collected from the end users are shared among market participants, which include 10 generating companies, 16 distribution companies, the national transmission company, and the national dispatching center. Many sector companies in Mongolia are not profitable or are only marginally profitable. It is therefore evident that, from among the electricity market participants, it is difficult to identify any entity that could have the financial strength to put forward the equity needed to satisfy a typical self-financing ratio of $10 \%$ to $30 \%$ of the scheme's capital requirement.

In this context, the Mongolian government has delegated authority to its national investment company Erdenes Mongol LLC to drive the commercial aspect of, and the Mongolian interest in, the development of regional interconnectivity. Erdenes Mongol is a company that manages key stateowned assets, especially in the mining sector but also increasingly in the infrastructure and energy fields. The company was established in 2007 as the government vehicle for ownership in strategic assets in coal mines as well as in copper (Oyu Tolgoi), precious metals, and uranium. Erdenes Mongol has expanded its portfolio to unconventional oil and gas, fuels, metals refining, steel production, mineral prospecting and exploration, services and maintenance, finance, and electricity generation and transmission. 
In the energy sector, Erdenes Mongol agreed in 2015 on cooperation with SGCC for developing a coalfired power complex of 5,280 MW at Shivee Ovoo coal mine, associated with a transmission line with the capability to transmit 4,600 MW at $660 \mathrm{kV}$ to the PRC. The concept also includes building renewable power plants with an installed capacity of $15 \%$ of that of the coal-fired capacity. In accordance with the agreement, SGCC selected three consulting design institutions in 2016 for various aspects of the project to carry out a feasibility study over 2 years. The government-assigned transboundary mission of Erdenes Mongol has continued thereafter and the company has been a Mongolian party in negotiations on NAPSI with the PRC's SGCC and GEIDCO, the ROK's KEPCO, the Russian Federation's Rosseti, and the Japanese Soft Bank.

A public-private partnership in some of its variants, such as the build-own-operate-transfer model, can be applied to develop some of the necessary projects that will collectively realize the Northeast Asia regional power interconnections and associated renewable energy development on a step-bystep basis over time. Apart from the very large utility partners-such as KEPCO, SGCC, Rosseti, and their subsidiaries - state-owned entities, including Erdenes Mongol in Mongolia, some of the PRC's big five power producers, or provincial utilities and private investors can act as principal developers in joint ventures. In addition, state funds, banks, and insurers can come in with infrastructure loans and other instruments. The role of concessional loans from international development banks and state exportimport agencies should be well targeted to crowd in commercial finance. Initial transmission interconnections can be supported by bilateral assistance or multilateral development banks, which have financed many similar cross-border projects with technical and financial support.

Rosseti and SGCC have signed an agreement to establish a joint venture to invest in the reconstruction of electric grid infrastructure and new power capacity in the Russian Federation, and potentially abroad, including in Mongolia. SGCC and KEPCO are also planning to establish a joint venture for the PRC-ROK interconnection project. These kinds of agreements are examples of the set-ups likely to be involved in the interconnectivity development. The Rosseti-SGCC joint venture will invest in new and reconstructed electrical grid facilities. In addition, it will act as an engineering, procurement, and construction contractor for the construction of turnkey facilities, providing engineering, procurement, and construction services in the Russian Federation and other countries.

To promote the NEA power interconnection associated with South Gobi's solar and wind power development, Erdenes Mongol signed an MOU with Rosseti in September 2019. Erdenes Mongol has discussed updates to its MOU with SGCC and is approaching KEPCO as well. These MOUs may build a cooperative foundation of mutual interest for future developments. The renewable energy development and associated infrastructure will potentially provide an important stimulus for the Mongolian economy. When wind farms and solar photovoltaic fields are built to the gigawatt range, the required value chains will create many opportunities for Mongolian companies and society to participate in planning, designing, and building these fields, as well as providing operations and maintenance and various services for the facilities.

\section{Legal and Regulatory Frameworks in Mongolia}

The NAPSI Study shows that the planned renewable energy development potential in South Gobi well exceeds the domestic electricity demand of Mongolia. For the purposes of NEA interconnection development, therefore, the South Gobi renewable energy base should be considered as supplying electricity primarily to other NEA countries. The same conclusion can consistently be applied to the associated transmission grid development since its primary purpose is to enable cross-border trading of electricity. However, it is possible that a small part of the renewable energy will also be used to serve 
Mongolia's domestic energy demand after opening an avenue for power export opportunities. Considering the huge investment requirements, it is more prudent to proceed by laying down the infrastructure base for the power export business first and scale it up for domestic consumption later. Therefore, the author of this report suggests that Mongolia adopt the essence of the quarantined DC grid system first while considering whether it will take the integrated DC or AC connection at a later stage (section IV.B), although the NAPSI Study recommends the integrated AC grid option for Mongolia's grid development.

Because the interconnection scheme is not driven only by Mongolia's interest but also by the interests of various power sector players from all the NEA countries, it is also sensible to consider the following initial strategies and approaches:

(i) International interconnecting lines can be constructed, owned, and operated by local-foreign joint enterprises as the public entity.

(ii) Renewable energy generation plants can be built based on PPAs and electricity transmission service agreements concluded with power importing parties without resorting to the local Mongolian electricity demand.

Mongolia's policies are basically supportive to enabling the above legal and commercial frameworks. They mainly include the following:

(i) Mongolia's State Policy on Energy (2015-2030) is a high-level policy but is clearly supportive of such premises. It states that Mongolia aims at being an energy-exporting country and pursues the development of mutually beneficial energy cooperation with regional countries. The policy also sets shares for renewable energy capacity that can be developed in Mongolia, 20\% by 2030 and up to 30\% by 2030.

(ii) The Foreign Investment Law (1993) provides rights for foreign investments in the country. It allows investors to conclude a Stability Agreement, mainly to ensure that taxation and other similar government-set obligations remain stable, for large investments of more than $\$ 10$ million for up to 15 years. Further, the law stipulates, concerning land use by foreign entities that a lease can be granted for up to 60 years with an option to extend once for a period of 40 years on the same conditions as the original land lease agreement.

(iii) The Law on Licensing (2001) is fundamental but not restrictive for transmission line and renewable energy development by foreign entities in the country. It regulates the issuing, suspending, and revoking of a license to conduct certain business activities that may negatively affect the public interest, human health, the environment, and national security that also require specific conditions and expertise. Energy sector investment licenses are granted by the Energy Regulatory Commission (ERC). The license alone is not a sufficient condition to start electricity generation, as the licensor needs to conclude a PPA for the off-take arrangement.

(iv) The Law on Concessions (2010) is important as some transmission lines could be developed on a build-own-operate-transfer basis. The law defines various modes of concession agreements. The law regulates tendering for granting investors concessions over state- and locally owned property, and the conclusion, revision, and termination of concession agreements, as well as the settlement of disputes. 
(v) The Renewable Energy Law (2007) was enacted with the aim of promoting green and sustainable energy development in the country. It was amended in 2015 to introduce feed-in tariffs, which were expressed as a range for different types of renewable energy. Further amendments, introduced in 2019, suggested abandoning the current approach of providing a tariff range and only legislating on the cap for renewable energy tariffs instead. Wind and solar energy tariffs are therefore capped up to $\$ 0.12$ per $\mathrm{kWh}$ and $\$ 0.08$ per kWh, respectively. The 2019 amendments also brought in renewable energy auctioning. The Ministry of Energy will oversee the formulation and adoption of the relevant implementing regulations on the renewable energy auction procedure, as well as organizing the auctions. The law amendments also set the responsibility for the grid connection so that the National Transmission Company, as the transmission license holder, will no longer be responsible for the financing of substation expansion, or other electrical facilities; instead it is the project developer's obligation to cover the cost of grid connection to the renewable energy generation facility.

Overall, Mongolia is favorably positioned in the international ease-of-doing-business rankings. However, there are cases of the government changing positions in dealings with foreign investors for large infrastructure and mining projects, and of extremely slow progress with some energy investments, when there has not been a political consensus over them.

The foreseen investments in NEA interconnections and renewable energy generation in South Gobi are so sizeable that it will be necessary to create a uniform scheme and a predictable investment environment for their realization. Therefore, certain legislative changes may prove necessary. As the Renewable Energy Law is now enacted with domestic supply in mind, the completely export-driven investments in renewable energy may require a different kind of legal and regulatory framework for power generation investments. For example, the party with whom a PPA must be concluded will be notably different for export-driven generators. Their PPA prices cannot take reference from the domestic business reality.

In a domestic business, the PPA is concluded with the National Dispatching Center and the PPA price must be in accordance with what is stated in the Renewable Energy Law. However, in the case of the planned wind and solar farms of the South Gobi renewable energy base, the PPAs will need to be concluded with export clients in the PRC, the Russian Federation, and possibly in the ROK. The price, if not set through auctioning, will be set through negotiations with these foreign parties rather than with the dispatching center. It is, of course, possible to have the dispatching center as a TSO party by designing a back-to-back arrangement linking the renewable energy generating company, the dispatching center, and the export client, which would allow the facility to be operated according to the agreed upon demand pattern of the importer. In this regard, the quarantined DC approach would be much simpler for the dispatching center to start to coordinate power trading operations without worrying about impacts on domestic power supply. This learning curve approach will be essential for the system operators on a step-by-step basis.

It is then necessary to review the readiness of Mongolia's overall regulatory system. There should be analysis of certain changes, such as allowing PPAs for exports, by-passing Mongolia's single-buyer dispatch system and feed-in-tariff, possibly allowing auctioning of project development rights for prepermitted sites, and government guarantees for the provision of certain infrastructures for wind and solar photovoltaic fields prior to bidding for the development rights. Regulations should make Mongolia and its South Gobi an attractive place to invest with foreseeable and stable revenues, priority 
dispatch with no or minimal curtailment, and coordinated provision of grid connection with sufficient capacity in the short and long term.

There is, however, a legitimate right for Mongolia to benefit from these developments, which will probably be driven by foreign investments. The next stages of the NAPSI Study need to establish what kind of benefit-sharing arrangements would realize such a right most efficiently, effectively, predictably, and transparently, as well as being maximally in accordance with the current legislation. Typical solutions include government participation in the investments as a shareholder, taxation or concessional fees charged either as a percentage of electricity export revenues or at a flat rate, or, for example, through land lease agreements, such as when a country's mineral resources are utilized. In the case that the quarantined grid option is taken, then it will be particularly crucial to set up a benefit sharing of the power export revenue with the government (section IV.B).

It is essential that Mongolia develops a mechanism that incorporates the government's long-term strategy to be an electricity-exporting country, political commitment, high-quality planning of the scheme, and a reliable set of template contracts for transmission agreements and PPAs. The government could, for example, choose to auction the land concessions for renewable energy production by preparing pre-permitted sites for wind and solar photovoltaic farms with pre-planned road infrastructure and transmission connections. It would be of benefit for the government to set up a one-stop window to deal with a series of issues and regulations without scattering these processes among different ministries, particularly considering the magnitude and importance of the opportunities to involve key stakeholders from other NEA countries to contribute to these developments.

\section{Institutional Development and Regional Interconnection Authority}

The multidimensional investment agenda calls for strengthening the national institutions and regulations as well as regional coordination. An enabling environment for the NEA region interconnection scheme rests on positive developments in the following four areas, of which the first three were discussed above:

(i) Commercial readiness. It is necessary to identify and analyze commercial drivers for the participants of regional interconnectivity. This will require concrete formulation of business models and revenue generation mechanisms for each part of the specific interconnectivity schemes. A useful first step is to analyze the feasibility of establishing a joint venture to own and operate key interconnection investments.

(ii) Investment and financial resources. Public enterprises across NEA countries are requested to consider jointly investing equities for interconnection projects. Bilateral and multilateral financial institutions should consider debt financing in favorable financing terms to prove cross-border interconnection projects and initial solar and wind power developments and create an enabling environment for subsequent private investments.

(iii) Legal and regulatory frameworks. As the renewable energy's source country initiating its export to neighboring countries, Mongolia should provide regulatory clarity, legal maturity, transparency, and incentives for the coordinated gigawatt-range renewable energy development in South Gobi.

(iv) Regional coordination platform institutionalized. It is essential to establish a multilateral regional platform to pursue, coordinate, and lead implementation of the NEA interconnectivity development. This body should be tasked and delegated power to bring regional plans and bilateral initiatives a step forward. 
The NAPSI Study's ambitions for 2026 are so high that, in addition to Mongolian companies, wideranging stakeholders will need to be involved and coordinated. They will include the NEA governments (both ministries of energy and foreign affairs), international organizations, bilateral and multilateral financial institutions, and public and private investors.

One of the mentioned barriers for international interconnections is that the benefits and investment burdens for the development of the physical cross-boundary infrastructure are not evenly distributed among the member countries. Some countries act predominantly as sellers, whereas others act as buyers, and some may not have any physical assets within their territory associated with next stage investment. Another country, such as the PRC, may be asked to offer transmission services through its grid, say for selling renewable electricity from Mongolia to the ROK. Further, some countries can provide technology, engineering, procurement, and construction services, or financing, whereas others may not be able to contribute in those terms.

Imbalances in the distribution of costs and benefits can be evened out if all interconnection investments are carried out by a joint venture company, in which all of the participating NEA countries and/or their respective major utilities/corporations are shareholders. There is international experience of such arrangements, for example the Gulf Cooperation Council Interconnection Authority created by six Gulf States, or the Turkmenistan-Afghanistan-Pakistan-India (TAPI) Pipeline Company in Central Asia. This kind of joint venture may also include national and international financial institutions in some roles, if the member countries so desire. For example, ADB provides the TAPI Pipeline Company with transaction advisory services. It would be of value to undertake a feasibility analysis of a corporatized joint venture for regional interconnectivity, which would coordinate, develop, invest, build, own, and operate all interconnections. The joint venture can be started by bilateral parties and expanded to trilateral or multilateral parties, but appropriate steps should be studied further.

There are two lessons to be learned from the above international experience about sustaining the thrust of regional cooperation. The first is the significance of the government's involvement. Crossnational interconnections will require both line ministries of energy and foreign affairs. Ministries in charge of energy affairs in the NEA countries are called to start a multilateral process for establishing permanent coordination and discussion frameworks to develop, invest, build, own, and operate crossborder interconnections and associated generation projects. Based on the region's high-level leaders' expressed support and the results of an accumulation of studies on the topic, including the NAPSI strategy study, there is momentum to accelerate the establishment of such a permanent framework. The second lesson is the need for the presence of public enterprises responsible for project implementation for cross-border interconnection. Without paying attention to investments and business deals from these implementing agencies, policy discussions among government officials may not be able to instantiate actual cross-border projects. The governments and public enterprises will both act as wheels to drive real development. However, this development cannot be realized if one of the two is lacking.

In 2014, three public utilities-KEPCO, SGCC, and Rosseti-and the private company Soft Bank from Japan signed MOU for researching and planning the NEA interconnected grid, but these MOU are not functional without diplomatic support from the relevant governments. The framework established by these parties is currently being explored and may be re-established to include Erdenes Mongol as the Mongolian party. In that case, it will be crucial to ensure each government provides initiative and backup support for their respective party as well as to ensure the involvement of international organizations and institutions in pursuing the MOU objectives. 
For this purpose, the NAPSI Study proposes the establishment of a NAPSI Authority with wideranging responsibilities for regional interconnectivity development. In line with this recommendation, an interim secretariat is proposed to initiate administration and coordination toward a more permanent multilateral framework. In the interim, the proposed secretariat would coordinate technical studies, policy planning, and operational modalities. It would also initiate negotiations and prepare agreements among the relevant parties relating to the NEA's interconnection investments.

The first responsibility of the proposed interim secretariat would be to provide participating countries with a platform for dialogue and cooperation and for administering the multilateral political process of negotiations aiming at establishing a permanent coordination framework or organization. The interim secretariat would provide technical, administrative, and logistical support to the region's energy and foreign ministries until it is replaced by a politically constituted multilateral body.

The interim secretariat should adopt a lean leadership structure and could initially be run by a consultant team backed up by key stakeholders and supporters of regional interconnectivity, such as ADB, UN-ESCAP, and/or IRENA. It should have a coordinator, a team of consultants in key areas of expertise, and staff (hired or seconded) from the participating countries. ADB coordinated regional frameworks, such as GMS, SASEC, and CAREC were all initiated in this way.

The interim secretariat should have the responsibility of collecting a registry of all bilateral and multilateral agreements, letters of intent, and memoranda of understanding pertaining to the NEA region's power system interconnections and cross-border electricity trading. Together with their signatories, it would review their current status and the ongoing and foreseen activities under the agreed cooperation. It would also promote, revitalize, or-if deemed necessary by the parties - wind up the activities.

The interim secretariat would act as:

(i) a body for drafting proposals and updates for the strategic priorities of NEA power system integration;

(ii) a focal point mobilizing studies and providing information about the state and trends of $\mathrm{HV}$ interconnections, regulation, and institutional development of cross-border interconnected power systems;

(iii) a facilitator and organizer of international cooperation, mobilizing knowledge and expert resources for the promotion of interconnections in the NEA;

(iv) an initiator/advisor of negotiations, promoting investments in cross border transmission lines and generation facilities and helping to conclude associated agreements for electricity trading and grid services;

(v) a coordinating body, ascertaining that multilateral interests are also taken into account in bilateral interconnection plans;

(vi) a supervisory body dedicated to ensuring that the agreed actions and intentions of bilateral MOUs for studies and investments on interconnections are fully implemented by all relevant parties in the NEA region;

(vii) a body for developing, according to the specific needs of the NAPSI strategy, recommendations of its own and recommendations supplementary to measures imposed by member countries and international organizations. 
Initially, the interim secretariat should avoid fixed structures for its work as these could prove too heavy or bureaucratic, considering that the needs and priorities of interconnectivity development may not be fully specified at the outset, until a permanent multilateral organization is established. Programmatic work should be practically oriented and could take place under task forces, which would include experts from stakeholders in specified areas of knowledge or practice, but which would disband once the work objective is completed. As a tentative plan, the interim secretariat may be located in Incheon inside UN-ESCAP's Subregional Office of East and Northeast Asia. In addition, $A D B$ is considering providing technical and financial assistance under a specific program, subject to further discussions and arrangements among the stakeholders. IRENA is also expected to continue to provide knowledge support for the Interim Secretariat.

This urgent promotional action and institutional development will support the thrust to promote development of the region's renewable energy resources and their shared cross-country electricity interconnections as well as the multitude of benefits from regional energy cooperation. 


\section{REFERENCES}

Asian Development Bank (ADB). 2015. Technical Assistance to Mongolia for Strategy for Northeast Asia Power System Interconnection. Manila.

ADB. n.d. Mongolia: Strategy for Northeast Asia Power System Interconnection. Manila. https://www.adb.org/projects/48030-001/main\#project-documents.

ADB. 2020. Concept Paper: Proposed Loan to Mongolia for Supporting Renewable Energy Development Project. Manila.

BP. 2019. BP Statistical Review of World Energy 2019, 68th edition. London. https://www.bp.com/content/dam/bp/business-sites/en/global/corporate/pdfs/energyeconomics/statistical-review/bp-stats-review-2019-full-report.pdf.

Électricité de France (EDF). 2017a. Strategy for NAPSI: Northeast Asia Power System Interconnection - Technical Assistance for Mongolia, Module 1: Inception Report. Consultant's report. Paris. (TA 9001MON)

EDF. 2017b. Strategy for NAPSI: Northeast Asia Power System Interconnection - Technical Assistance for Mongolia, Module 3: Planning \& Evaluation Criteria-Assumptions for the Studies. Consultant's report. Paris. (TA 9001-MON)

EDF. 2018a. Strategy for NAPSI: Northeast Asia Power System Interconnection - Technical Assistance for Mongolia, Module 2: Market and Power Trade Assessment, Final Version. Consultant's report. Paris. (TA 9001-MON)

EDF. 2018b. Strategy for NAPSI: Northeast Asia Power System Interconnection - Technical Assistance for Mongolia, Module 4: Mongolia Energy Sector Profile and Projections - Conventional Generation and Renewable Energy Capacity Expansion Plan. Consultant's report. Paris. (TA 9001-MON)

EDF. 2018c. Strategy for NAPSI: Northeast Asia Power System Interconnection - Technical Assistance for Mongolia, Module 5: Mongolia and North East Asia Power Grid Development. Consultant's report. Paris. (TA 9001-MON)

EDF. 2019a. Strategy for NAPSI: Northeast Asia Power System Interconnection - Technical Assistance for Mongolia, Module 6: Power Trade and Regulation. Consultant's report. Paris. (TA 9001-MON)

EDF. 2019b. Strategy for NAPSI: Northeast Asia Power System Interconnection - Technical Assistance for Mongolia, Draft Final Report. Consultant's report. Paris. (TA 9001-MON)

Energy Regulatory Commission of Mongolia. 2019. 2018 Statistics on Energy Performance. Ulaanbaatar.

Fraunhofer ISE. 2018. Energy Master Plan for Ulaanbaatar (Mongolia), Final Report. Bonn. The report was presented to the Government of Mongolia from the GIZ, Germany. 
Global Carbon Project. n.d. $2018 \mathrm{Co} 2$ Global Carbon Atlas, $\mathrm{CO}_{2}$ Emission and Population. http://www.globalcarbonatlas.org/en/CO2-emissions (accessed 2 June 2020).

Government of Mongolia, Ministry of Energy. 2018. The Role and Expectation of Mongolia in Promoting Energy Cooperation in North East Asia. Presented by Yeren-Ulzii Batmunkh, Head of Investment and Production Division, during the North-East Asia Regional Power Interconnection Forum in Ulaanbaatar, 31 October-1 November 2018. Ulaanbaatar. https://www.unescap.org/ sites/default/files/Session\%203-4.\%20Mongolia-Ministry\%20of\%20Energy.pdf.

International Council on Large Electric Systems (CIGRE) Study Committee. 2017. Substations. Springer Nature: Switzerland.

Inter Rao. 2020. Electricity export and import. Moscow.https://www.interrao.ru/en/activity/traiding/ (accessed 15 April 2020).

International Renewable Energy Agency (IRENA). 2019. Renewable Power Generations Costs in 2018. Abu Dhabi.

Institute for Sustainable Energy Policy. 2019. Share of Renewable Energy Power in Japan, 2018 (Preliminary Report). https://www.isep.or.jp/en/717/.

Japan Electric Power Information Center. 2019. The Electric Power Industry in Japan 2019. https://www.jepic.or.jp/pub/pdf/epijJepic2019.pdf.

Lee, S. 2019. Renewable Energy 3020 Plan and Beyond. https://www.renewable-ei.org/pdfdownload/ activities/S3_Sanghoon\%20Lee.pdf.

Liu, Z. 2015. Global Energy Interconnection. Amsterdam: Academic Press.

Murshed, S. Mansoob. 2018. The Resource Curse. Newcastle upon Tyne: Agenda Publishing.

Nakayama, M. 2019. Obstacles to Transboundary Power Trade: Domestic Issue as Impasse. Presented during the international conference of the North-East Asia Regional Power Interconnection and Cooperation Forum 2019 in Seoul, 24 October 2019.

Oyu Tolgoi. 2017. Summary of Environmental Management Plan 2017 of Oyu Tolgoi mine. Ulaanbaatar. https://www.ot.mn/media/ot/content/reports/Environment/emp/EMP_2017_ENG.pdf.

Renewable Energy Institute. 2017. Asia International Grid Connection Study Group Interim Report. Tokyo. https://www.ot.mn/media/ot/content/reports/Environment/emp/EMP_2017_ENG.pdf.

State Grid Corporation of China. 2020. State Grid UHV Projects Under Construction and in Operation. Beijing. http://www.sgcc.com.cn/ywlm/index.shtml (accessed 18 April 2020).

United Nations Economic and Social Commission of Asia and Pacific. 2019. Electricity Connectivity Roadmap for Asia and the Pacific: Strategies Towards Interconnecting the Region's Grids. Bangkok.

World Bank. n.d.a. 2018 GDP (Current US\$). Washington DC. https://data.worldbank.org/indicator/ NY.GDP.MKTP.CD (accessed 2 June 2020). 
World Bank. n.d.b. 2018 Population Total. Washington DC. https://data.worldbank.org/indicator/ SP.POP.TOTL (accessed 2 June 2020).

World Bank. n.d.c. Population density (people per sq. $\mathrm{km}$ of land area). Washington DC. https://data.worldbank.org/indicator/EN.POP.DNST (accessed 25 May 2020). 


\section{A Review of the Strategy for the Northeast Asia Power System Interconnection}

This paper examines, summarizes, and updates the study of a strategy for the Northeast Asia Power System Interconnection conducted by the Asian Development Bank. It presents independent reviews and assessments by various stakeholders from Japan, Mongolia, the People's Republic of China, the Republic of Korea, and the Russian Federation together with additional analysis by experts from the private and public sectors, academe, and international research and development institutions. It also calls for further discussions, studies, and activities in the development of the vast renewable energy potential of Mongolia's South Gobi. Specific integrated investment project approaches for solar and wind power development and two cross-border transmission links in the region are proposed.

\section{About the Asian Development Bank}

ADB is committed to achieving a prosperous, inclusive, resilient, and sustainable Asia and the Pacific, while sustaining its efforts to eradicate extreme poverty. Established in 1966, it is owned by 68 members -49 from the region. Its main instruments for helping its developing member countries are policy dialogue, loans, equity investments, guarantees, grants, and technical assistance.

$\mathrm{ADB}$ 